\title{
Field Evaluation of the System for Calibration of the Marshall Compaction Hammer
}

\section{Harry W. Shenton III}

Building and Fire Research Laboratory

National Institute of Standards and Technology

Gaithersburg, Maryland 20899

\section{Michael M. Cassidy}

AASHTO Materials Reference Laboratory

Gaithersburg, Maryland 20899

\section{February 1995}

Prepared for the Federal Highway Administration under Interagency Agreement DTFH61-92-Y-30052. Also published as Federal Highway Research Report FHWA-RD-95-063.

$Q C$

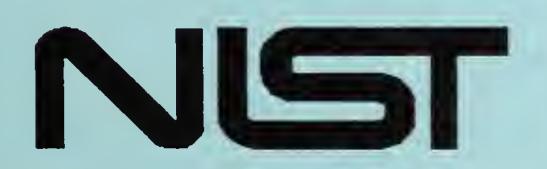

Inited States Department of Commerce nology Administration

100

.056 


\section{Field Evaluation of the System for Calibration of the Marshall Compaction Hammer}

Harry W. Shenton III

Building and Fire Research Laboratory

National Institute of Standards and Technology

Gaithersburg, Maryland 20899

Michael M. Cassidy

AASHTO Materials Reference Laboratory

Gaithersburg, Maryland 20899

Prepared for the Federal Highway Administration under Interagency Agreement DTFH61-92-Y-30052. Also published as Federal Highway Research Report FHWA-RD-95-063.

February 1995

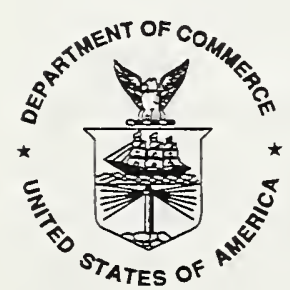

U.S. Department of Commerce

Ronald H. Brown, Secretary

Technology Administration

Mary L. Good, Under Secretary for Technology

National Institute of Standards and Technology

Arati A. Prabhakar, Director 


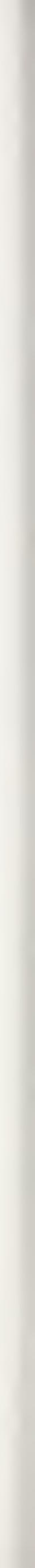




\section{ABSTRACT}

A system for calibrating the Marshall compaction hammer has recently been developed at the National Institute of Standards and Technology, in collaboration with the American Association of State Highway Transportation Officials (AASHTO), Materials Reference Laboratory (AMRL). The calibration system consists of a spring-mass device with an integral force transducer and a high-speed data acquisition system. The force delivered by the hammer to the calibration device is recorded as a function of time and analyzed to determine the peak force and impulse. Time histories from a series of hammer blows are analyzed to determine the average peak force, average impulse, and cumulative impulse. The proposed calibration procedure is based on adjusting the number of hammer blows delivered to a specimen, such that a standard compactive effort is supplied during the compaction process, regardless of slight variations in the Marshall hammer. In an earlier laboratory evaluation program, the calibration system and procedure proved to be effective in reducing the variability of Marshall test results.

Presented in the report is a summary of a field evaluation program of the calibration system and procedure. In this study, Marshall specimens were prepared in bituminous laboratories using "production" Marshall hammers: twelve laboratories, or field "sites", participated in the study. Sixteen Marshall specimens were prepared at each site. Four specimens were prepared using a standard 50-blow Marshall procedure and four using a standard 75-blow Marshall procedure; these are referred to as the uncalibrated specimens. Four specimens were prepared using a calibrated blow count corresponding to a standard 50-blow cumulative impulse, and four were prepared using a calibrated blow count corresponding to a standard 75-blow cumulative impulse; these are referred to as the calibrated specimens. Height, air voids, flow and stability were determined for each of the specimens. Results were compiled and analyzed to determine the between-laboratory variability of the data for the uncalibrated and calibrated specimens.

The system was, in general, ineffective in reducing the between-laboratory variability of the test results in the full data set. The variability of the calibrated test results increased or decreased relative to the uncalibrated results for different specimen properties. The system was effective, however, in reducing the variability of the test results when evaluated in the reduced data set, that included results from nine sites; data from three sites were eliminated in the statistical analysis because these results were believed to be flawed, in a way that may have compromised the Marshall test results. In the reduced data set, the variability of the calibrated test results decreased by as much as thirty percent, relative to the uncalibrated results. One possible explanation for the marginal reduction in variability with calibration is that the study sample of Marshall hammers was atypical of the total population: nine of the twelve machines were from the same manufacturer, and six of those were less than three years old. The machines provided reasonably consistent results, thus, there was little room for improvement. This is supported by comparison of the uncalibrated test results to data from the AASHTO Materials Reference Laboratory, Proficiency Sample Program. 


\section{Acknowledgements}

The authors would like to acknowledge the effort and hard work of a number of individuals who contributed to this study. From the AASHTO Materials Reference Laboratory, in Gaithersburg, Maryland, this includes Peter Spellerberg, David Savage, Tracy McInturff and Tim Maust. From the National Institute of Standards and Technology, this includes Jim Pielert and Will Guthrie. Finally, the authors would like to acknowledge the managers and technicians from the many laboratories that participated in the field evaluation program. Their time and efforts are greatly appreciated. 


\section{Disclaimer}

Certain trade names and company products are mentioned in the text or identified in an illustration in order to adequately specify the equipment, experimental procedure, or fabricated device. In no case does the identification imply recommendation or endorsement by the National Institute of Standards and Technology or research sponsor, nor does it imply that the products are necessarily the best available for the purpose. 



\section{TABLE OF CONTENTS}

ABSTRACT $\ldots \ldots \ldots \ldots \ldots \ldots \ldots \ldots \ldots \ldots \ldots \ldots \ldots$

TABLE OF CONTENTS $\ldots \ldots \ldots \ldots \ldots \ldots \ldots \ldots \ldots \ldots$

LIST OF FIGURES $\ldots \ldots \ldots \ldots \ldots \ldots \ldots \ldots \ldots \ldots \ldots \ldots \ldots$

LIST OF TABLES $\ldots \ldots \ldots \ldots \ldots \ldots \ldots \ldots \ldots \ldots \ldots \ldots$

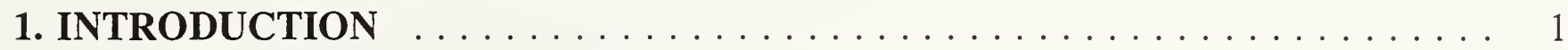

2. CALIBRATION SYSTEM $\ldots \ldots \ldots \ldots \ldots \ldots \ldots$

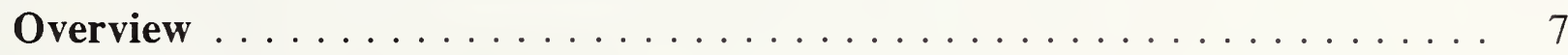

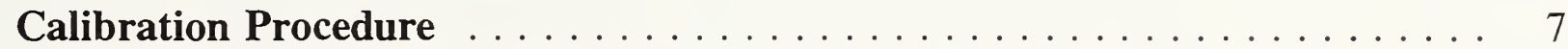

Laboratory Evaluation Program . . . . . . . . . . . . . . . . 11

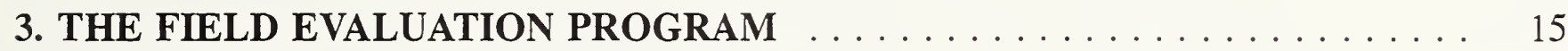

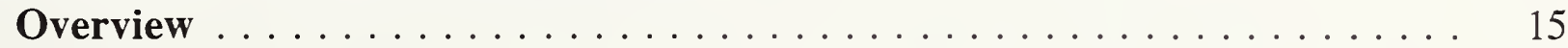

Selection of Field Sites $\ldots \ldots \ldots \ldots \ldots \ldots$

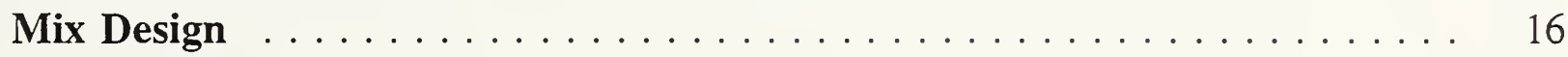

Details of the First Site Visit . . . . . . . . . . . . . . . . . . . 16

Determination of the Standard Cumulative Impulse $\ldots \ldots \ldots \ldots \ldots$

Details of the Second Site Visit . . . . . . . . . . . . . . . . . . . . . . 19

Analysis of Results . . . . . . . . . . . . . . . . . . . . . . 19

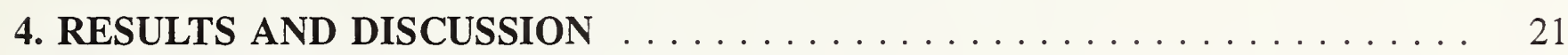

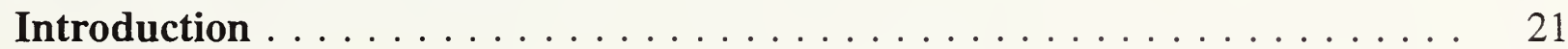

Machine Inspections . . . . . . . . . . . . . . . . . . . . . . 21

Problems Encountered During the Site Visits . . . . . . . . . . . . . . 24

Summary of Diagnostic Data and Determination of the Standard

Cumulative Impulses . . . . . . . . . . . . . . . . . . 29

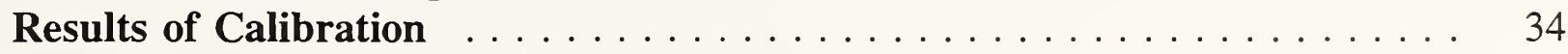

Uncalibrated and Calibrated Test Results . . . . . . . . . . . . . 36

Discussion of the Results $\ldots \ldots \ldots \ldots \ldots \ldots \ldots$

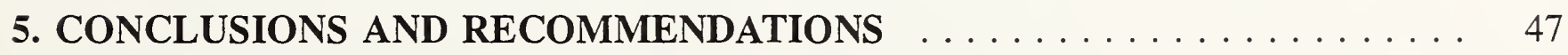

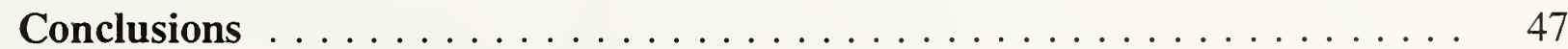

Recommendations ....................... 48

APPENDIX A. PROPOSED AASHTO CALIBRATION STANDARD . . . . . . . . 51 
REFERENCES 


\section{LIST OF FIGURES}

Figure No.

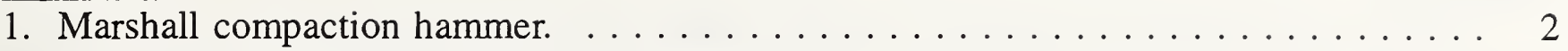

2. Mechanical Marshall compaction hammer. . . . . . . . . . . . . . . . 3

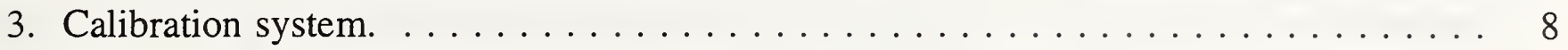

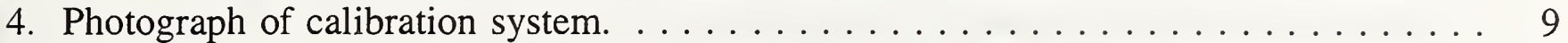

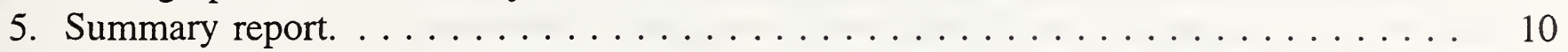

6. Determination of calibrated blow count. . . . . . . . . . . . . . . 12

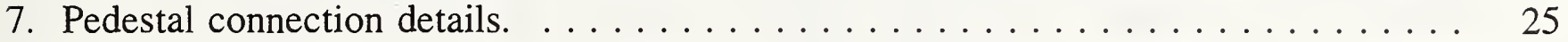

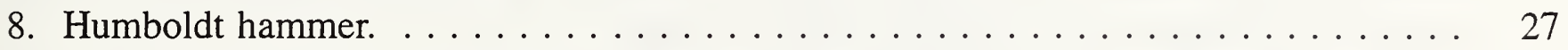

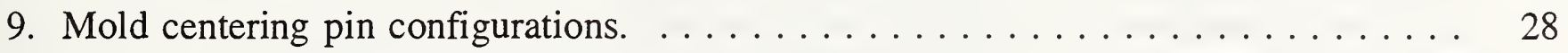

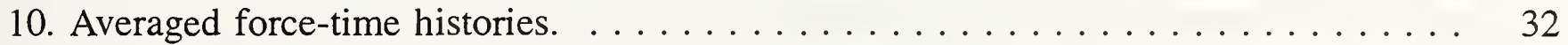

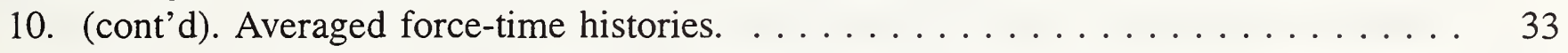

11. Calibration Device .......................... 56

12. Typical Force Time History Showing

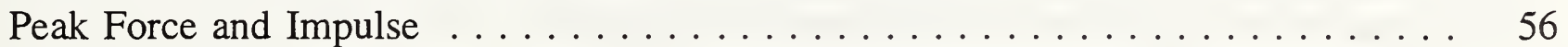

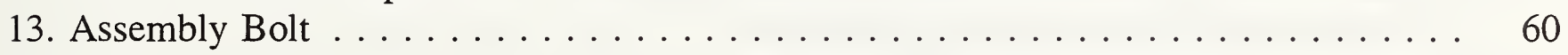

14. Base ............................... 61

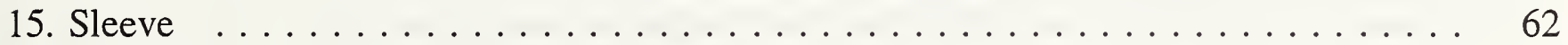

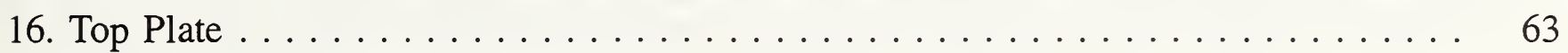

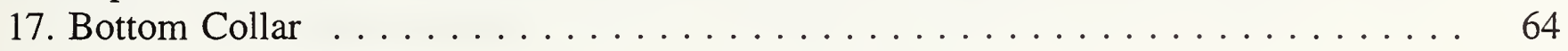

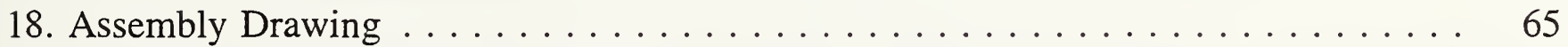

19. Typical Bi-Linear Calibration Curve $\ldots \ldots \ldots \ldots \ldots \ldots \ldots \ldots \ldots \ldots$ 


\section{LIST OF TABLES}

Table No.

1. Participating laboratories. . . . . . . . . . . . . . . . . . . . . 17

2. Asphalt $\operatorname{mix}$ design. . . . . . . . . . . . . . . . . . . . . . . . 18

3. Description of Marshall hammers used in the study . . . . . . . . . . . . . 22

4. Summary of diagnostic data from Marshall compaction hammers . . . . . . . . . . 30

5. Projected calibrated blow counts . . . . . . . . . . . . . . . . . . . . 34

6. Calibrated blow counts ........................... 35

7. Uncalibrated Marshall test results (50 blows per side) . . . . . . . . . . . . . . . . . . . . . . . . .

8. Calibrated Marshall test results $\left(\mathrm{N}_{50}\right.$ blows per side $) \ldots \ldots \ldots \ldots$

9. Uncalibrated Marshall test results (75 blows per side) . . . . . . . . . . . . . . . 39

10. Calibrated Marshall test results $\left(\mathrm{N}_{75}\right.$ blows per side $) \ldots \ldots \ldots \ldots \ldots$

11. Comparison of variability of uncalibrated and calibrated test results (all 12 sites) $\ldots \ldots \ldots \ldots \ldots \ldots \ldots \ldots \ldots$

12. Comparison of variability of uncalibrated and calibrated test results (all 12 sites, excluding Fairmont) . . . . . . . . . . . . . . . 43

13. Comparison of variability of uncalibrated and calibrated test results (all 12 sites, excluding Fairmont, Culpepper and Richmond) . . . . . . 43 


\section{CHAPTER 1. INTRODUCTION}

Historically, hot-mix asphalt has been designed using the Marshall method of mix design. Originally developed in the early 1920s, the procedure is relatively inexpensive, and requires little in the way of sophisticated equipment. More advanced techniques for mix design have been developed under the Strategic Highway Research Program (SHRP); however, the Marshall method is still the method of choice of most state highway agencies. Improvements in the Marshall mix design procedure will continue to be of benefit to the industry, as the results of the SHRP program are gradually adopted in the coming years.

AASHTO T-245 outlines the Marshall method of mix design; the procedure is briefly summarized as follows. A sample of hot-mix asphalt is placed in a $102 \mathrm{~mm}$ (4 in) diameter cylindrical steel mold and spaded twenty-five times with a spatula. The sample is then compacted using a manually-operated or mechanically-operated Marshall compaction hammer. Fifty blows are applied to each side of the specimen in a standard "50-blow" Marshall design. Other designs require thirty-five or seventy-five blows per side, depending on the pavement classification. After allowing the mold to cool slightly, the compacted asphalt concrete specimen is extruded from the mold. Tests are then conducted on the sample to determine the properties of the mix. The properties include bulk specific gravity, stability, flow, percent air voids and height. Test procedures for determining these properties are outlined in other AASHTO and ASTM standards.

A manually-operated Marshall compaction hammer is illustrated in figure 1. It includes the hammer assembly and pedestal with mold hold-down device. The hammer assembly, as referred to here, consists of the tamping foot, shaft, drop weight, and handle. Specifications for the critical components of the hammer design are outlined in AASHTO T-245, these are: $98 \mathrm{~mm}$ (3.875 in) diameter tamping foot, $4.5 \mathrm{~kg}$ (10 lb) drop weight and $457 \mathrm{~mm}$ (18 in) drop height. Details on the construction of the pedestal are also given in the standard. With a manually-operated hammer, the operator must raise and release the drop weight for each blow applied. A total of 100 blows are required for each specimen in a standard 50-blow Marshall design, or 300 blows for a typical 3 replicate set. The manual hammer is obviously labor intensive. Some years ago, to alleviate the burden of manual operation, mechanically-operated Marshall hammers were developed.

An example of a mechanically-operated Marshall hammer is shown in figure 2. The mechanically-operated hammer must adhere to the same specifications as the manual hammer, with regard to design and construction. A mechanical hammer automatically raises the drop weight to the proper height and releases it. Most mechanical hammers also have automatic counters and are designed to stop at a preselected number of blows. There are several manufacturers of mechanical Marshall hammers: the design and method of operation of mechanical hammers varies considerably from one manufacturer to the next. Although the standard does not provide specific guidelines or details to calibrate the mechanical hammer, AASHTO T-245 states, "a mechanically operated hammer may be used provided it has been calibrated to give results comparable with the hand operated hammer". 


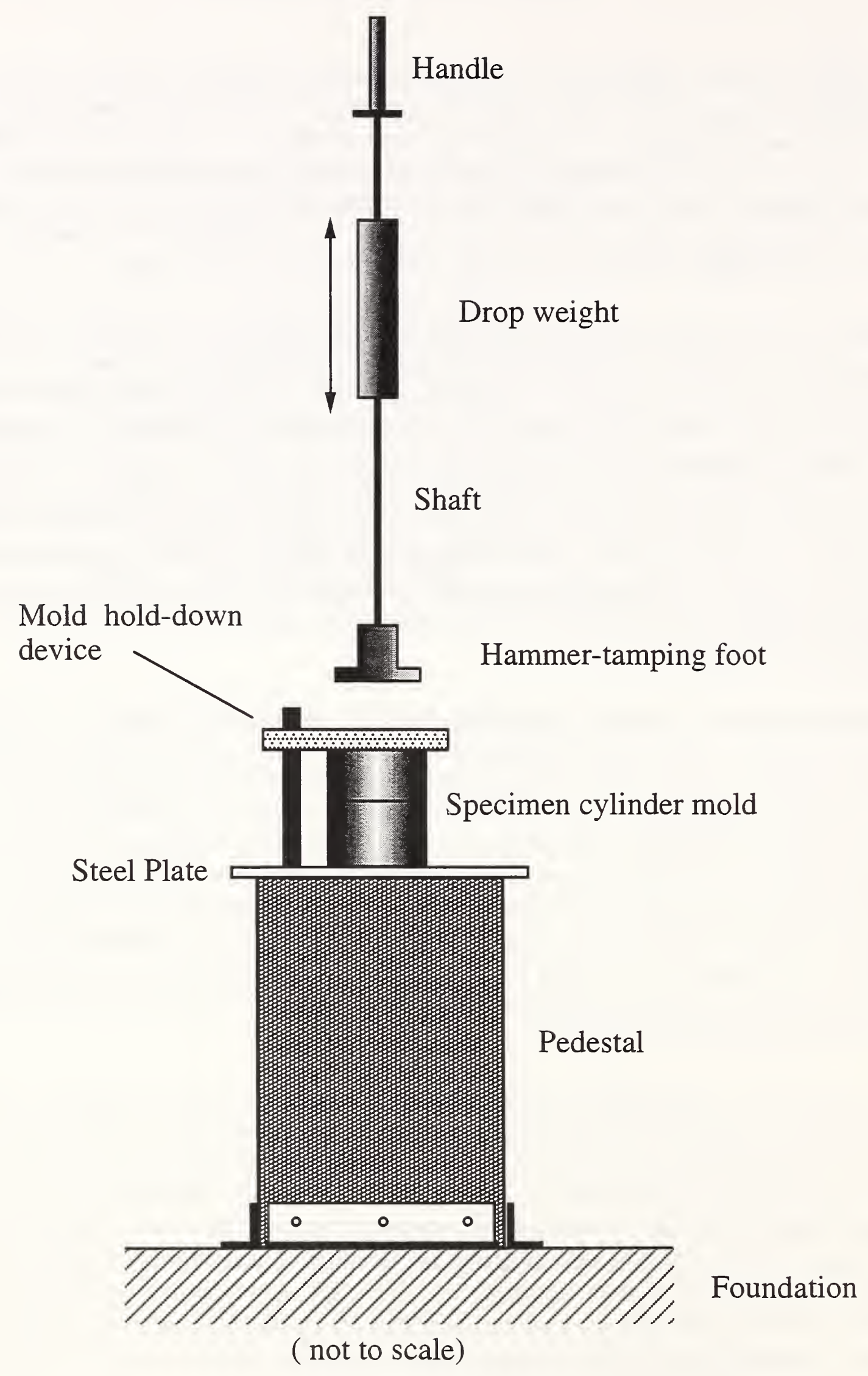

Figure 1. Marshall compaction hammer. 
Holder for hammer and $\longrightarrow$ release mechanism

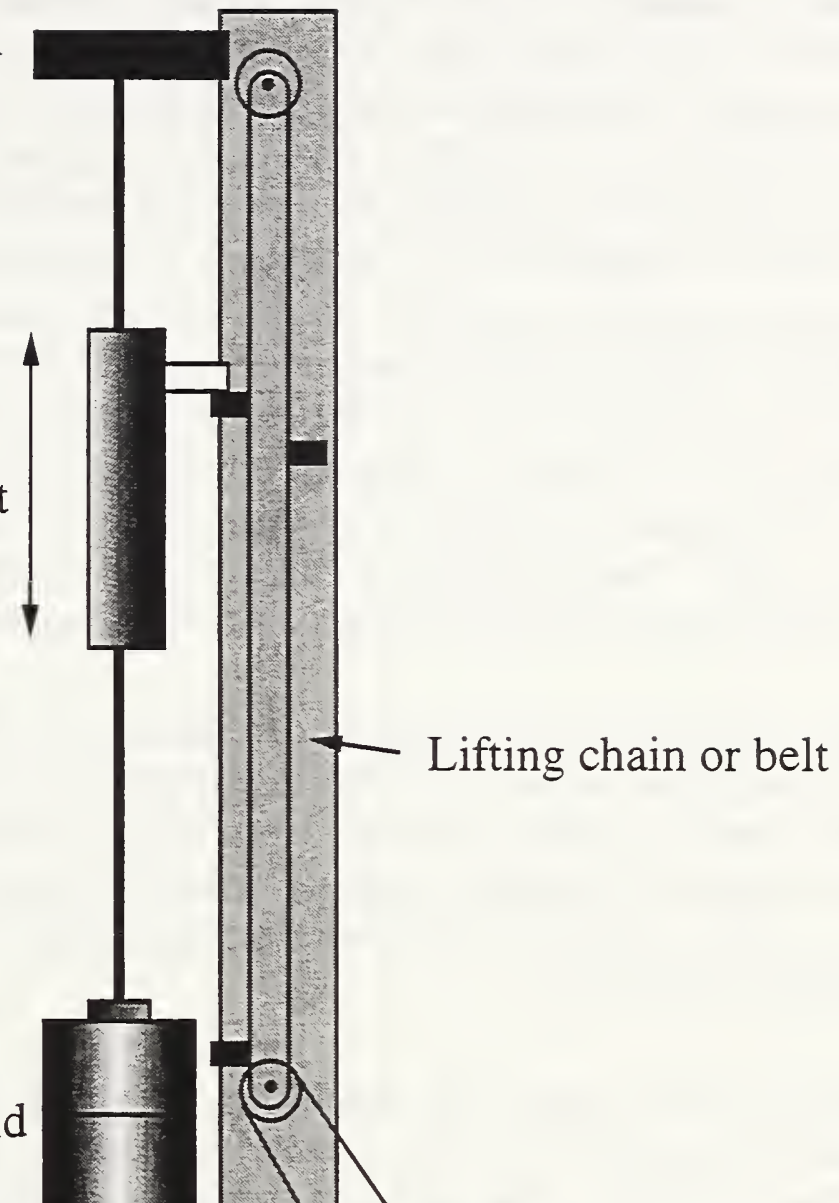

Specimen cylinder mold

Drop weight

Motor

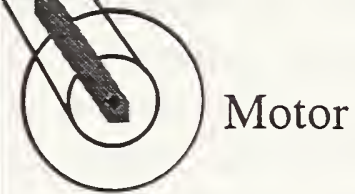

( not to scale)

Figure 2. Mechanical Marshall compaction hammer. 
Although the Marshall procedure is simple, relatively inexpensive, and described in several national standards, test results are known to be subject to wide variability. One indication of the wide variability can be found in the results of the AASHTO Materials Reference Laboratory (AMRL) Proficiency Sample Program (PSP) (Dickey, 1992). In the PSP, laboratories from across the country prepare and test Marshall specimens in accordance with AASHTO T-245, using similar materials provided by AMRL. Test results are then compiled and analyzed to determine the between- and within-laboratory variability of the test method. Between-laboratory variability refers to the variation of the test results, obtained from different laboratories following the same test procedure. Within-laboratory variability refers to the variation in replicate test results from a single laboratory, obtained by repeating the same test under controlled conditions. More than nine years of data have been compiled in the PSP for hot-mix asphalt designed using the Marshall method. On average, the between-laboratory variability, measured by the coefficient of variation (standard deviation divided by the average), for air voids is in the range of 20 to $35 \%$, stability is near $20 \%$, and flow is in the 15 to $25 \%$ range. The within-laboratory variability for each of these properties is generally less than $10 \%$. The variability of Marshall test results has also been demonstrated in several round-robin mix exchange programs and is discussed in Siddiqui, et al, (1987).

Siddiqui, Tretheway and Anderson (Siddiqui, et al, 1987) report that much of the scatter in the Marshall data can be attributed to compaction hammer related variables. Hammer variables that may affect the test results include, variation in drop weight or drop height, friction, hammer alignment, pedestal construction and foundation compliance. Each of these factors is likely to have an influence on the compactive effort of the hammer, and in turn, the mix design properties.

Research to date suggests the need for a systematic procedure for calibrating the Marshall compaction hammer, so that a standard compactive effort can be supplied to specimens regardless of slight variations in machines. A calibration system was recently developed at the National Institute of Standards and Technology (NIST), in collaboration with the AASHTO Materials Reference Laboratory (Shenton, et al, 1994). The calibration system is based on a mechanical spring-mass device, with integral force transducer, and a high speed data acquisition system. Calibration involves adjusting the number of blows to be delivered by a particular hammer, such that a standard "compactive effort" is supplied to the specimen. As part of the initial development study, a laboratory evaluation program was conducted to assess and evaluate the calibration system. Results clearly demonstrated the effectiveness of the calibration system in reducing the between-laboratory variability of Marshall test data.

To further evaluate the calibration system a field evaluation study has been conducted. The purpose of the study was to assess and evaluate the system using "production" Marshall equipment. The results of the field evaluation study are presented in this report. 
The report is organized as follows. An overview of the calibration system and a brief discussion of the laboratory evaluation program is presented in chapter 2. Chapter 3 describes the field evaluation program. The presentation and discussion of results is found in chapter 4. Conclusions and recommendations for future work are presented in chapter 5 . The proposed calibration procedure, as originally presented in Shenton, et al, 1994, is reprinted in Appendix A of this report. 


\section{CHAPTER 2. CALIBRATION SYSTEM}

\section{Overview}

The calibration system consists of three main components, (1) the elastic spring-mass calibration device with integral force transducer, (2) power supply, and (3) high-speed data acquisition system. The calibration system was developed specifically for a mechanical hammer with non-rotating base, flat tamping foot and $102 \mathrm{~mm}$ (4 in) diameter specimen mold. A schematic drawing of the calibration system is shown in figure 3; a photograph of the system is shown in figure 4 .

The principal components of the calibration device include the base plate, top plate, assembly bolt, Belleville springs and force transducer. During operation the tamping foot of the Marshall hammer rests on top of the calibration device. A blow from the hammer causes the Belleville springs to compress, and the force from the blow is transferred through the piezoelectric force transducer, into the machine pedestal and to the foundation. The force of the hammer blow is recorded as a function of time by the high-speed data acquisition system and stored for subsequent analysis. For calibration (Appendix A), three sets of seventy-five blows are recorded, with the calibration device oriented in the machine in the 4-, 8- and 12o'clock positions, respectively.

Analysis of the recorded force time histories includes determining the peak force, impulse (integral of the force pulse from the start of the pulse to the first zero crossing) and peak energy (proportional to the square of the peak force). The running total or cumulative impulse and cumulative energy are also computed for a set of recorded blows. Results are listed as a function of blow count in a summary report, and are saved to a file that can be displayed on screen or printed. Statistics on the peak force, energy and impulse are also computed for the set of blows and displayed at the top of the summary report. An example summary report is shown in figure 5 .

The results obtained from the recorded hammer blows provide important diagnostic data on the Marshall hammer. One can, by examining the average and standard deviation of force, and average and cumulative impulse, easily assess the "health" of the machine.

\section{Calibration Procedure}

Calibration involves determining a calibrated blow count for the hammer, such that a standard "compactive effort" is delivered to the specimen. In the proposed calibration procedure (Appendix A), the standard compactive effort is based on a standard cumulative impulse. An alternative that was explored in the laboratory evaluation program, but found to be less effective, is calibration based on cumulative energy. Alternative methodologies for calibrating are discussed in Shenton, et al , 1994.

Establishing a national standard cumulative impulse would be essential for the adoption and implementation of the calibration procedure. In the original study (Shenton, et al, 1994), and 


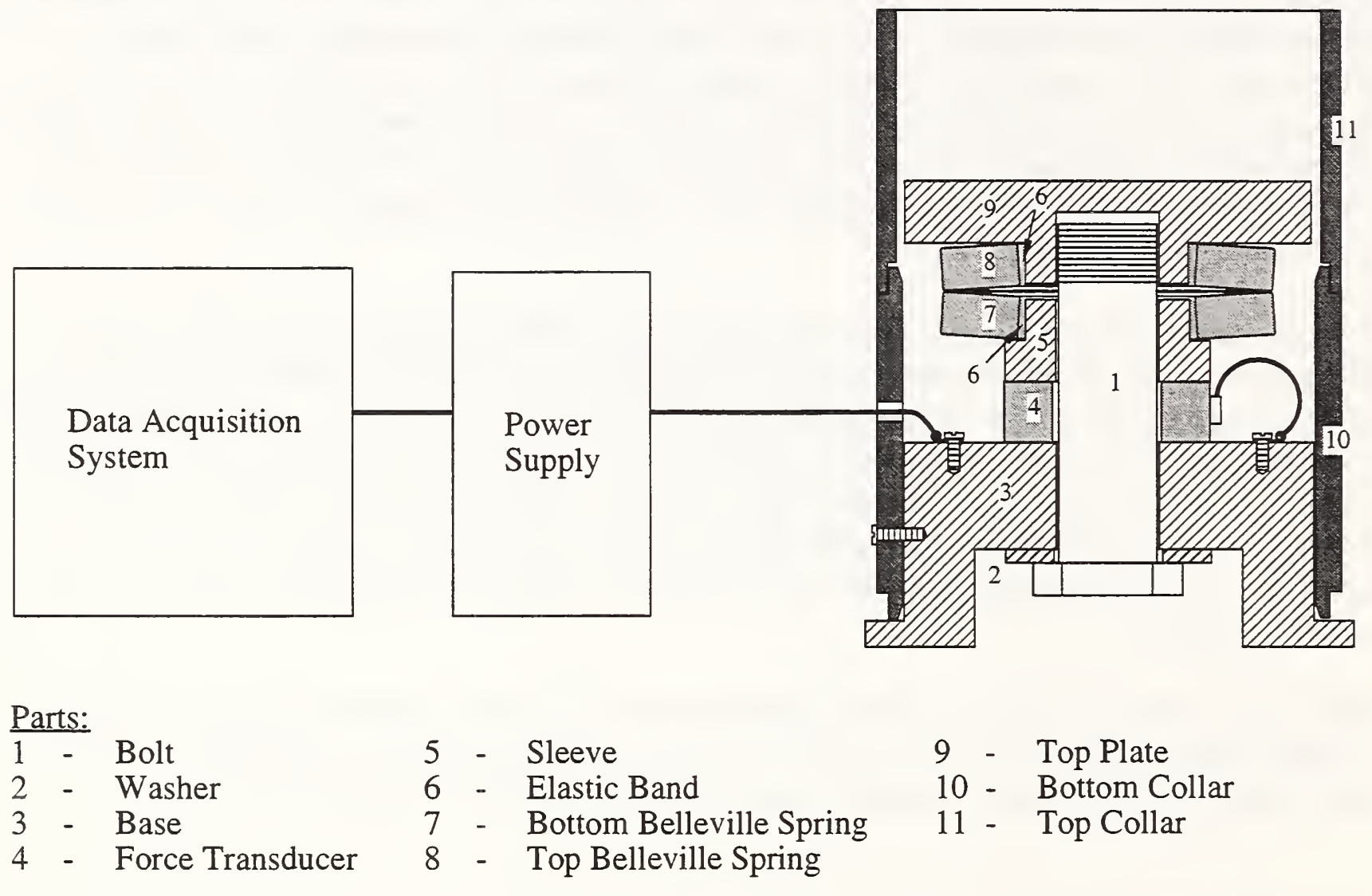

Figure 3. Calibration system. 


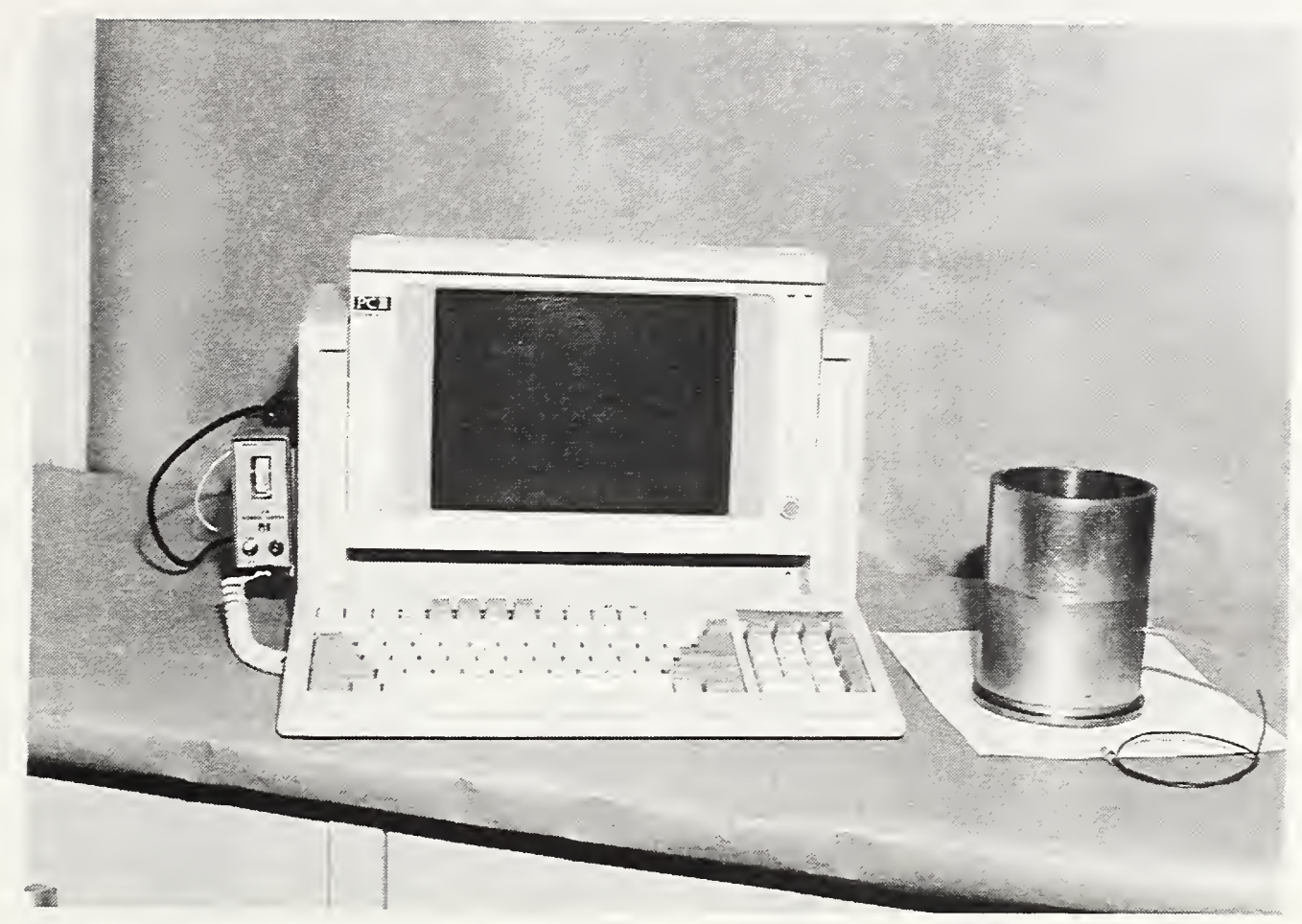

(a) Data acquisition system, power supply and device.

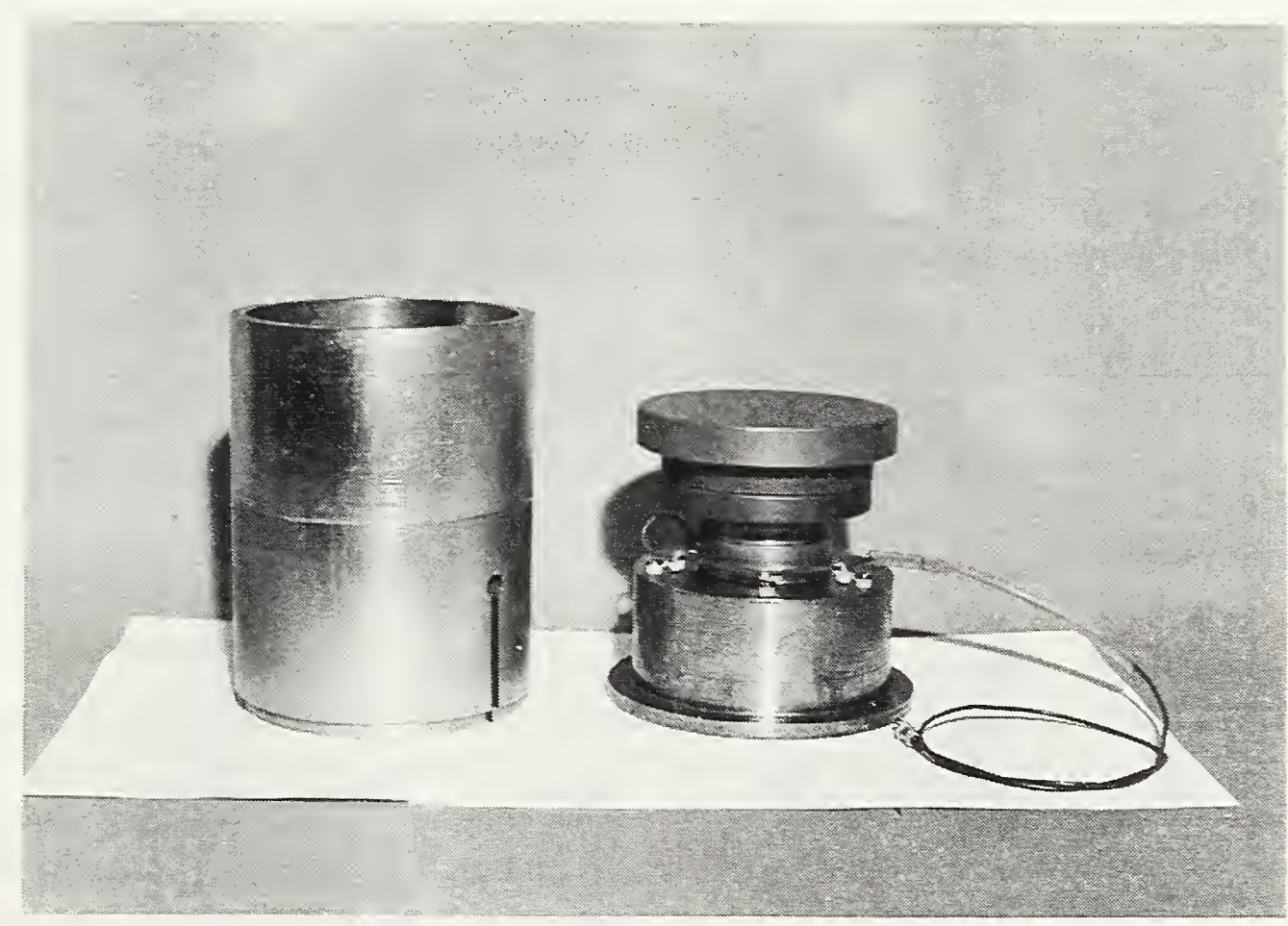

(b) Device with collars removed.

Figure 4. Photograph of calibration system. 
Summary of Results:

$\begin{array}{llc} & & \text { Peak } \\ & & \text { Force } \\ & (\mathrm{kN}) \\ \text { Average } & & 68.4 \\ \text { Standard Deviation }: & 1.5 \\ \text { Maximum } & : & 72.3 \\ \text { Minimum } & : & 63.7\end{array}$

Summary of Per Blow Results:
Blow

1
2
3
4
5
6

$P_{(\mathrm{kN})}^{\max }$

69.0
66.5

66.5
71.0

67.5

68.2

68.0

68.8

68.8
67.9

68.2

68.5

66.9

68.4

67.9

68.7

68.2

69.7

71.2

70.2

67.9

67.8
68.8

69.7

68.2

70.2

68.3

70.4

67.3

70.0

67.8

67.7
66.6

71.7

64.4

70.3

67.5

72.3

63.7

70.6

68.0

67.9

68.9

68.3

66.9

67.5

69.6

68.4

68.2

68.2

66.9

69.5

68.0

69.4

65.6

68.1

68.2

70.9
69.2

68.3

67.8

68.1

68.7

68.5

67.4

68.2

68.5

68.6

66.5

68.2

69.8
Number of blows: 70

Peak

Energy

( $\mathrm{kN}-\mathrm{mm}$ )

12.74

0.55

14.22

11.05

Impulse

$(\mathrm{kN}-\mathrm{sec}$

22.96

0.30

23.60

22.28 $\underset{(k N-m m)}{E_{\max }}$

12.9

12.0
13.7

12.4

12.7

12.6

12.5

12.9

12.6

12.7

12.7

12.2

12.7

12.5

12.8

12.6

13.2
13.8

13.4

12.5

12.5

12.9

13.2

12.7

13.4

12.7

13.5

12.3

13.3

12.5

12.5
12.1

14.0

11. 3

13.4

12.4

14.2

11.0

13.6

12.6

12.5

12.9
12.7

12.2

12.4

13.2

12.7

12.6

12.7

12.2

13.1

12.6

13.1

12.6
12.7

13.7

13.0

12.7

12.5

12.6

12.8

12.7

12.3

12.6

12.7

12.8

12.0

12.6
E_sum

( $\mathrm{kN}-\mathrm{mm}$ )

12.9

25.0

38.7
51.1

51.1

76.3

88.8

101.6

114.2

126.9

139.6

151.8

164.5

177.0

189.8

202.5

215.7

229.5

242.9

255.4

267.9

280.8

294.0

306.7

320.1

332.8

346.3

358.6

371.9

384.4

396.9

409.0

422.9

434.2

447.7

460.0

474.3

485.3

498.9

511.4

524.0

536.9

549.6

561.7

574.1

587.3

600.0

612.6

625.3

637.4

650.6

663.1

676.2

687.9

700.6

713.2

726.9

739.9

752.6

765.1

777.7

790.6

803.3

815.7

828.3

841.0

853.8

865.9

878.5

891.8

\begin{tabular}{|c|c|}
\hline & \\
\hline $\begin{array}{l}\text { I_max } \\
(\mathrm{kN}-\mathrm{sec}\end{array}$ & $\underset{(\mathrm{kN}-\mathrm{sec}}{\mathrm{I} \text { sum }}$ \\
\hline$\times\left(0^{-3}\right)$ & $\times 10^{-3}$ ) \\
\hline 22.8 & 22.8 \\
\hline 23.4 & 46.2 \\
\hline 23.0 & 69.2 \\
\hline 23.6 & 92.8 \\
\hline 23.5 & 116.2 \\
\hline 23.2 & 139.4 \\
\hline 23.3 & 162.7 \\
\hline 23.4 & 186.1 \\
\hline 23.5 & 209.6 \\
\hline 23.3 & 232.9 \\
\hline 23.3 & 256.2 \\
\hline 23.5 & 279.7 \\
\hline 23.3 & 303.0 \\
\hline 23.1 & 326.0 \\
\hline 23.0 & 349.0 \\
\hline 23.0 & 372.0 \\
\hline 22.8 & 394.8 \\
\hline 22.8 & 417.6 \\
\hline 22.9 & 440.5 \\
\hline 23.3 & 463.9 \\
\hline 23.2 & 487.1 \\
\hline 22.9 & 509.9 \\
\hline 22.6 & 532.5 \\
\hline 22.7 & 555.2 \\
\hline 22.8 & 578.0 \\
\hline 22.8 & 600.7 \\
\hline 22.8 & 623.6 \\
\hline 22.9 & 646.5 \\
\hline 23.1 & 669.7 \\
\hline 23.3 & 693.0 \\
\hline 23.1 & 716.1 \\
\hline 23.0 & 739.1 \\
\hline 22.8 & 761.9 \\
\hline 23.0 & 784.9 \\
\hline 22.6 & 807.6 \\
\hline 23.2 & 830.8 \\
\hline 22.9 & 853.6 \\
\hline 23.4 & 877.0 \\
\hline 22.9 & 900.0 \\
\hline 22.9 & 922.9 \\
\hline 23.2 & 946.1 \\
\hline 23.2 & 969.4 \\
\hline 23.2 & 992.5 \\
\hline 23.3 & 1015.9 \\
\hline 23.2 & 1039.1 \\
\hline 22.9 & 1062.0 \\
\hline 22.9 & 1084.9 \\
\hline 23.1 & 1108.0 \\
\hline 22.9 & 1130.9 \\
\hline 23.2 & 1154.1 \\
\hline 23.0 & 1177.0 \\
\hline 23.0 & 1200.1 \\
\hline 22.6 & 1222.7 \\
\hline 23.1 & 1245.8 \\
\hline 22.5 & 1268.3 \\
\hline 22.5 & 1290.8 \\
\hline 22.5 & 1313.3 \\
\hline 22.4 & 1335.7 \\
\hline 22.6 & 1358.3 \\
\hline 22.5 & 1380.8 \\
\hline 22.3 & 1403.1 \\
\hline 22.7 & 1425.8 \\
\hline 22.7 & 1448.5 \\
\hline 22.5 & 1470.9 \\
\hline 22.8 & 1493.7 \\
\hline 22.6 & 1516.3 \\
\hline 22.7 & 1539.1 \\
\hline 22.9 & 1561.9 \\
\hline 22.8 & 1584.8 \\
\hline & \\
\hline
\end{tabular}

Figure 5. Summary report. 
here, the standard cumulative impulse is associated with a corresponding blow count (n), and denoted by $I_{n}$. For example, $I_{50}$ denotes the "standard 50-blow cumulative impulse". For example, a national standard 50-blow cumulative impulse would represent the average cumulative impulse measured at 50 blows, from a sample of typical Marshall compaction hammers; therefore, $\mathrm{I}_{50}$ would represent the average compactive effort of a typical Marshall hammer. Using this value, the calibrated blow count of a sample of machines should be distributed about, and not skewed above or below the standard 50 blows. Other standard cumulative impulses could be established, for example, $\mathrm{I}_{35}$ or $\mathrm{I}_{75}$, corresponding to the different blow counts used today.

Using the standard cumulative impulse, the calibrated blow count for a particular machine is determined as follows. A set of seventy-five hammer blows are recorded and the summary report generated. The user enters the summary report (figure 5) and reads down the column for cumulative impulse until reaching the largest value that is equal to or less than the standard cumulative impulse. Reading across the row yields the calibrated blow count. $N_{n}$ is used to denote the calibrated blow count and corresponds to the notation used for standard cumulative impulse. The process is illustrated in figure 6 with $\mathrm{I}_{50}=1100 \mathrm{~N}-\mathrm{s}(247 \mathrm{lb}-\mathrm{s})$. A calibrated blow count is determined independently for each of the three recorded data sets measured in the 4-, 8- and 12-o'clock positions, respectively. The final calibrated blow count for the machine is the average of the three.

\section{Laboratory Evaluation Program}

A laboratory evaluation program was conducted in the original study (Shenton, et al, 1994) to, (1) demonstrate proof-of-concept of the calibration system, and (2) expose any problems that might remain with the calibration device or procedure. In addition, the effect of calibration based on different measures for "compactive effort" was studied. Namely, calibration based on cumulative impulse and calibration based on cumulative energy was considered. The laboratory evaluation program involved comparing the Marshall test results of uncalibrated specimens with those of calibrated specimens. An uncalibrated specimen refers to a sample prepared using the standard procedure (e.g., 50-blows per side); a calibrated specimen refers to a sample prepared using the calibrated blow count that is determined as described previously.

Five machine set-ups were used in the laboratory to simulate expected variations in field equipment and to deliberately produce variability in the Marshall test results. Two mechanical hammers were used, a Pine Instruments Marshall compaction hammer and a Rainhart Testing Equipment Marshall compaction hammer. These two machines made up two of the five machine set-ups. Two other set-ups were developed to deliberately produce variability in the test results; a $0.227 \mathrm{~kg}(0.5 \mathrm{lb})$ mass was added to the drop weight of the Pine hammer, and a rubber pad was placed between the mold and pedestal in the Rainhart machine. Although it was not in the scope of development of the calibration system, a manually-operated hammer was selected for the fifth machine set-up. 


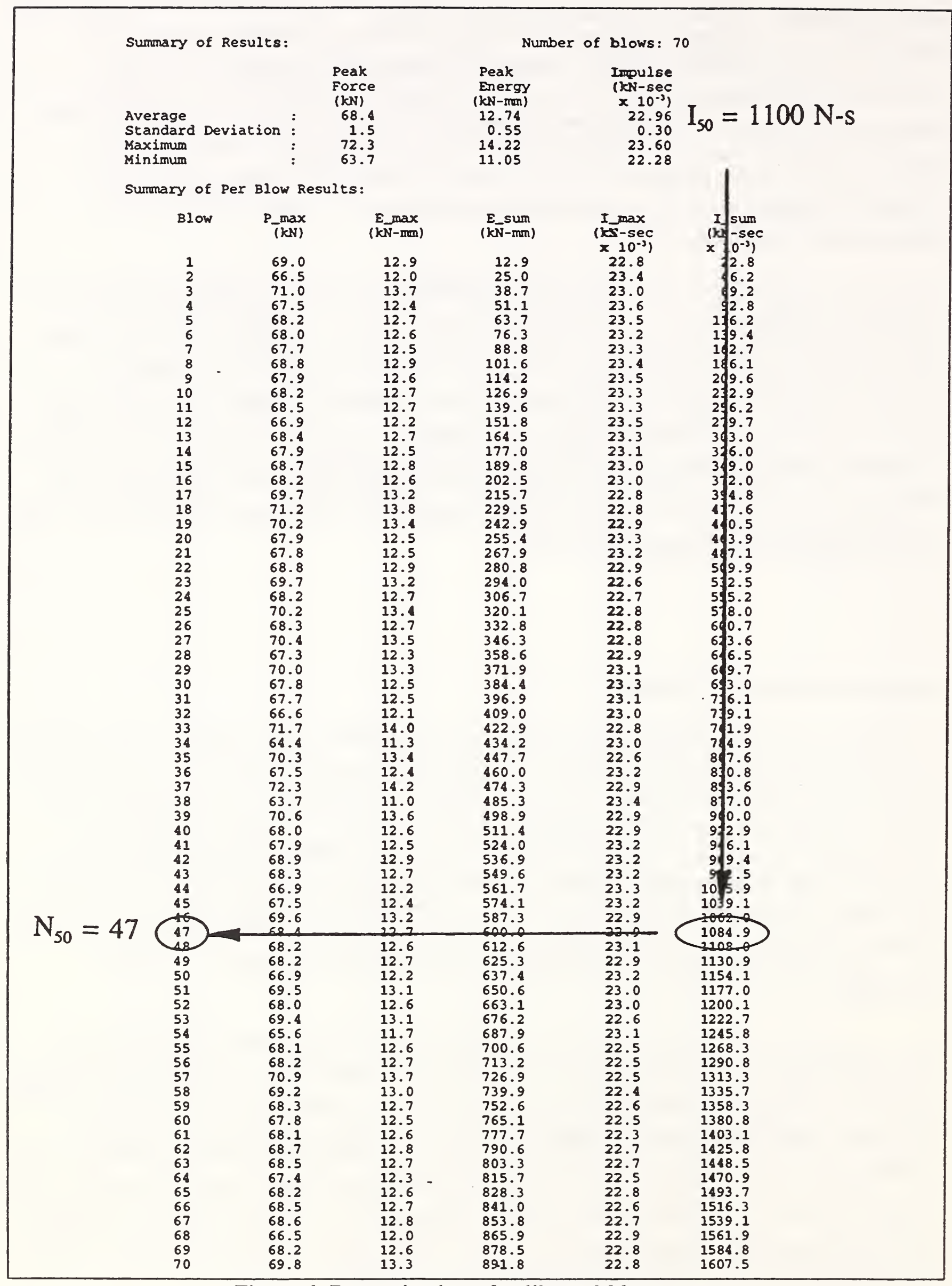

Figure 6. Determination of calibrated blow count. 
Three, three-replicate sets of specimens were compacted in each of the machine set-ups, i.e., nine samples per set-up or forty-five specimens total. One set was compacted using a standard 50-blow procedure, one set using a calibrated blow count that was determined based on cumulative impulse, and one set using a calibrated blow count that was determined based on cumulative energy. The standard 50-blow cumulative impulse used in the study was taken as the average of the cumulative impulse measured at fifty blows in each of the five machine set-ups. Air voids, stability, flow, height and bulk specific gravity were measured for each of the specimens. Statistics for each of the three sets were compiled and the "betweenlaboratory" (i.e., between-machine set-up) variability of each set established.

The important results of the laboratory evaluation program are summarized below:

- The variability in the data of the calibrated specimens was greatly reduced, compared to the uncalibrated specimens.

- A fifty to sixty percent reduction in standard deviation and range (maximum minus minimum) was achieved in four out of five design properties (bulk specific gravity, stability, air voids and height) for the specimens prepared with a calibrated blow count based on cumulative impulse.

- Calibration based on cumulative impulse was clearly more effective in reducing the variability of the data than calibration based on cumulative energy.

Based on the favorable outcome of the laboratory evaluation program, a recommendation was made to evaluate further the calibration system using actual field equipment. 



\section{CHAPTER 3. THE FIELD EVALUATION PROGRAM}

\section{Overview}

The field evaluation study was undertaken to:

assess and evaluate the calibration system, using "production" Marshall equipment, in terms of its ability to reduce the between-laboratory variability of Marshall test results, and

expose any problems that might remain with the system and recommend necessary changes, and

develop recommended values for the standard 50- and 75-blow cumulative impulse for the proposed calibration procedure (Appendix A).

Similar to the laboratory evaluation program, these objectives were accomplished by comparing the between-laboratory variability of uncalibrated and calibrated Marshall test results. In this case, however, specimens were prepared using compaction hammers at state or federal highway laboratories. All the compaction hammers were used in their "as-is" condition.

Twelve bituminous laboratories, or "sites", were selected to participate in the study. Over the course of three months, a team of researchers from NIST and AMRL visited each site twice. The purpose of the first site visit was to inspect the laboratory compaction hammer, collect diagnostic data and prepare the uncalibrated Marshall specimens. Diagnostic data refers to statistics on the force, impulse and cumulative impulse for a Marshall hammer, measured using the calibration system. Two, four-replicate sets of uncalibrated specimens were made during the first site visit. One set used the 50-blow Marshall and the other used 75 blows. The purpose of the second site visit was to calibrate the compaction hammer and prepare the calibrated Marshall specimens. Two, four-replicate sets of calibrated Marshall specimens were made at each site during the second visit. One set was made using a calibrated blow count based on a standard 50-blow cumulative impulse, and one set was made using a calibrated blow count based on a standard 75-blow cumulative impulse. All total, 192 Marshall specimens were made and tested for the field evaluation program. Results for the uncalibrated and calibrated specimens were compiled and the between-laboratory variability established.

In developing the field evaluation program, every effort was made to reduce the variability in the Marshall test results due to non-hammer related effects. To reduce the variability due to materials and mix design, each site was given the materials needed to prepare the specimens for the study. Sample materials were pre-weighed, individually wrapped and shipped by AMRL. The local site technicians were responsible for preparing the mix and compacting the sample; however, an AMRL inspector was present during each visit to ensure that specimens were prepared in accordance with AASHTO T-245. To reduce the variability of subsequent testing, i.e., in testing to determine air voids, stability, etc., all subsequent tests were conducted by AMRL personnel, at the AMRL laboratory. Further details on the study are described in the sections to follow. 


\section{Selection of Field Sites}

Several factors were considered in selecting the laboratories for the study, including: proximity to the Washington, D.C. area, proper Marshall equipment, scheduling and AASHTO laboratory accreditation. Since each site was to be visited twice by the research team it was desirable that they be located within a reasonable driving distance of Washington, D.C. (where NIST and AMRL are located). The site had to have, in operation, a mechanically-operated Marshall compaction hammer with a flat foot and non-rotating base. The site had be accessible for two days, once during the winter and once during the early spring. Finally, the laboratory had to be familiar with the Marshall method of mix design. To be accredited by AASHTO, a laboratory must be competent in the mix design procedure; therefore, accreditation was considered important, but not absolutely necessary when selecting the laboratories.

Twelve sites were invited and agreed to participate in the field evaluation program. Ten were state highway laboratories, one a federal laboratory, and one was the AMRL laboratory. Of the twelve, three are AMRL accredited. All of the laboratories are within a three to four hour drive of Washington, D.C. The twelve laboratory sites are listed in Table 1.

Prior to each visit, the sites were given detailed instructions that outlined the tasks to be completed, the equipment required for the visit, oven temperature settings, and the responsibilities of the laboratory personnel.

\section{Mix Design}

No particular target design parameters were established for the mix design used in the study. Realizing that there could be room for error and confusion if different designs were used for the 50- and 75-blow samples, a trial-and-error design was undertaken to find a mix that was suitable for both the 50 - and 75 -blow series. The design was completed using a relatively new Pine Instruments compaction hammer at the AMRL laboratory. The final mix design is presented in Table 2.

All materials for the evaluation program were prepared and shipped by AMRL. The aggregate for all samples came from the same lot of bulk material. The material was separated, weighted and recombined into quantities for individual Marshall specimens. Each participating laboratory received two shipments of material, one for each site visit. Each shipment included nine individually wrapped portions of aggregate material, eight for the Marshall specimens and one to "butter the bowl", and a quart of AC-20 asphalt cement.

\section{Details of the First Site Visit}

The purpose of the first site visit was to, (1) inspect the site machine, (2) collect diagnostic data on the machine using the calibration system, and (3) prepare uncalibrated specimens. 
Table 1. Participating laboratories.

\begin{tabular}{|c|c|c|c|}
\hline \# & Organization/Agency & Location & Contact \\
\hline 1 & $\begin{array}{l}\text { AASHTO Materials Reference } \\
\text { Laboratory (AMRL) }\end{array}$ & $\begin{array}{l}\text { Gaithersburg, } \\
\text { Maryland }\end{array}$ & Mr. Peter Spellerburg \\
\hline 2 & $\begin{array}{l}\text { Federal Highway Administration, } \\
\text { Turner Fairbanks Research Center }\end{array}$ & $\begin{array}{l}\text { McLean, } \\
\text { Virginia }\end{array}$ & Mr. Kevin Stuart \\
\hline 3 & $\begin{array}{l}\text { Maryland State Highway } \\
\text { Administration }\end{array}$ & $\begin{array}{l}\text { Greenbelt, } \\
\text { Maryland }\end{array}$ & Mr. Milt Simms \\
\hline 4 & " & $\begin{array}{l}\text { Brooklandville, } \\
\text { Maryland }\end{array}$ & Mr. Bob Voelkel \\
\hline 5 & $"$ & $\begin{array}{l}\text { Hancock, } \\
\text { Maryland }\end{array}$ & Mr. Larry Michael \\
\hline 6 & $"$ & $\begin{array}{l}\text { Easton, } \\
\text { Maryland }\end{array}$ & Mr. Gary Dolin \\
\hline 7 & $\begin{array}{l}\text { Virginia Department of } \\
\text { Transportation }\end{array}$ & $\begin{array}{l}\text { Culpepper, } \\
\text { Virginia }\end{array}$ & Ms. Kathy Jefferson \\
\hline 8 & $"$ & $\begin{array}{l}\text { Richmond, } \\
\text { Virginia }\end{array}$ & Mr. Joe Love \\
\hline 9 & $\begin{array}{l}\text { West Virginia Department of } \\
\text { Transportation }\end{array}$ & $\begin{array}{l}\text { Fairmont, } \\
\text { West Virginia }\end{array}$ & Mr. Robert Wolfe \\
\hline 10 & $"$ & $\begin{array}{l}\text { Weston, } \\
\text { West Virginia }\end{array}$ & Mr. Dave Kraus \\
\hline 11 & $\begin{array}{l}\text { Delaware Department of } \\
\text { Transportation }\end{array}$ & $\begin{array}{l}\text { Dover, } \\
\text { Delaware }\end{array}$ & Mr. Delmar Dudasik \\
\hline 12 & $\begin{array}{l}\text { Washington, District of Columbia, } \\
\text { Department of Public Works }\end{array}$ & Washington, D.C. & Mr. Ignat V. Kalcheff \\
\hline
\end{tabular}

Tasks were completed in that order. Presented below is a description of the procedure followed during the first visit.

1. Upon arrival, the NIST/AMRL team placed their eight Marshall molds in the site oven to be warmed. All ovens were checked to be sure they were at the correct temperature as outlined in the instructions to the laboratories.

2. As the molds were being heated, the team inspected the Marshall hammer, noting the manufacturer and approximate age, checked for conformance with AASHTO T-245 and noted any defects or obvious problems with the machine. Polaroid photographs 
Table 2. Asphalt mix design.

\begin{tabular}{|c|c|c|}
\hline \multicolumn{2}{|c|}{ Aggregate } & \multirow{2}{*}{ Asphalt Cement } \\
\cline { 1 - 2 } Size (mm [in]) & Mass (g) & \\
\hline $19(3 / 4)$ & 120 & \\
$12.7(1 / 2)$ & 130 & \\
$9.5(3 / 8)$ & 185 & 55 g AC-20; \\
No. 4 & 165 & \\
No. 8 & 170 & \\
$>$ No. 8 & 370 & \\
Filler & 45 & \\
\hline
\end{tabular}

were taken of the machine.

3. The NIST/AMRL team collected diagnostic data on the compaction hammer using the calibration system. Three sets of data were recorded with the device oriented in the 4-, 8-, and 12- o-clock positions, with sets consisting of 70 blows each. This is similar to the calibration procedure outlined in Appendix A, with the only change being that 70 blows were delivered to the device, and not 75 . The 70 blow data set is a carry-over from the original study (Shenton, et al, 1994), where the focus was on calibrating for a 50-blow Marshall.

For each set of data the average and standard deviation of peak force, average and standard deviation of impulse, and the cumulative impulse at 50 and 75 blows were recorded. Since only 70 blows were recorded, the cumulative impulse at 75 blows was computed by multiplying the average impulse for the data set times 75 , rather than reading the value off the report. This procedure was found to give accurate results when verified for the 50 blow cumulative impulse.

4. In preparation for mixing the actual specimens, the site technicians prepared the "butter batch", using the extra material supplied. Site technicians then made the eight uncalibrated Marshall specimens, four using 50 blows per side and four using 75 blows per side.

5. The NIST/AMRL team departed after the last specimen was compacted, taking with them all eight specimens. Specimens were returned to AMRL for immediate testing to determine height, air voids, stability, flow and bulk specific gravity.

\section{Determination of the Standard Cumulative Impulse}

After completing the first series of site visits the diagnostic data was compiled and analyzed, and used to establish the standard cumulative impulses $\left(\mathrm{I}_{50}, \mathrm{I}_{75}\right)$, which were needed for the 
second series of site visits. The standard 50-blow cumulative impulse $\left(I_{50}\right)$ was taken as the average 50-blow cumulative impulse from the twelve machines. Likewise, the standard 75blow cumulative impulse $\left(\mathrm{I}_{75}\right)$ was taken as the average 75-blow cumulative impulse from the twelve machines.

\section{Details of the Second Site Visit}

The purpose of the second visit was to, (1) calibrate the site compaction hammer, and (2) make calibrated specimens. The tasks were completed in that order. Presented below is a detailed description of the procedure followed during the second site visit.

1. Upon arrival, the NIST/AMRL team placed their eight Marshall molds in the site oven to be warmed. All ovens were checked to be sure they were at the correct temperature as outlined in the instructions to the laboratories.

2. The NIST/AMRL team calibrated the site compaction hammer in accordance with the procedure outlined in Appendix A, with the exception of the following change. As before, 70 blows were delivered to the device, and not 75 . The team determined the calibrated blow counts $\left(\mathrm{N}_{50}, \mathrm{~N}_{75}\right)$ for that particular machine.

3. In preparation for mixing the actual specimens, the site technicians prepared the "butter batch", using the extra material supplied. Site technicians then made the eight calibrated Marshall specimens, four using $\mathrm{N}_{75}$ blows per side and four using $\mathrm{N}_{50}$ blows per side.

4. The NIST/AMRL team departed after the last specimen was compacted, taking with them all eight specimens. Specimens were returned to AMRL for immediate testing to determine height, air voids, stability, flow and bulk specific gravity.

\section{Analysis of Results}

Following completion of the site visits, the properties of the Marshall specimens were compiled and summarized. The results were analyzed to establish the between-laboratory variability of the uncalibrated and calibrated test results. 



\section{CHAPTER 4. RESULTS AND DISCUSSION}

\section{Introduction}

Results of the field evaluation study are presented in the following. A brief description of the twelve Marshall hammers used in the study is presented first. Observed variations in the hammers that could potentially introduce scatter into the Marshall test data are discussed. Next, a few problems that were encountered during the study are discussed. These problems have to do with the design of the calibration device and should be addressed if refinements or enhancements to the device are made in the future. This is followed by a summary of the diagnostic data and the determination of the standard cumulative impulses. The results of calibration are then discussed, followed by the presentation and discussion of the uncalibrated and calibrated Marshall test results and between-laboratory variability.

\section{Machine Inspections}

Overall, the machines were well maintained and in good operating condition. Presented in table 3 is a brief description of the twelve hammers. The table lists, for each site, the hammer manufacturer, approximate age of the machine, drop height, mass of the entire hammer assembly, a 1 to 5 rating of the general condition of the machine (5 being good), a 1 to 5 rating of the operating condition of the machine, and a comment section. General condition is an assessment of the overall physical condition of the machine; operating condition is an assessment of the mechanical operation of the hammer (i.e., does the machine run smoothly, do the blows sound similar and are they repeatable, is the drop-height consistent). Some of the differences found in the study machines that might contribute to variability of the Marshall test results are discussed below.

The inventory included machines manufactured by Pine Instruments, Rainhart Co. and Humboldt Manufacturing: nine of the twelve were manufactured by Pine Instruments. The age of the machines varied from less than one, to over twenty years. Eight of the twelve are less than five years old, with six of those being less than three years old.

During the first site visit, the drop height of each hammer was measured. Measuring the height consistently and accurately, however, proved to be difficult. Each hammer design has its own unique release mechanism which complicates the task. The drop height can be measured for some machines with reasonable accuracy, while the machine is not operating, but for others, the height can only be measured while the machine is operating. To be consistent, the drop heights listed in table 3 were measured with the machines in operation. A metal bar was used to mark the highest release point of the drop weight while the machine was running, and the height of the mark was later measured. The heights listed in table 3 are at best approximate, and are presented to illustrate the relative variation in drop height among the machines. The heights varied from a low of $450 \mathrm{~mm}$ (17.7 in) to a high of $473 \mathrm{~mm}$ (18.6 in), or approximately $\pm 2.5 \%$ about the required height of $457 \mathrm{~mm}$ (18 in).

A possibly significant cause of variability in test results is the variation in the mass of the drop weight and other hammer assembly components. The mass of the weight is specified in 


\begin{tabular}{|c|c|c|c|c|c|c|c|c|c|c|c|c|}
\hline 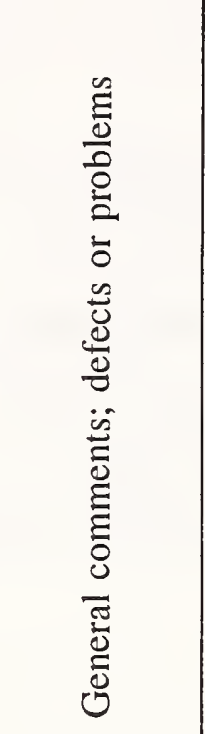 & $\stackrel{\mathscr{E}}{\Xi}$ & 巳ั & 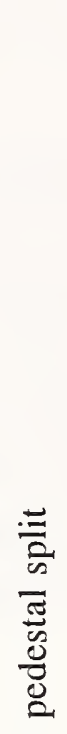 & 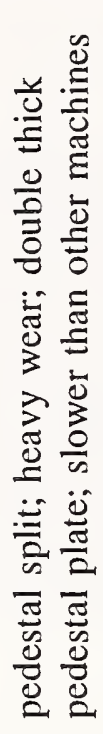 & 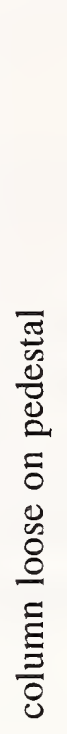 & $\stackrel{\mathscr{\Xi}}{\Xi}$ & 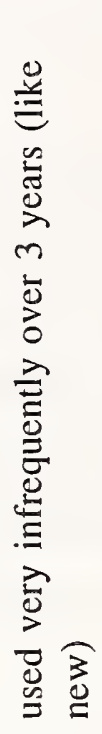 & 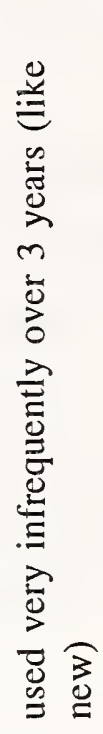 & 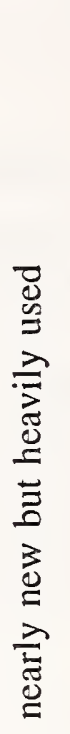 & 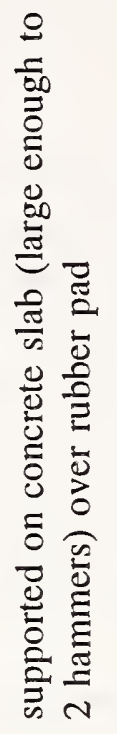 & 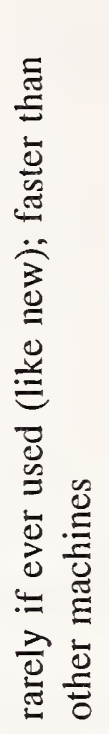 & 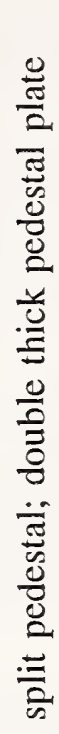 \\
\hline 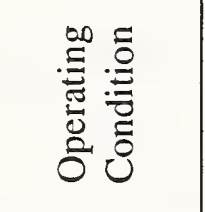 & $n$ & $n$ & $m$ & $\nabla$ & $\nabla$ & $\nabla$ & $n$ & $n$ & $n$ & $m$ & $\nabla$ & $\nabla$ \\
\hline 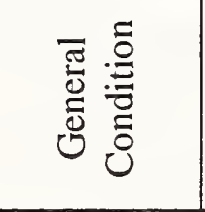 & $n$ & $n$ & $\nabla$ & $m$ & $m$ & $\nabla$ & $n$ & $n$ & $\nabla$ & $\nabla$ & $\nabla$ & $m$ \\
\hline 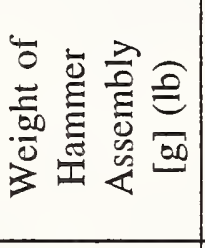 & $\begin{array}{l}\underset{\partial}{0} \\
\stackrel{\infty}{=} \\
\frac{n}{\infty}\end{array}$ & $\begin{array}{l}\underset{0}{\infty} \\
\stackrel{\infty}{=} \\
\frac{\hat{\sigma}}{\infty}\end{array}$ & $\begin{array}{l}20 \\
\stackrel{0}{\infty} \\
ٍ \\
0 \\
\frac{0}{\infty}\end{array}$ & $\begin{array}{l}\underset{\infty}{\infty} \\
\stackrel{\infty}{=} \\
\frac{\infty}{\infty}\end{array}$ & 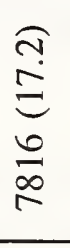 & 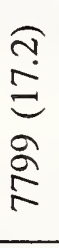 & 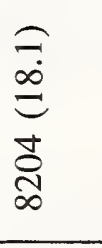 & $\begin{array}{l}\underset{\infty}{\infty} \\
\stackrel{\infty}{=} \\
\frac{\infty}{\infty}\end{array}$ & $\begin{array}{l}\underset{0}{0} \\
\stackrel{\infty}{=} \\
\stackrel{n}{\infty}\end{array}$ & $\begin{array}{l}\underset{\vdots}{\Xi} \\
\frac{m}{\infty}\end{array}$ & 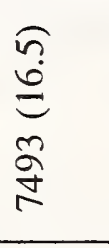 & $\begin{array}{l}\underset{f}{\infty} \\
\stackrel{\infty}{\infty} \\
\underset{\sim}{\infty} \\
\infty\end{array}$ \\
\hline 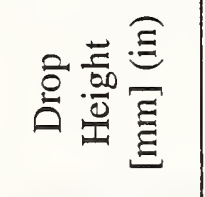 & 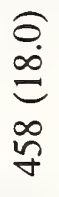 & $\begin{array}{l}\underset{\partial}{\infty} \\
\underset{\infty}{=} \\
\stackrel{\infty}{\vartheta}\end{array}$ & 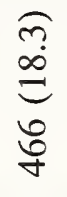 & 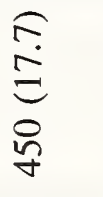 & $\begin{array}{l}\underset{\sigma}{\infty} \\
\underset{n}{\sigma} \\
\tilde{\sigma}\end{array}$ & $\begin{array}{l}\underset{\infty}{\infty} \\
\qquad \\
\frac{\pi}{\sigma}\end{array}$ & $\begin{array}{l}\underset{\partial}{\infty} \\
\underset{\infty}{\sigma} \\
\tilde{\sigma}\end{array}$ & 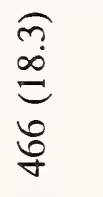 & 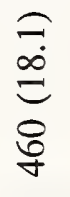 & 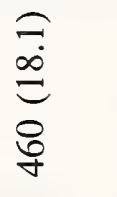 & 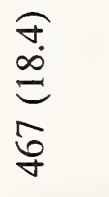 & 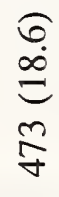 \\
\hline 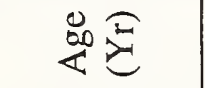 & $N$ & - & 6 & 交 & $\simeq$ & $n$ & $m$ & $m$ & - & - & $n$ & 克 \\
\hline 离 & $\stackrel{\Xi}{\Xi}$ & $\stackrel{\varrho}{\Xi}$ & $\stackrel{\varrho}{\Xi}$ & $\stackrel{\mathscr{E}}{\Xi}$ & 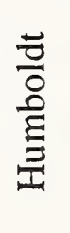 & $\begin{array}{l}\frac{\bar{\sigma}}{8} \\
\frac{8}{E} \\
\text { 吾 }\end{array}$ & $\stackrel{\mathscr{\Xi}}{\Xi}$ & $\stackrel{\varrho}{\Xi}$ & $\stackrel{\varrho}{\varrho}$ & $\stackrel{\varrho}{\Xi}$ & 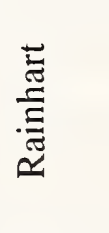 & $\stackrel{\varrho}{\Xi}$ \\
\hline 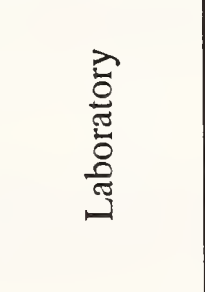 & $\sum_{\bar{\alpha}}^{\vec{\alpha}}$ & 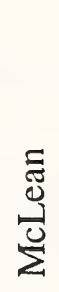 & 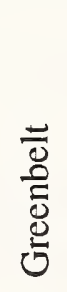 & $\begin{array}{l}\frac{0}{3} \\
\frac{3}{0} \\
\frac{\pi}{0} \\
\frac{1}{0} \\
\frac{0}{9}\end{array}$ & 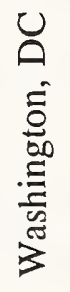 & 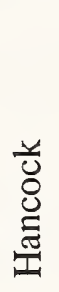 & 芯 & $\begin{array}{l}\overline{0} \\
\frac{0}{0} \\
3 \\
3\end{array}$ & 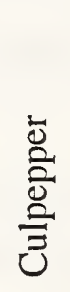 & 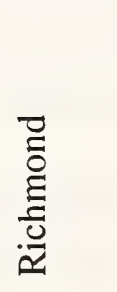 & 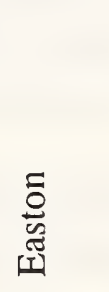 & $\begin{array}{l}\bar{\circlearrowright} \\
\stackrel{0}{0}\end{array}$ \\
\hline
\end{tabular}


AASHTO T-245 as $4536 \mathrm{~g}$ [10 lb]; however, perhaps equally important are the masses of the other components of the hammer assembly (tamping foot, shaft, etc), which are not specified in the standard. The weight of the entire hammer assembly was recorded for the field study and is presented in table 3 . The mass of the drop weight was not recorded since this would have required dismantling the hammer assembly. There was considerable variation in the weight of the hammer assemblies in the inventory, ranging from a low of $7493 \mathrm{~g}(16.5 \mathrm{lb})$ to a high of $8328 \mathrm{~g}(18.4 \mathrm{lb})$.

The mass of the other components may have a significant affect on the compaction process, for the following reason. During a hammer blow, the drop weight impacts the tamping foot, which in turn causes the sample to densify. The mass of the tamping foot, and perhaps a portion of the mass of the other hammer components, is involved in the dynamics of the hammer blow. A simple dynamic analysis will show that for a given drop weight and drop height, the initial velocity of the tamping foot will be greater for a tamping foot with lower mass. The extent to which the mass of the other components participate in the compaction process depends on the details of the connection of the tamping foot to the shaft, which varies from one hammer design to the next.

The blow interval, or time between blows, was generally consistent among the machines. On average, a typical mechanical hammer delivers a blow about once every second. One machine, however, had a very long blow interval, on the order of 1.5 seconds, while another had a very short blow interval, on the order of 0.75 seconds. The blow interval may or may not have an affect on the compaction process, for two reasons. First, a hammer with a longer blow interval may be supplying additional smaller blows after the initial blow, because of bouncing (a bouncing or "ring-down" phase can be heard in some machines with a long blow interval). A machine with a shorter blow interval may pick up the drop weight for the next blow, before it has had a chance to deliver additional, smaller blows because of bouncing. Second, the overall time required to complete the compaction process will be longer for a machine with a longer blow interval, which may result in greater heat loss. For example, assuming it takes thirty seconds to rotate the sample for the second series of blows, it will take approximately 2.4 minutes to prepare a 75-blow Marshall specimen in a machine that blows every 0.75 seconds. It will take approximately 4.3 minutes to prepare the same sample in a machine that blows every 1.5 seconds. The extra two minutes required to prepare the sample in the second machine may be sufficient time to reduce the temperature of the sample enough to have an effect on the results. This effect should be studied further.

According to AASHTO T-245, the steel plate for the pedestal shall have dimensions 304.8 by 304.8 by $25.4 \mathrm{~mm}$ ( 12 by 12 by 1 in). Two of the machines had double thick steel plates (i.e., $50.8 \mathrm{~mm}(2$ in) thick). This would increase the mass of the pedestal by approximately by $18 \mathrm{~kg}(40 \mathrm{lb})$, which could have an effect on the compaction process, as described in Shenton, et al (1994).

A variety of methods for attaching the steel plate to the pedestal were also noted. Some designs use lightweight angles and screws to secure the plate to the wooden pedestal. Others use heavier angles, lag bolts, and a threaded rod through the pedestal to secure the plate. There are illustrated in figure 7. Similar details are used at the base of the pedestal to connect 
the angles that anchor the machine to the foundation (figure 1.). The concern here is whether the steel plate is actually bearing on the pedestal. Ideally, the load should be transferred through the plate and into the pedestal by bearing only. However, some pedestals show little or no evidence of bearing on their top or bottom surface when the steel plate is removed, which indicates that the load is not being transferred by bearing, but through the bolts and/or threaded rod. This may vary the effective stiffness of the pedestal which may affect the compaction process (Shenton, et al, 1994). The same is true for the pedestal bearing on the support foundation.

It is not clear whether splits or cracks in the hammer pedestal affect the compaction process, but several of the pedestals in the field study were split. Some pedestals are constructed by laminating or nailing several boards together to achieve the specified dimensions. Based on field observations, pedestals of this construction tend to delaminate and open at the board joints.

A variety of foundation support systems were encountered. All hammers were located on the first floor of the buildings that housed the machine, and in only one case was there a basement or crawl space below the first floor of the building. Six of the twelve machines were bolted directly to a concrete slab on grade. Four were secured to a concrete pedestal that was anchored or simply rested on the floor of the building. The concrete pedestals ranged in thickness from 50 to $220 \mathrm{~mm}$ ( 2 to $8.5 \mathrm{in}$ ). In plan, the concrete pedestals ranged from just slightly larger than the footprint of the machine, to large enough to hold two or three machines. Two machines were secured to concrete pedestals, which in turn rest on a pad $(\sim 25$ $\mathrm{mm}[1$ in]) of dense plastic or rubber.

The affect of variations in the foundation stiffness was studied in Shenton, et al (1994) and shown to have little effect on Marshall test results. Except for the two machines that are supported on pads, the variations in foundation observed in the field were not expected to influence the Marshall test results. However, for the machines supported on pads, the concrete slab on which they are bolted is, in effect, isolated from the floor and may influence the compaction process.

\section{Problems Encountered During the Site Visits}

A few problems were encountered during the field study that suggest possible changes or modifications to the calibration device. The problems are discussed below.

The calibration device, as designed, was intended to be used with any Marshall hammer, regardless of the manufacturer. Until the field study, however, the device had been tested in only two hammers, a new machine manufactured by Pine Instruments and a very old machine manufactured by Rainhart Co. Two problems were encountered while using the device in the Humboldt machines in the study inventory. First, the current calibration device is approximately $5 \mathrm{~mm}(0.2 \mathrm{in})$ too high to fit easily into the Humboldt machine. Humboldt machines uses an "arm" with a square pin to secure the hammer in the machine. Thus, there is limited clear distance between the top of the pedestal and the arm for the calibration device 


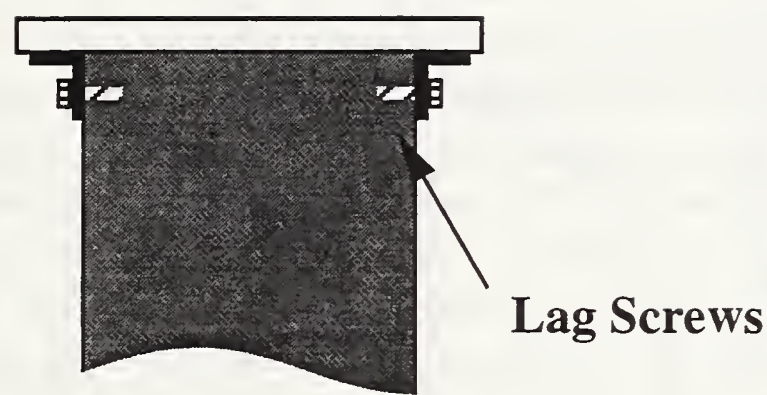

Front

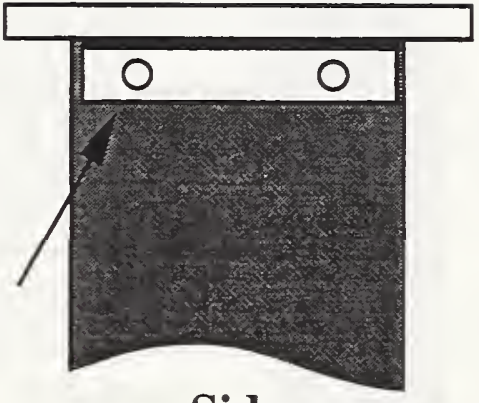

Side

(a. Lag screw connection detail)

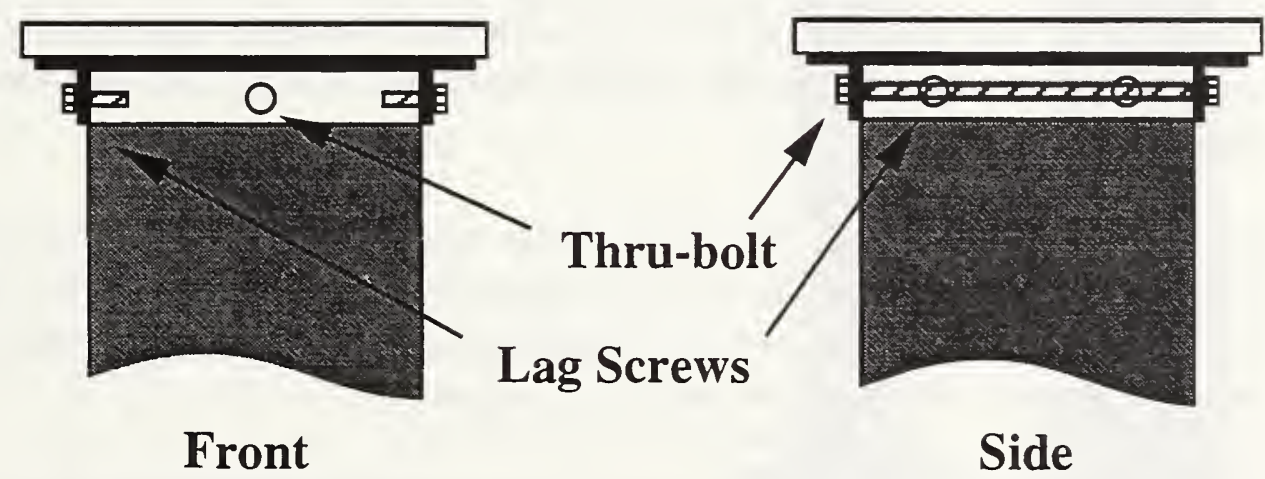

(b. Lag screw and thru-bolt connection detail)

Figure 7. Pedestal connection details. 
and hammer assembly. This is shown in figure 8. The problem was overcome in the field study by cutting $5 \mathrm{~mm}(0.2 \mathrm{in})$ off of the length of the Humboldt hammer. This modification was not as difficult or damaging as it might seem. The hammer uses a short section of square tube, bolted to the top of the shaft, as the key hole for the pin that holds the hammer in place. A section of old tube from an abandoned hammer was cut shorter and mounted to the hammer used in the study. The calibration device and hammer then fit into the machine and operated without additional problem. After completion, the original tube was replaced on the hammer shaft.

The second problem dealt with the mechanism for keeping the mold or device centered on the Humboldt pedestal. Referring to figure 9, the Humboldt design uses a single pin in the center of the pedestal and a mating hole in the mold base. The Pine and Rainhart machines use three pins in the pedestal around the circumference of the mold base. The calibration device was designed to take advantage of the three-pin design and does not have a mating hole for the Humboldt pedestal. Without additional restraint, the device had a tendency to "walk" around the pedestal as the blows were delivered in the Humboldt machine. To overcome this problem in the field study, the calibration device was gently held in place by hand while the Humboldt machine was in operation.

The final problem encountered deals with the assembly detail of the calibration device. The current design relies solely on thread adhesive to keep the device together, and to maintain the small preload on the springs and force transducer (see figure 3 ). The device was assembled at the start of the field study with a medium grade thread adhesive. This grade of adhesive proved to be adequate in all previous testing with the device, but not for the field study. At the fifth site (Hancock, Maryland) in the first series of visits, after collecting two sets of seventy-blow data, the calibration device came loose and lost its preload. The device could not be used after this happened because the preload is essential for the proper operation of the device and affects the calibration of the force transducer. The visit was not a complete loss, the site machine was inspected and the uncalibrated Marshall specimens were made as originally planned. Two other site visits, already scheduled during that sequence of trips, were similarly affected.

The research team had to return to the laboratory to reassemble the device before continuing with the first site visits. There, the device was reassembled with the highest grade thread adhesive available, the device load cell was recalibrated and the spring stiffness measured. Site visits were resumed and work proceeded as planned.

To complete the sample set of diagnostic data, one member of the research team returned to Hancock, and the other two sites scheduled during that trip (Fairmont, West Virginia and Weston, West Virginia) and collected new diagnostic data. It should be pointed out that the integrity of the diagnostic data collected prior to the first visit to Hancock could be questioned, because of the unknown state of the device during those visits. That is, the device could have been slowly loosening, which would have affected the data, and only finally come apart during the Hancock visit. Although it was not possible to visit all the other sites again, new diagnostic data was collected at the AMRL site. 


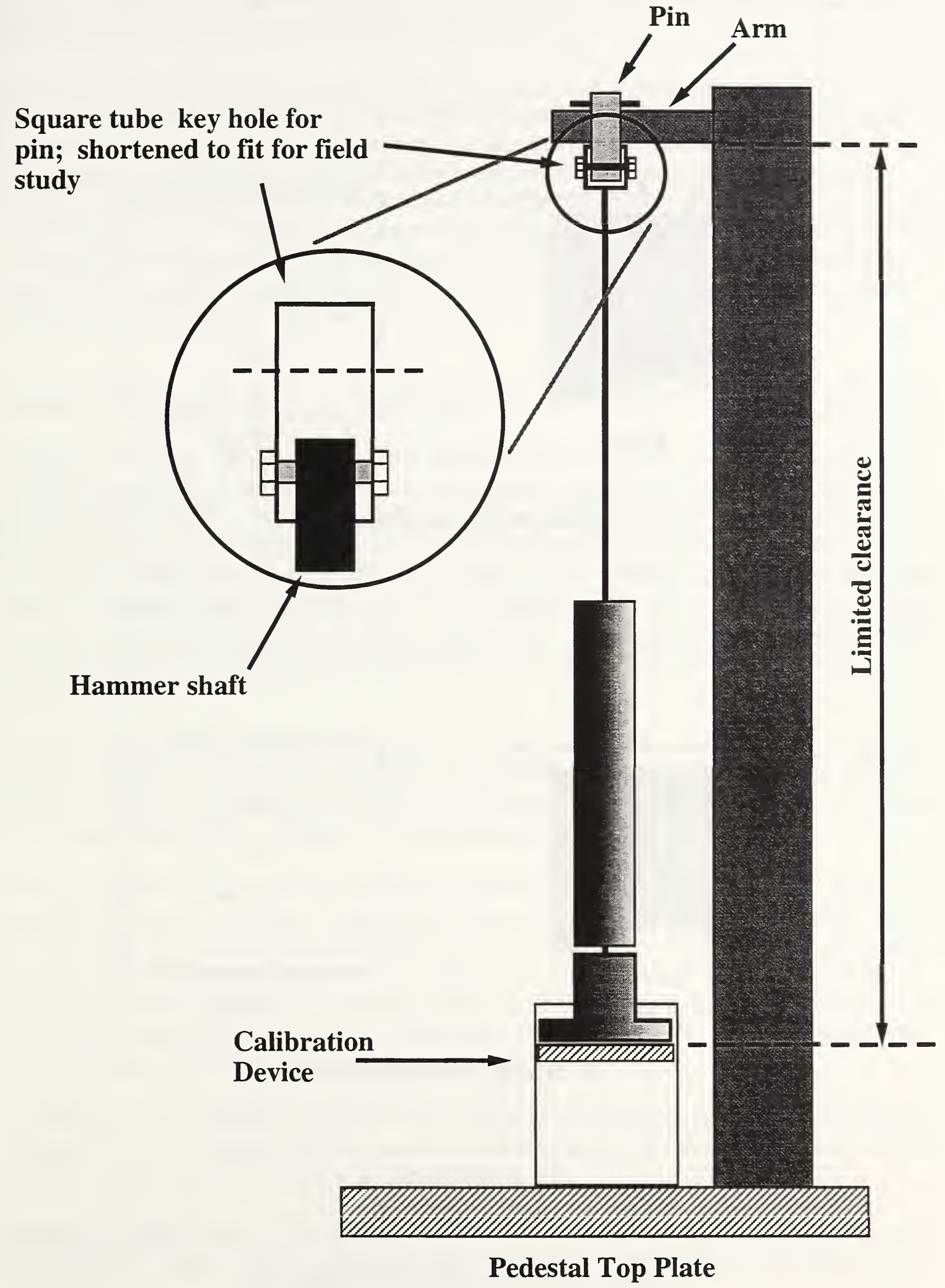

Figure 8. Humboldt hammer. 

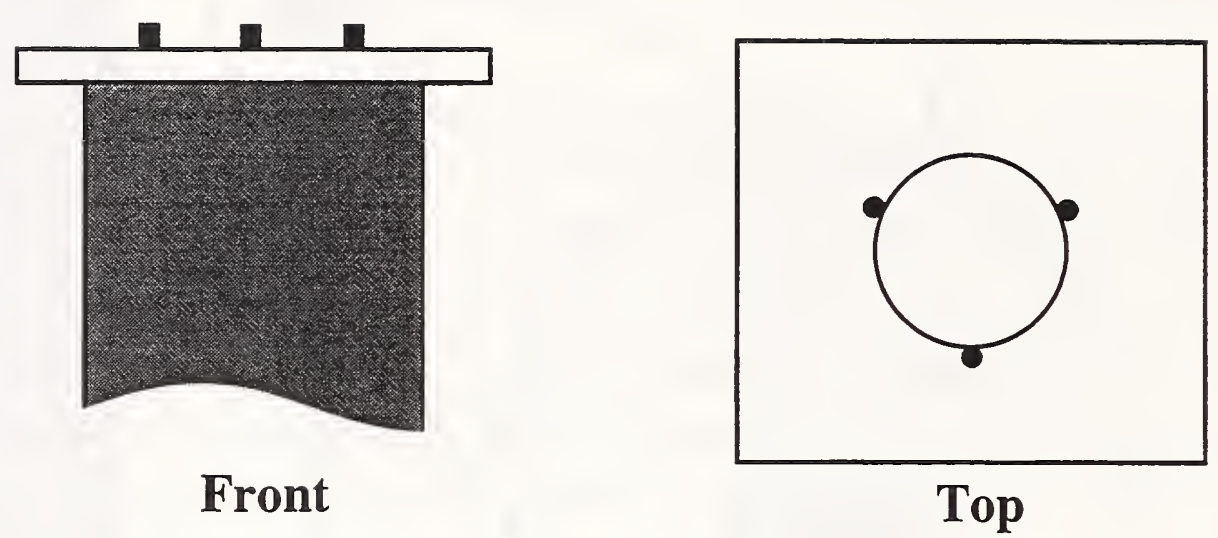

(a. Three pin configuration)

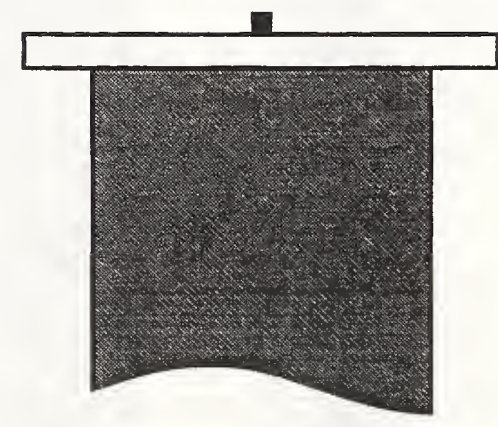

Front

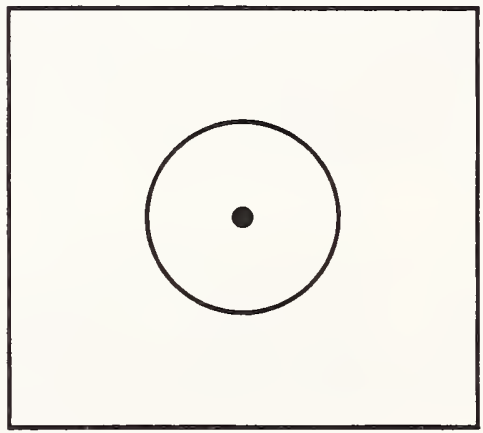

Top

(b. Single pin configuration)

Figure 9. Mold centering pin configurations. 
For the remainder of the study, which included nineteen site visits, seven to complete the first series and twelve in the second series, the calibration device remained together. Nearly four thousand blows were delivered to the device during that time.

This problem was not totally unexpected and was noted as a potential problem in the conclusions of the original report on the calibration system (Shenton, et al, 1994). A higher grade thread adhesive may be a satisfactory solution, but a more robust mechanism for holding the device together is needed. The other two problems mentioned can be easily addressed with slight modifications to the calibration device. The height of the device can be reduced by reducing the thickness of one or more parts; for example, the base, bottom sleeve and top plate (see figure 3). A centering hole for Humboldt machine can be provided by a simple insert. Any such modifications would require a design review to check for possible over stress or interference of the device parts.

\section{Summary of Diagnostic Data and Determination of the Standard Cumulative Impulses}

Diagnostic data were collected at each site during the first site visit, compiled and used to establish the standard cumulative impulses. At each site, three sets of data were collected, with the device in the 4-, 8-, and 12-0-clock positions. Data sets consisted of 70 blows each. The average peak force, average impulse, cumulative impulse at 50 blows, and cumulative impulse at 75 blows were then determined for each of the 3 data sets. An overall average and standard deviation of these quantities was then computed for the site, based on the individual data set averages and cumulative impulses. These results are presented in the top half of table 4 for the twelve sites. These statistics correspond to the within-laboratory variability of diagnostic data.

Summary statistics are presented at the bottom of table 4, i.e., these are the average, standard deviation, coefficient of variation (standard deviation divided by the average, times onehundred), minimum, and maximum of the 12 site averages. The summary statistics correspond to the between-laboratory variability of diagnostic data.

Machine variability is clearly evident from the results shown in bottom of table 4 . The average peak force, for example, ranges from a low of $47.1 \mathrm{kN}$ (10.6 kip) to a high of 71.2 $\mathrm{kN}$ (16.0 kip). The between-laboratory coefficient of variation for peak force is approximately $10 \%$; the within-laboratory coefficient of variation, on the other hand, is on the order of 3 to $4 \%$ for most sites. There is less variability, however, in the between-laboratory average impulse. The coefficient of variation in that case is approximately $6 \%$, and the corresponding within-laboratory coefficient of variation is less than $1 \%$.

The variability in cumulative impulse is not as large as it is for peak force. The coefficient of variation for the 50-blow cumulative impulse is approximately 6\%; the coefficient of variation for the 75-blow cumulative impulse is approximately $5 \%$.

Presented in figure 10 are force time histories for the twelve machines. Each time history is the average of seventy blows for that particular machine, recorded with the calibration device 


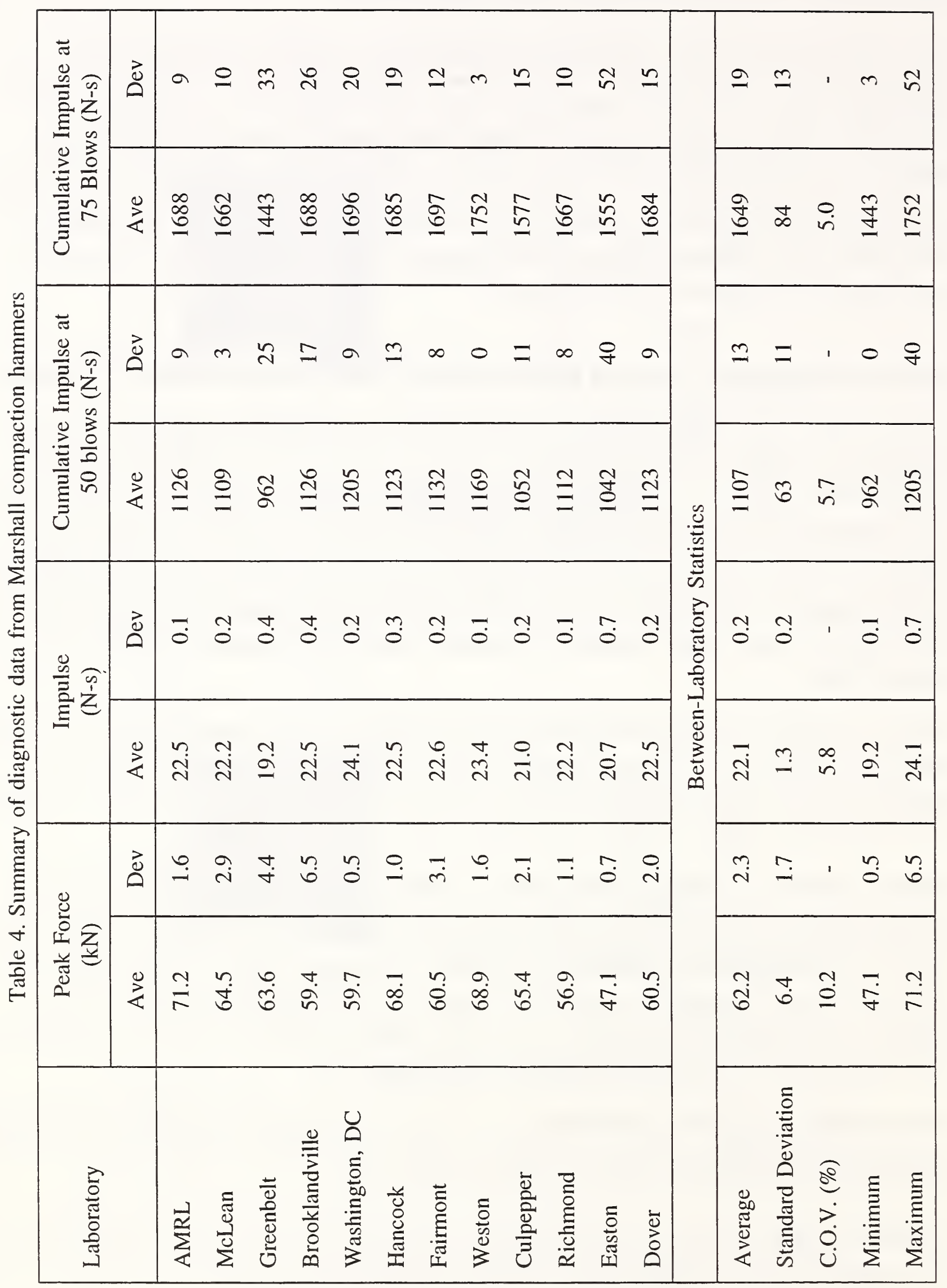


oriented in the 8 o'clock position on the pedestal. The time histories are similar in their general shapes and durations, but they do have subtle differences. The time history is characterized by a primary pulse, followed by a "ring-down" phase that has any oscillatory shape. A negative (tensile) force in the ring-down phase is possible because of the compression preload in the device. On average, the primary pulse has a duration between 0.6 and 0.7 milli-seconds. The primary pulses for several of the machines manufactured by Pine Instruments have very similar shapes; the pulse has a sharp initial rise and fall, with a plateau on the falling side of the primary pulse before the first zero crossing. The average time history for Easton, Maryland is unique, compared with the others: the Easton machine was the only one of its type in the inventory. Although obvious differences exist, the 50- and 75-blow cumulative impulses for the twelve machines are reasonably consistent. This is most likely because the cumulative impulse is based on the sum of the integrated areas (from the start of the initial pulse to the first zero crossing) under numerous time histories, and consequently, small differences in time histories have little affect on the cumulative impulse.

\section{Standard 50- and 75-blow Cumulative Impulse}

The standard 50- and 75-blow cumulative impulses were selected based on the summary averages presented in table 4 , i.e.:

standard 50-blow cumulative impulse $-\mathrm{I}_{50}=1100 \mathrm{~N}$-s $(247 \mathrm{lb}-\mathrm{s})$ standard 75-blow cumulative impulse $-\mathrm{I}_{75}=1650 \mathrm{~N}-\mathrm{s}(371 \mathrm{lb}-\mathrm{s})$

Dividing $\mathrm{I}_{50}$ by the average impulse for the twelve machines $(22.1 \mathrm{~N}$-s [4.97 lb-s]) yields 50 blows, after rounding. Similarly, dividing $I_{75}$ by the average impulse yields 75 blows, after rounding.

Before beginning the second series of site visits, a projected calibrated blow count was computed for each of the twelve sites. The projected calibrated blow count was determined as it would be during normal calibration, using the summary reports from the diagnostic data. The results are presented in table 5. The projected calibrated blow count was used as a cross check on the consistency of the machine and calibration system, and to provide insight into the range of calibrated blow counts expected during the second visits.

The projected calibrated blow counts ranged from 45 to 57 , for the 50-blow series, and from 68 to 85 for the 75-blow series. Note that the distribution of projected blow counts is biased toward the low end, with nine of twelve sites below the average of 50 and 75 , respectively. The skew is due in part to the projected calibrated blow counts for the Greenbelt site. Referring to table 4, the average impulse for Greenbelt is, for some reason, much lower than the average impulse for the other sites, which resulted in much larger projected calibrated blow counts for Greenbelt. The values are more symmetrically distributed about the mean when the projected calibrated blow counts for Greenbelt are excluded. Note that Greenbelt was the last site visited prior to the calibration device coming apart at Hancock, and therefore, as mentioned previously, the diagnostic data (i.e., average impulse) for that site may be suspect. 

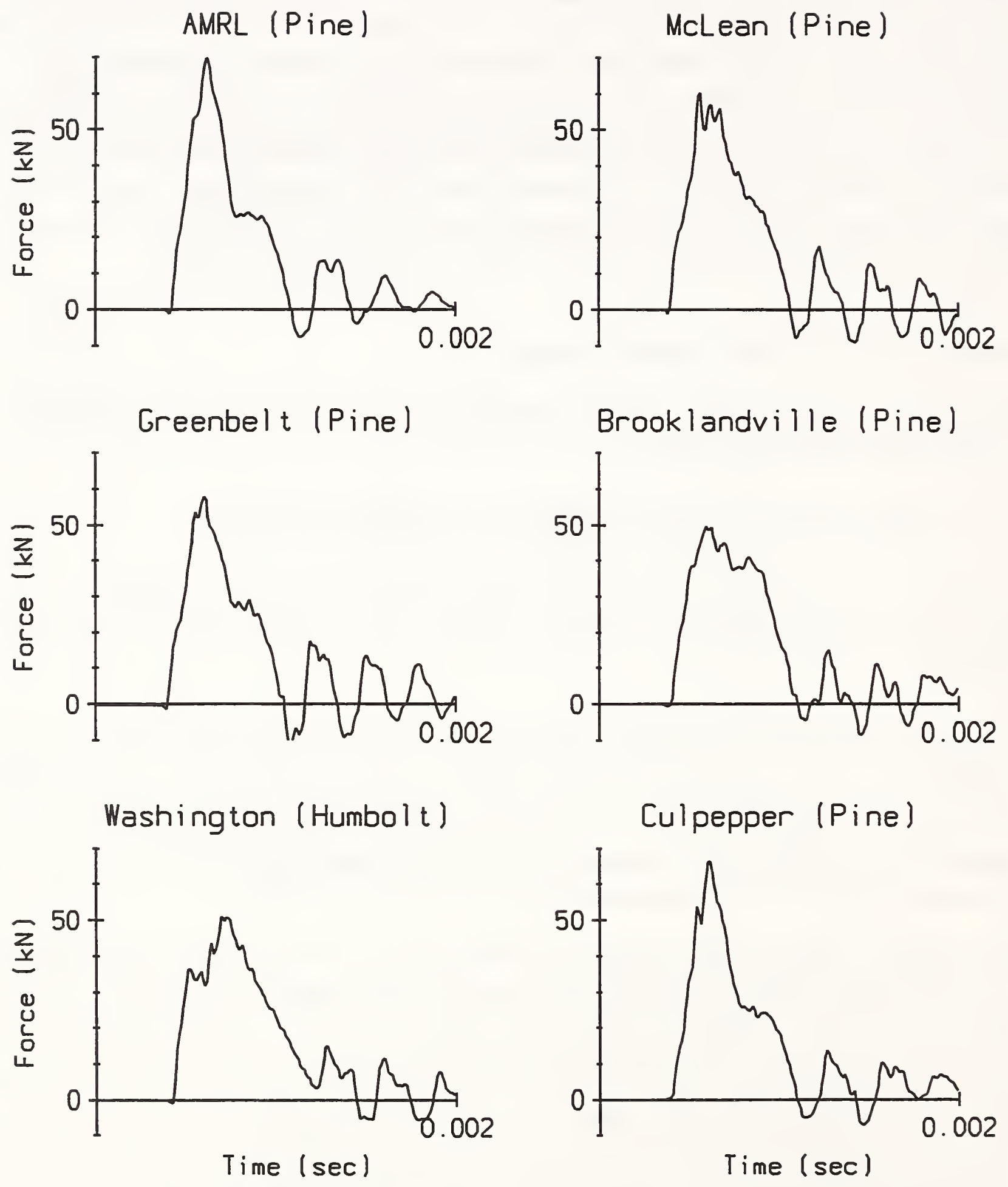

Figure 10. Averaged force-time histories. 

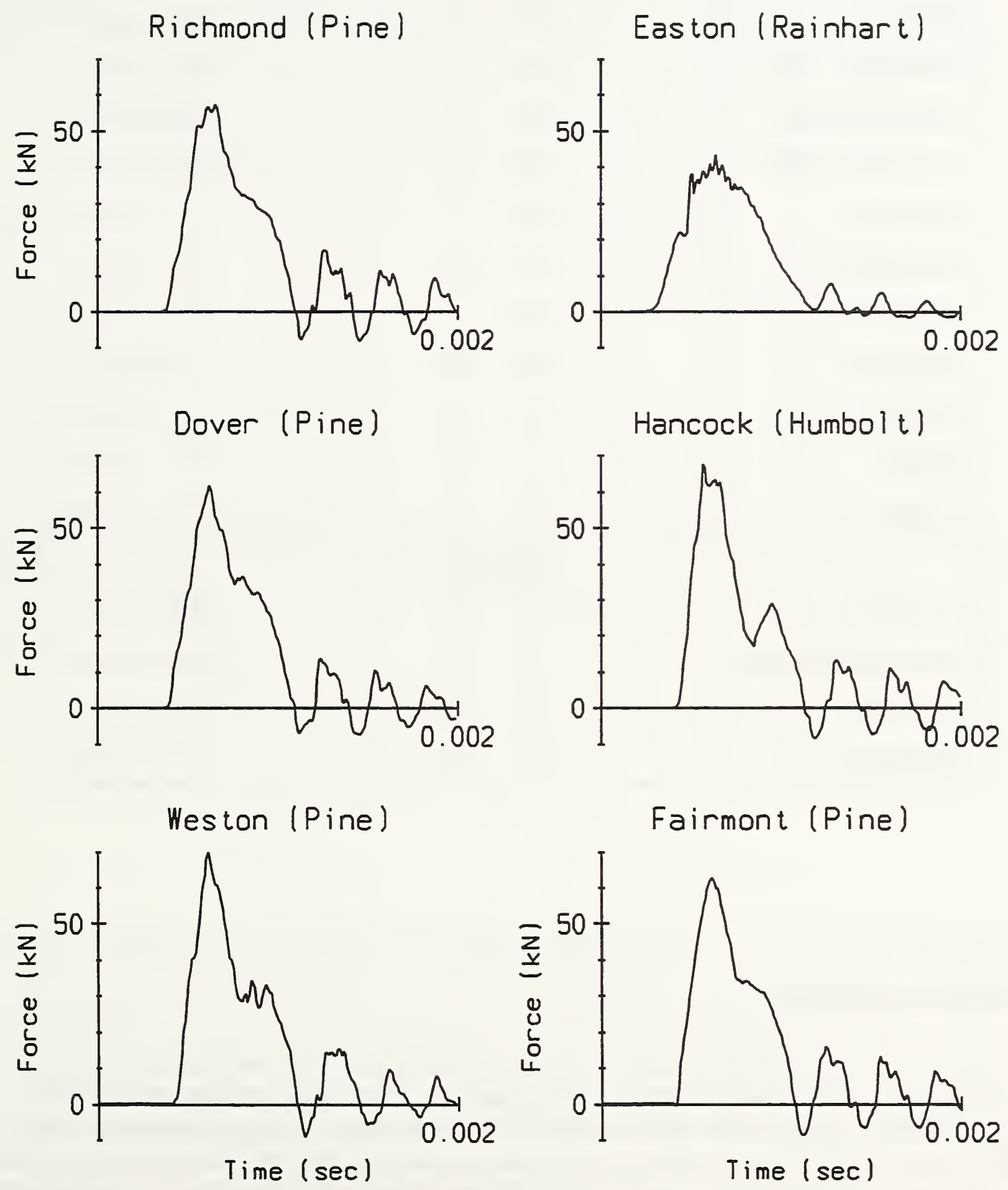

Figure 10 (cont'd). Averaged force-time histories. 
Table 5. Projected calibrated blow counts

\begin{tabular}{|c|c|c|}
\hline Laboratory & $\begin{array}{c}\text { Projected } \mathrm{N}_{50} \\
\text { (based on } \mathrm{I}_{50}=1100 \mathrm{~N}-\mathrm{s} \text { ) }\end{array}$ & $\begin{array}{c}\text { Projected } \mathrm{N}_{75} \\
\text { (based on } \mathrm{I}_{75}=1650 \mathrm{~N}-\mathrm{s} \text { ) }\end{array}$ \\
\hline AMRL & 48 & 73 \\
\hline McLean & 49 & 74 \\
\hline Greenbelt & 57 & 85 \\
\hline Brooklandville & 48 & 73 \\
\hline Washington, DC & 45 & 68 \\
\hline Hancock & 48 & 73 \\
\hline Fairmont & 48 & 72 \\
\hline Weston & 46 & 70 \\
\hline Culpepper & 52 & 78 \\
\hline Richmond & 49 & 74 \\
\hline Easton & 52 & 79 \\
\hline Dover & 48 & 73 \\
\hline \multicolumn{3}{|c|}{ Statistics } \\
\hline Average & 49.2 & 74.3 \\
\hline Standard Deviation & 3.2 & 4.5 \\
\hline Minimum & 45 & 68 \\
\hline Maximum & 57 & 85 \\
\hline
\end{tabular}

\section{Results of Calibration}

Calibration of the machines proceeded without problem during the second site visits. The machines were calibrated according to the procedure outlined in Appendix A, with the exception that seventy blows were recorded for each data set, and not seventy-five. Two calibrated blow counts were determined for each machine, one corresponding to $I_{50}=1100 \mathrm{~N}$ $\mathrm{s}$, and one corresponding to $\mathrm{I}_{75}=1650 \mathrm{~N}$-s. Results of calibration are presented in table 6 .

The calibrated blow counts ranged from 46 to 53, for the 50-blow series, and from 69 to 80 , for the 75 -blow series. The spread of calibrated blow counts was not as broad as projected 
Table 6. Calibrated blow counts

\begin{tabular}{|l|c|c|}
\hline Laboratory & $\mathrm{N}_{50}$ & $\mathrm{~N}_{75}$ \\
\hline AMRL & 47 & 72 \\
McLean & 47 & 71 \\
Greenbelt & 53 & 80 \\
Brooklandville & 52 & (based on $\mathrm{I}_{75}=1650 \mathrm{~N}-\mathrm{s}$ ) \\
Washington, DC & 46 & 78 \\
Hancock & 47 & 69 \\
Fairmont & 47 & 72 \\
Weston & 47 & 72 \\
Culpepper & 50 & 71 \\
Richmond & 46 & 76 \\
Easton & 51 & 69 \\
Dover & 48 & 77 \\
\hline \multicolumn{2}{|c|}{ Statistics } \\
\hline Average & 48.4 & 73 \\
Standard Deviation & 2.4 & 73.3 \\
Minimum & 46 & 3.6 \\
Maximum & 53 & 69 \\
\hline
\end{tabular}

from the diagnostic data, or perhaps as originally expected before the study began. Comparing the actual to the projected calibrated blow counts, some differences are apparent. The actual calibrated blow count was within one or two blows of the projected, for nine of twelve sites, for the 50-blow series, and eight of twelve sites for the 75-blow series.

The difference between the projected and actual calibrated blow at some sites could be attributed to several factors. The projected blow counts for four sites, McLean, Greenbelt, Brooklandville and Washington, were based on diagnostic data recorded before the calibration device came apart at Hancock. As previously discussed, it is possible that the device had already begun to loosen during these earlier visits and only fully loosened during the visit to Hancock. A gradual loosening of the device would have an affect on its output, and consequently, the projected calibrated blow count. The agreement between the projected and 
calibrated blow count is reasonably good, for the rest of the inventory of machines, with the exception of Richmond. A possible explanation for the Richmond case is that routine maintenance had been completed on their machine between visits. Because the maintenance was completed by the agencies equipment maintenance personnel, and not the laboratory technician, the extent of the maintenance was unknown.

\section{Uncalibrated and Calibrated Test Results}

Test results for the uncalibrated and calibrated specimens are presented in tables 7 through 10. The average and standard deviation of stability, flow, air voids and height, for the four replicate specimens and a given test configuration, are presented in the top half of these tables. Note that results for bulk specific gravity are not reported, since the same maximum theoretical specific gravity was used in all calculations for percent air voids.

Between-laboratory variability may be quantified in a number of ways. The most common measures are standard deviation, variance (square of the standard deviation) and coefficient of variation (standard deviation divided by the mean). Another measure is the range or spread in the data. At the bottom of the tables 7 through 10 are the summary, or between-laboratory statistics: average, standard, minimum, maximum and range (maximum minus minimum). Note, these statistics are for the sample set that includes the average value of the respective property, from all twelve sites (i.e., $\mathrm{n}=12)$. The coefficient of variation $(1 \mathrm{~s} \%)$, and 2.83 times the coefficient of variation $(\mathrm{d} 2 \mathrm{~s} \%)$ are also presented at the bottom of tables 7 through 10 in percentage form. $1 \mathrm{~s} \%$ and $\mathrm{d} 2 \mathrm{~s} \%$ are typically reported in the AMRL proficiency sample program to measure the between-laboratory variability and are provided here for direct comparison.

The essence of the results of the field evaluation study are summarized in table 11. Presented in the table are the standard deviation and range of the average uncalibrated and calibrated results. Also presented is the ratio of the two variability measures; for example, standard deviation of stability for the calibrated set, divided by the standard deviation of stability for the uncalibrated set. The effect of calibration is easily interpreted from the ratio of the two measures. Ratios less than one indicate a reduction in variability of the calibrated results, whereas ratios greater than one indicate an increase in variability of the calibrated results, relative to the uncalibrated results. Results for the $50-\mathrm{N}_{50}$ blow series are presented in the top half of the table, results for the $75-\mathrm{N}_{75}$ blow series are presented in the bottom half of the table.

Overall, calibration of the Marshall hammers did not significantly reduce the variability of the test results in the field evaluation study. The variability was reduced in some tests, but not in others. Comparing the $50-\mathrm{N}_{50}$ sets, calibration reduced the variability in the measurement of height: a fifteen percent reduction in standard deviation and an eleven percent reduction in range of the results were achieved. However, the variability of the calibrated data increased for stability, flow and air voids. The greatest increase was found in the measurement of flow. 


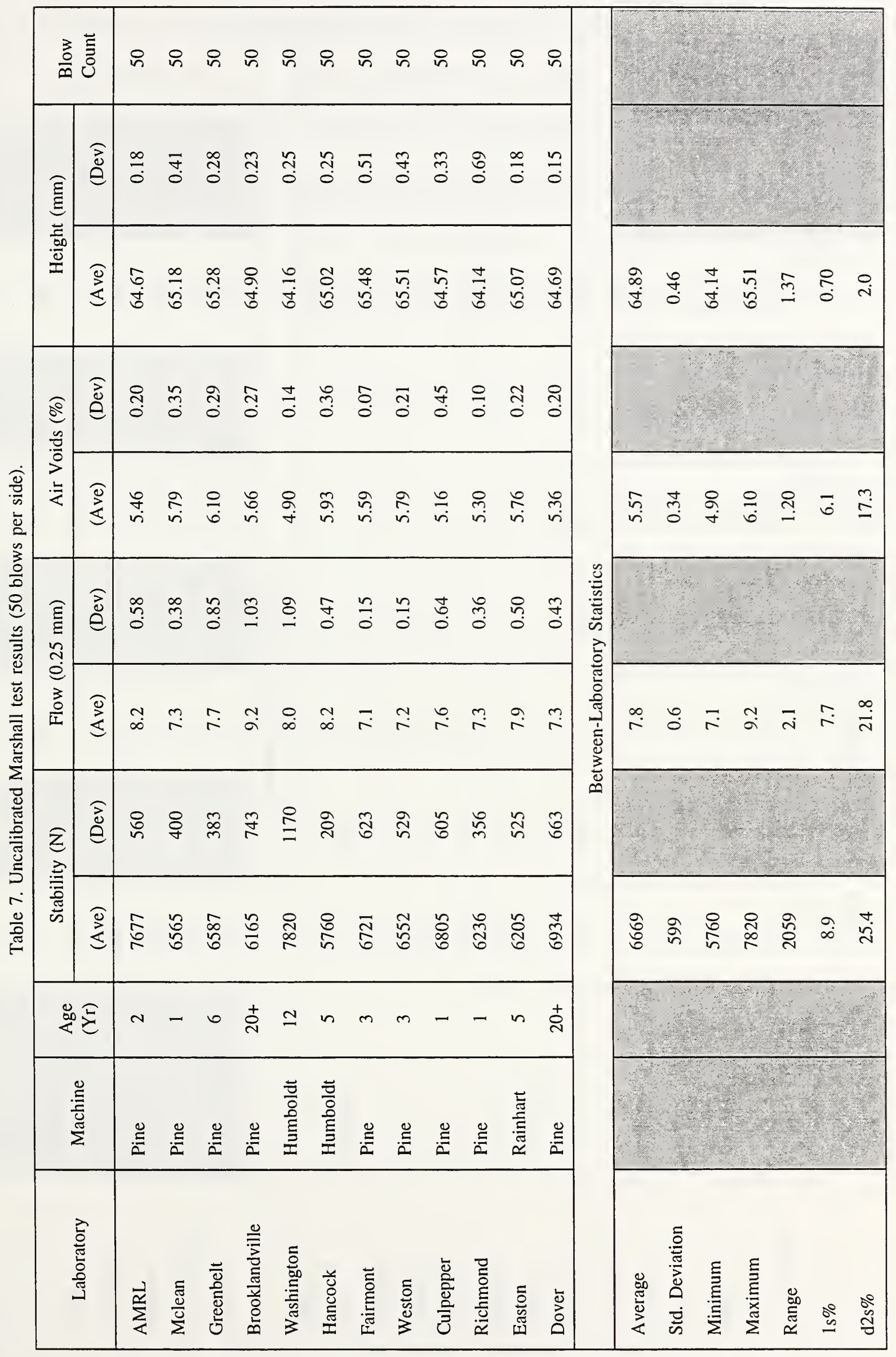




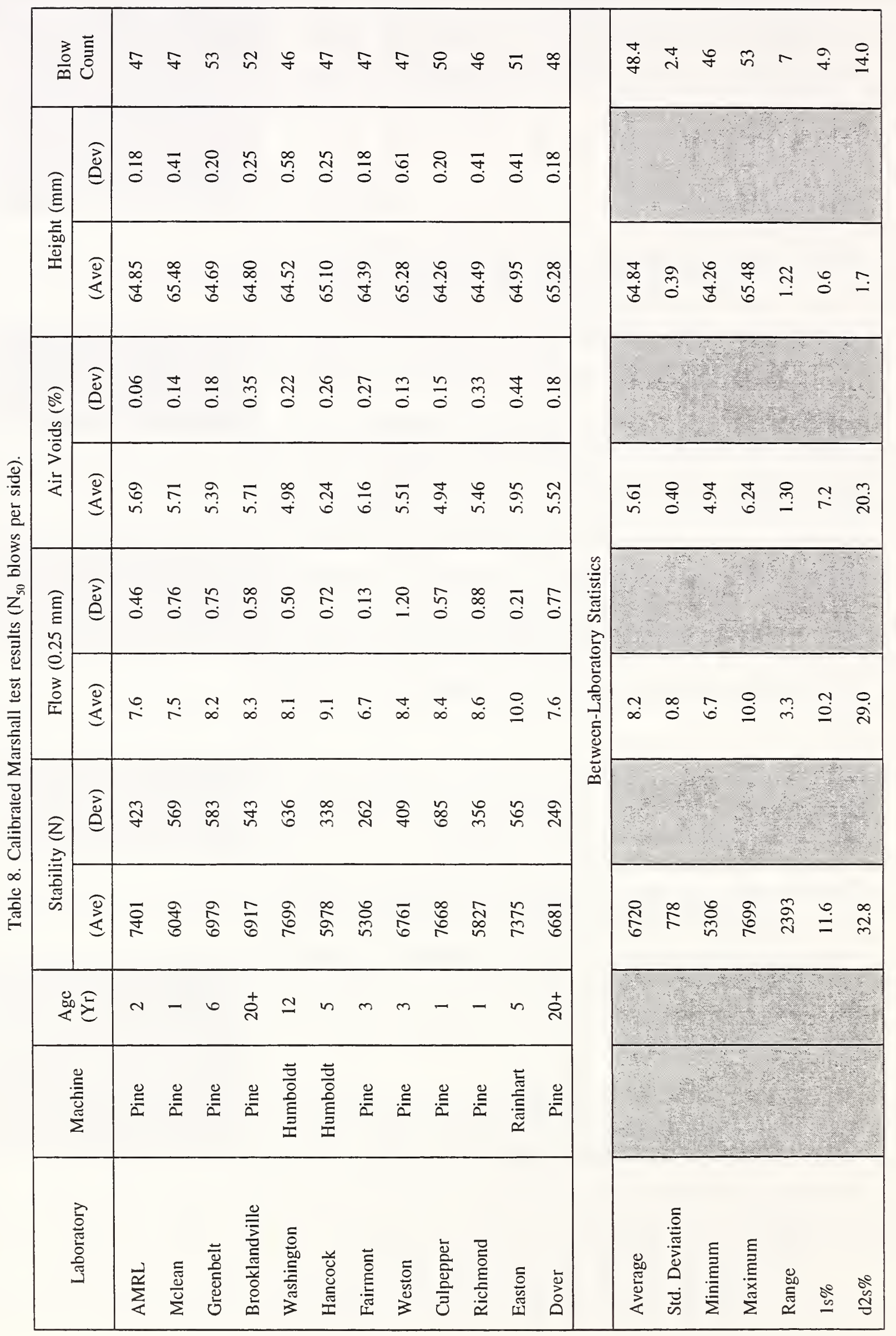




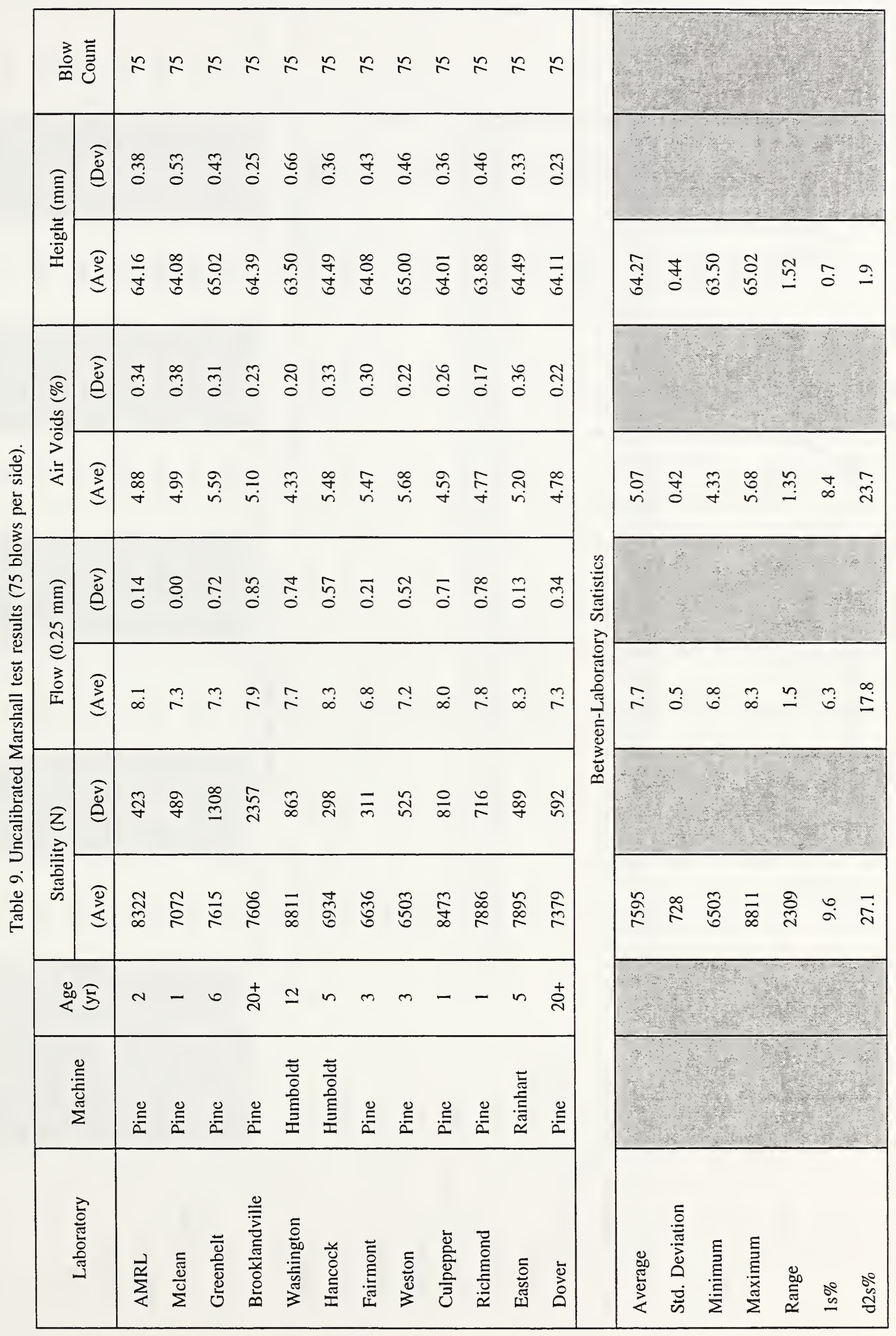




\begin{tabular}{|c|c|c|}
\hline 譥高 & $\approx=8 x 8 z \approx=88=8$ & 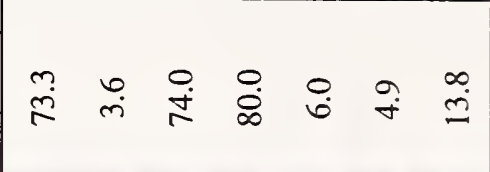 \\
\hline 悥 & 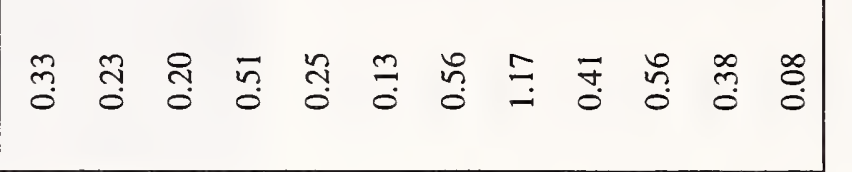 & \\
\hline 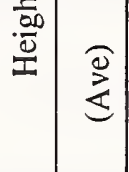 & 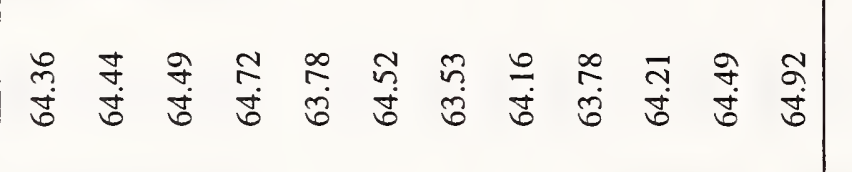 & 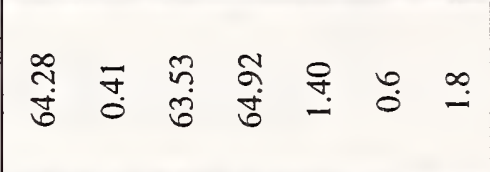 \\
\hline$\frac{8}{8}$ & 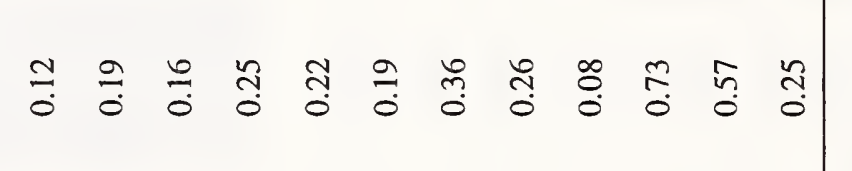 & \\
\hline 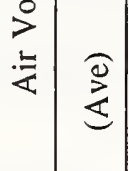 & 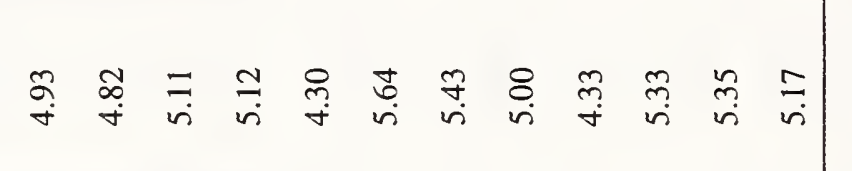 & 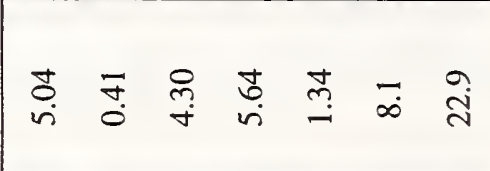 \\
\hline 䜌 & 영 옹 옹 공 & \\
\hline 童高 & 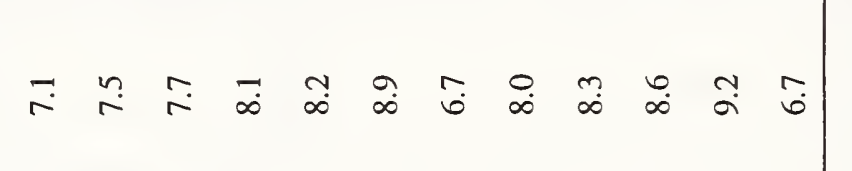 & $\because 83: 3 \cong$ \\
\hline$\frac{8}{8}$ & 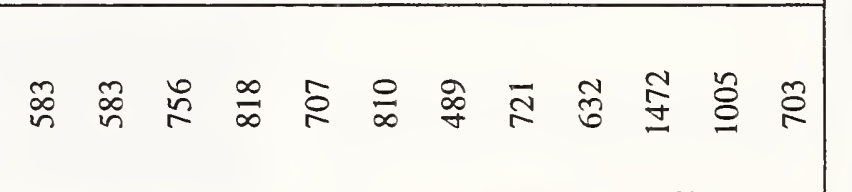 & \\
\hline 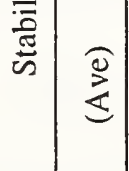 & 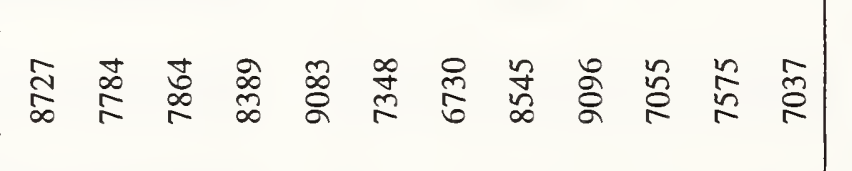 & 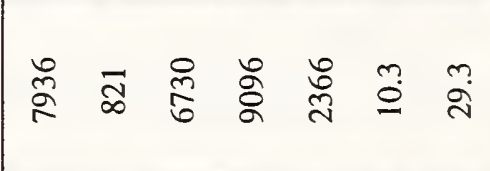 \\
\hline 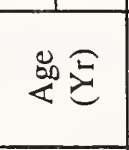 & 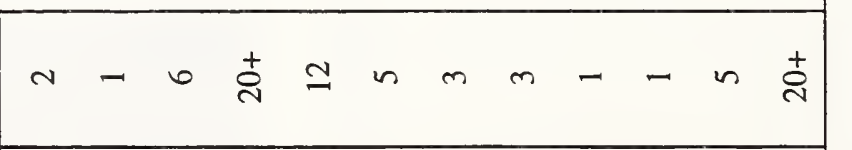 & \\
\hline 高 & 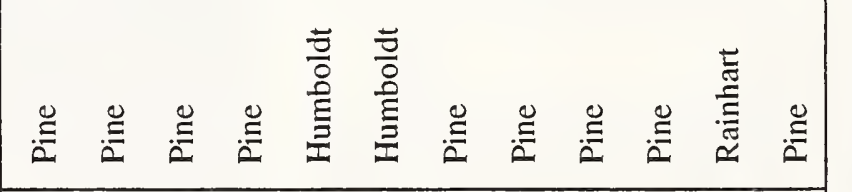 & \\
\hline & 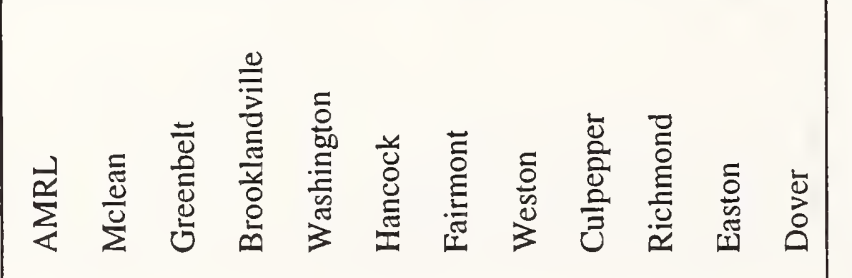 & 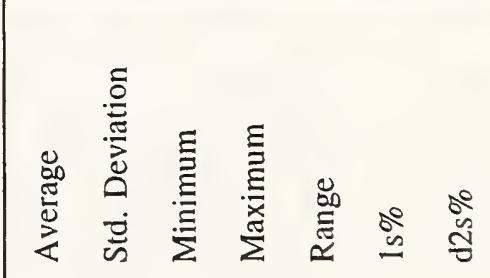 \\
\hline
\end{tabular}




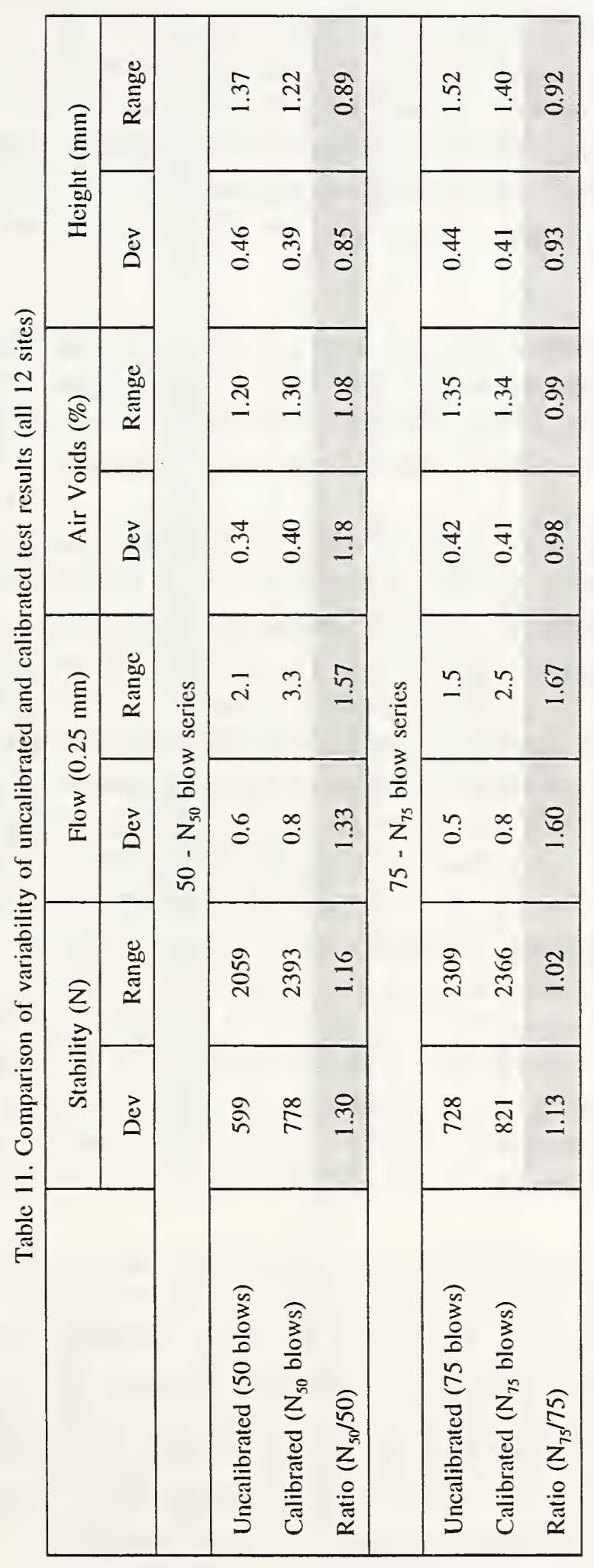


Similar results were noted for the $75-\mathrm{N}_{75}$ blow sets. Calibration reduced variability in the measurements of height and air voids. The reduction for height was on the order of seven to eight percent.

Although the overall variability was not reduced, calibration reduced the variability in the measurement of height in both the $50-\mathrm{N}_{50}$ and $75-\mathrm{N}_{75}$ sets. This is significant because the test to measure height is the simplest of those conducted on the compacted sample. Any additional variability introduced in measuring height is most likely small, compared to that for stability, flow and air voids, since measuring these parameters requires other complicated equipment, or several steps and intermediate measurements to obtain the final measurement. Consequently, height is the most direct measure of the compaction process and machine differences.

In light of the results obtained, the raw data and procedures for the study were reexamined in detail for possible problems or inconsistencies that might explain the marginal reduction, and even increase in variability of the calibrated test results. Two potential problems were uncovered that could have affected the outcome of the results. These are discussed below.

There is evidence that the data obtained from the Fairmont site are flawed and should be excluded from the statistical analysis. Referring to table 2, the theoretical dry air mass of the compacted Marshall specimen is $1240 \mathrm{~g}$. Allowing for some loss, the actual mass would be expected to be between 1230 and $1240 \mathrm{~g}$. The average dry air mass of all the samples (196 total) was $1230.5 \mathrm{~g}(2.71 \mathrm{lb})$, with a standard deviation of $8.9 \mathrm{~g}(0.02 \mathrm{lb})$. The dry air masses of many of the calibrated specimens prepared at Fairmont, however, were extremely low: eight were less than two standard deviations below the grand average (i.e., less than $1212.7 \mathrm{~g}$ [2.67 lb]), and four were less than three standard deviations below the study average (i.e., less than $1203.8 \mathrm{~g}[2.65 \mathrm{lb}])$. Only two other specimens in the entire study fell below the two standard deviation level. Furthermore, one uncalibrated specimen from Fairmont had a dry air mass more than three standard deviations above the grand average. The cause of the problem is not known, however, one possibility is a faulty scale. The effect on the Marshall test results, however, is fairly significant. In reviewing the test data (table 7 through 10), the results for Fairmont are consistently at or near the extreme in every case. Based on this information, the data from Fairmont can, with reasonable certainty, be regarded as suspect and excluded from the statistical analysis. Results of the analysis, excluding the uncalibrated and calibrated data from Fairmont (i.e., eleven sites only), are shown in table 12.

The variability of the calibrated test results, excluding the data from Fairmont, is in general smaller than it is for the full data set and is also reduced relative to the uncalibrated results. Comparing the results in tables 11 and 12 , all of the variability ratios for the $50-\mathrm{N}_{50}$ sets are reduced, except one that is unchanged, and three out eight ratios are less than one. The reduction in variability of the height measurement is about the same, and there is a nine percent reduction in the range of the results for stability. The effect of eliminating the Fairmont data is similar on the $75-\mathrm{N}_{75}$ results. In this case, five out of eight variability ratios are less than one. The reductions range from 1 to 25 percent. 


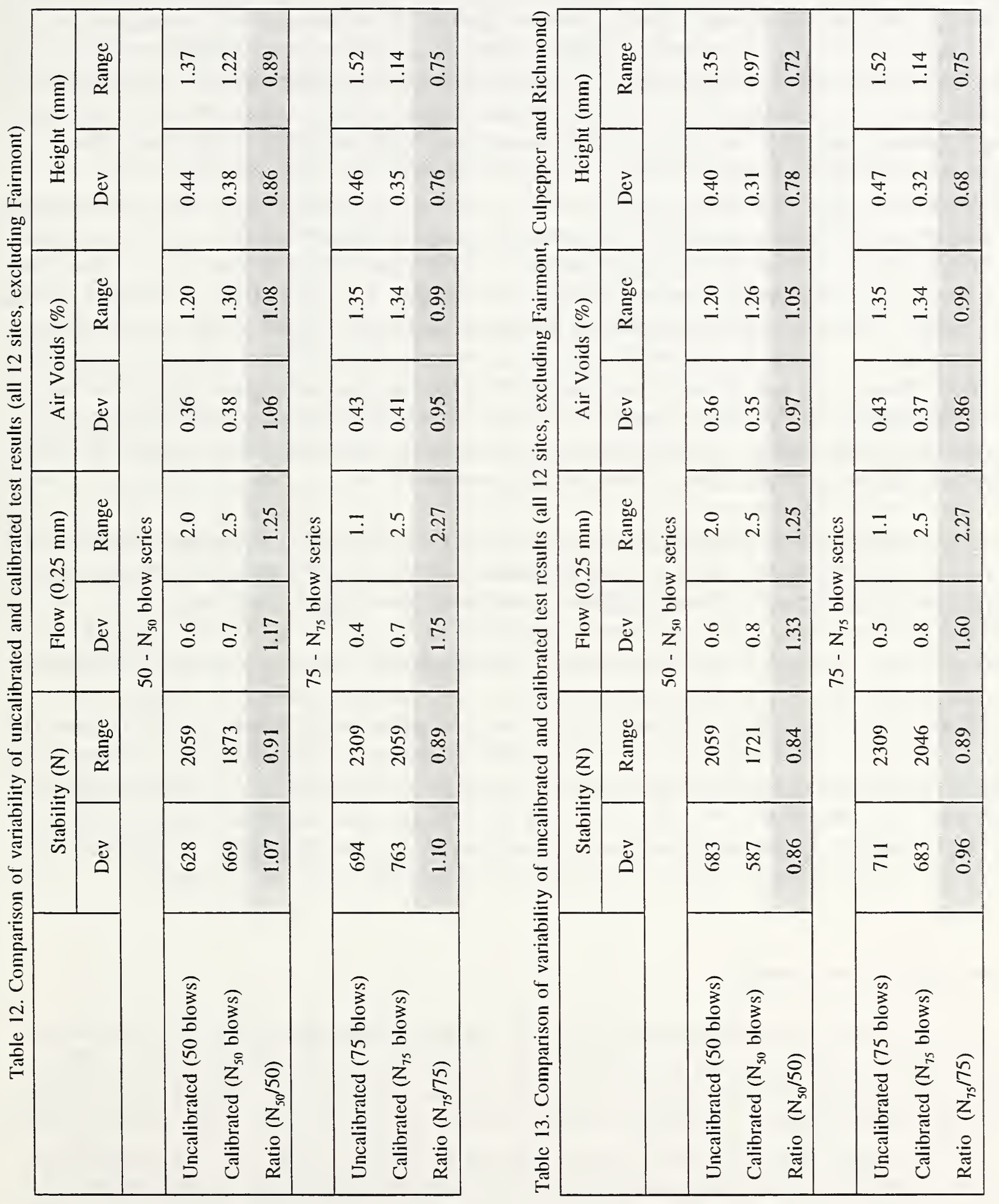


One other problem was noted that could have affected the Marshall test results in the study. All of the first site visits occurred in late winter during the construction slow-season. Consequently, all of the machines were cold when the uncalibrated specimens were prepared. The second site visits occurred in early spring, at the beginning of the construction season, when the laboratories were just beginning to use their Marshall equipment. No instructions were given to the laboratories regarding the use their Marshall hammer on the day of the scheduled visit; however, because of the time of the scheduled visit or the laboratories' work load, most of the site hammers were also cold at the start of their second site visit. This was not the case for the Culpepper and Richmond sites. Upon arriving at these two sites, it was noted that the machines had been in use for some period of time earlier in the day. The hammer at Richmond had delivered approximately 1000 blows, while the hammer at Culpepper had delivered about 1500 blows. The extent to which this could affect the outcome of calibration and preparation of the calibrated Marshall specimens is not clear; however, the environment and state of the Marshall hammer was not consistent with that of the other sites, or consistent with the conditions encountered at these sites during the first visit. Based on this information, the data from Culpepper and Richmond can also be regarded as suspect and can be excluded from the statistical analysis. It should be emphasized that the data has not been excluded based on a formal statistical analysis of the results, in fact, upon review, the data from Culpepper and Richmond appears to be well within the distribution of the sample set. Rather, the data is being excluded because the conditions encountered during these two visits were not consistent with those of the other 22 site visits.

Results of the statistical analysis, excluding data from Fairmont, Culpepper and Richmond are shown in table 13. Again, the data from Fairmont, Culpepper and Richmond was excluded from both the calibrated and the uncalibrated data sets, leaving just nine sites.

With the three data sets excluded, the effect of calibration is more pronounced. Comparing the results in table 11 with the results in table 13, the standard deviation and range of the calibrated results are smaller than they are for the corresponding full data set. In contrast, the standard deviation and range of the uncalibrated results are generally equal to or greater than they are for the corresponding full data set. Consequently, the variability ratios are reduced for both the $50-\mathrm{N}_{50}$ and $75-\mathrm{N}_{75}$ data sets. Five out of eight variability ratios for the $50-\mathrm{N}_{50}$ results are less than one: reductions range from 3 to 28 percent. Six out of eight ratios are less than one in the $75-\mathrm{N}_{75}$ data set, with reductions ranging from 1 to 32 percent.

\section{Discussion of the Results}

The results of the field study presented here do not demonstrate the benefit of calibration as dramatically as did the results of the laboratory evaluation program (Shenton, et al, 1994). Although a slightly different procedure was used in the analysis of the data in the laboratory program, the reduction in variability measured in that study was on the order of fifty percent, for all the design properties. When the full data set is analyzed (table 11), the variability of the calibrated data in the field study increased or decreased, depending on the property. The results of calibration are clearly evident when the analysis is conducted on the reduced data set, excluding possibly flawed data from three sites. In this case, the variability of the 
calibrated data in the field study in general decreased. The reductions range 1 percent to about 35 percent. Some of the reductions obtained with the reduced data set are substantial; however, they are still small compared with those obtained in the laboratory program.

One possible explanation for the marginal reductions obtained in the field study can be found in the inventory of study hammers. Referring to table 3 , the inventory of machines includes nine hammers manufactured by Pine Instruments, two manufactured by Humboldt Co., and one manufactured by Rainhart Co. Of the nine hammers manufactured by Pine instruments, six are less than three years old, one is approximately six years old, and two are more than twenty years old. Thus, half the sample population of hammers were from one manufacturer and are just a few years old. These hammers were all in good operating condition and were generally well maintained. One would expect these Marshall hammers to provide reasonably consistent results, at least from the six or seven newer Pine hammers. Evidence to support this can be found in table 7 . The coefficient of variation (1s\%) of stability for the 50-blow series of uncalibrated specimens is approximately $9 \%$. This can be compared to the average coefficient of variation for stability measured in the AMRL Proficiency Sample Program (PCP) of approximately $20 \%$. Similarly, the coefficient of variation for flow, air voids and height of the 50-blow uncalibrated series are approximately $8 \%, 6 \%$ and $1 \%$. These can be compared with the average coefficients of variation measured in the PCP of approximately $18 \%, 22 \%$ and $1.5 \%$, respectively. These variabilities can not be directly compared because there is additional variability in the PCP data due to operator and equipment variability that is not in the field study data; however, the variability of the uncalibrated field data set was clearly low to begin with. In other words, the sample population provided reasonably consistent results to begin with, leaving limited room for improvement with calibration. A formal statistical analysis of the between-laboratory variability of the uncalibrated test results would determine if the variabilities were statistically significant or not, and therefore, whether the effect of calibration could be measured in this particular data set or not.

In summary, the inventory of hammers used in the study may be atypical and may not be representative of the variation in machines found in the field. As a result, the betweenlaboratory variability of Marshall test results was low, even for specimens prepared using the standard 50- and 75-blow procedures. Calibration did, however, reduce the between-laboratory variability of Marshall test results when the analysis considered nine of the original twelve sites. 



\section{CHAPTER 5. CONCLUSIONS AND RECOMMENDATIONS}

\section{Conclusions}

A system for calibrating the Marshall hammer has recently been developed at the National Institute of Standards and Technology, in collaboration with the AASHTO Materials Reference Laboratory. The calibration system is based on a spring-mass device with integral force transducer, and high speed data acquisition system. The calibration system was demonstrated recently in a laboratory evaluation program and shown to be effective in reducing the variability of Marshall test results for bulk specific gravity, air voids, stability, flow and height (Shenton, et al, 1994). A follow-up field evaluation study of the calibration system has been conducted, and the results of this study have been presented in this report.

The objective of the field evaluation program was to compare the between-laboratory variability of uncalibrated and calibrated Marshall test results, for specimens prepared using "production" Marshall hammers. Twelve laboratories participated in the study. Uncalibrated and calibrated specimens were prepared at each of the twelve sites. This included, for the uncalibrated specimens, four 50- and four 75-blow replicate specimens, and for the calibrated specimens, four $\mathrm{N}_{50^{-}}$and four $\mathrm{N}_{75}$-blow replicate specimens. Stability, flow, air voids and height were measured for each of the specimens. Results for the uncalibrated specimens and calibrated specimens were compiled and the variability of the data sets established. The variability of the two data sets were then compared to determine how effective the calibration system and procedure were in reducing the variability of the test results.

Based on the results of the study the following conclusions are drawn:

1. The system and procedure for calibrating the Marshall compaction hammer were in general, ineffective in reducing the between-laboratory variability of the test results in the full data set, which included results from all twelve field sites. The variability of the calibrated test results for stability, air voids and flow increased relative to the uncalibrated results; the variability of the calibrated test results for height decreased relative to the uncalibrated results.

2. The system and procedure for calibrating the Marshall compaction hammer was effective in reducing the between-laboratory variability of the test results, in the reduced data set. The reduced data set included results from nine sites; data from three sites were eliminated in the statistical analysis because these results were believed to be suspect or flawed, and may have affected the between-laboratory variability. The variability of the calibrated test results decreased by as much as thirty percent, relative to the uncalibrated results, when computed for the reduced data set. Further study would be needed to determine if the reductions were statistically significant, or not.

3. The system for calibrating the Marshall compaction hammer was effective in reducing the variability of the measurement of height in both the full and reduced data sets. The reduction was about 10 percent in the full data set, and about 30 percent in the reduced data set. In that height is the simplest and most straight forward measure of 
the compaction process, one can conclude that the system and procedure have fulfilled their intended purpose. Whether the reductions in variability that can be achieved with the calibration system and procedure are practically or statistically significant is not clear at this time.

4. The between-laboratory variability of the uncalibrated test results in the full data set was low, relative to that observed or expected from a much larger sample of Marshall test results (Dickey, 1992). The low variability is attributed to the sample population of hammers used in the study: most of the hammers were of one type, of similar age, and in generally good condition. Consequently, there was little margin for improvement in the calibrated results, relative to the uncalibrated results. This is submitted as a possible explanation for the marginal reduction in between-laboratory variability of the calibrated results, relative to the uncalibrated, even in the reduced data set. A formal statistical analysis of the uncalibrated test results would be required to answer this question in more detail.

5. Estimates for the standard 50- and 75-blow cumulative impulse have been established based on the diagnostic data collected at the twelve field sites. These are:

$$
\begin{aligned}
& \mathrm{I}_{50}=1100 \mathrm{~N}-\mathrm{s}(247 \mathrm{lb}-\mathrm{s}) \\
& \mathrm{I}_{75}=1650 \mathrm{~N}-\mathrm{s}(371 \mathrm{lb}-\mathrm{s}) .
\end{aligned}
$$

These values have been incorporated into a revised draft standard for calibration that is presented in Appendix A.

The field and laboratory evaluation programs have demonstrated that the calibration system is a viable and effective method for assessing the condition of the Marshall compaction hammer. The system is not only useful for calibration, but could be used to detect serious problems with a mechanical hammer. Further, it has been demonstrated that calibration using an adjusted blow count is a simple and practical approach to ensure that a standard compactive effort is delivered to all specimens, regardless of slight variations in the equipment.

\section{Recommendations}

Future versions of the calibration device, or commercially produced systems, should be modified to remedy a few problems encountered in the field evaluation program. Recommended modifications include:

Develop a more robust mechanism for assembling the calibration device. The existing design relies solely on thread adhesive between the assembly bolt and the top plate to keep the device from vibrating loose after repeated blows. This proved to be inadequate during the field study. A design that relies on some form of mechanical anchorage is preferred.

The overall height of the calibration device (i.e., height of the top plate relative to the base) needs to be reduced by approximately 6 to $8 \mathrm{~mm}$. This can be achieved by reducing the thickness of the base, sleeve and top plate. 
Develop an insert, or modify the device, so that it can be used with Marshall hammers that have a single pin mold centering device (e.g., Humboldt design).

The calibration device was developed for Marshall hammers that have a flat foot, non-rotating base and $102 \mathrm{~mm}$ (4 in) diameter mold. Although this is perhaps the most widely used type of mechanical hammer in the country, there are other variations in use that cannot be calibrated with the current system. Other versions have a rotating base and a slightly tapered tamping foot, run two or three abreast in tandem, or use a heavier drop weight (10 kg [22.5 lb]) and larger mold (152 mm [6 in]). Further study and testing would be required to develop a calibration system for these types of hammers. It is envisioned that the basic device would be the same, however, substantial modifications to the existing calibration would be required to accommodate these hammers. Other versions of the calibration system that are recommended for further development include:

A system that can be used in a Marshall hammer with a tapered foot and rotating base.

A system for the $10 \mathrm{~kg}(22.5 \mathrm{lb})$ hammer and $152 \mathrm{~mm}(6 \mathrm{in})$ diameter mold.

Hammer related variables contribute to the variability of Marshall test results; however, other factors may also contribute to the scatter in the data that, as of yet, have not been studied in detail. Some of the factors include, for example, the method of mixing the sample (e.g., by hand or using an automatic mixer), the compaction temperature, blow interval (as related to compaction temperature) and mold preparation (i.e., how well the mold is cleaned between uses). These factors are not specified in detail in AASHTO T-245, and based on observations made during the field study could affect the test results. The effect of these factors on the Marshall test results warrants further investigation.

The system and procedure for calibrating the Marshall compaction hammer have the potential to affect the quality of hot-mix asphalt produced in the United States. This can only be realized, however, if the necessary steps are taken to introduce and promote the system to the user community. To this end, it is recommended that concrete steps be taken to, (1) encourage commercial development of the calibration system, (2) promote the use of the calibration system to state highway administrations, and (3) promote adoption of a national standard for calibration of the Marshall hammer using the calibration system. 



\section{APPENDIX A. PROPOSED AASHTO CALIBRATION STANDARD}

Presented in this appendix is the draft standard for calibration of Marshall compaction hammers. The draft standard is similar to the one originally presented in Shenton, et al, (1994), except that values have been added for the standard 50- and 75-blow cummulative impulse. The proposed standard has been formatted according to AASHTO guidelines, and does not conform to the format or numbering of the remainder of this report. 


\section{Proposed Standard Practice for Calibrating Mechanical Marshall Compaction Hammers ${ }^{1}$}

\section{Scope}

1.1 This practice addresses the calibration of mechanical compaction hammers that are used in the test for $\mathrm{R}$ resistance to plastic flow of bituminous mixtures using the Marshall apparatus T245.

1.2 The practice is limited to mechanical compaction hammers capable of applying an average peak force of at least $33 \mathrm{kN}$ with a flat hammer foot and a non-rotating base. The practice is intended for single-hammer machines, although it may be applicable to dual- or triple-hammer machines under certain circumstances. It is the responsibility of the user to establish the applicability of the procedure in those cases.

1.3 The values stated in SI units are to be regarded as the standard.

1.4 This standard may involve hazardous materials, operations, and equipment. This standard does not purport to address all of the safety problems associated with its use. It is the responsibility of the user of this standard to establish appropriate safety and health practices and determine the applicability of regulatory limitations prior to use.

\section{Reference Documents}

\subsection{AASHTO Standards}

T245 Method of Test for Resistance to Plastic Flow of Bituminous Mixtures Using Marshall Apparatus

\section{Terminology}

\subsection{Symbols}

3.1.1 $m_{1}, m_{2}, \mathrm{~b}_{2}=$ calibration factors (slope $\mathrm{e}_{1}-\mathrm{mV} / \mathrm{kN}$, slope ${ }_{2}-\mathrm{mV} / \mathrm{kN}$, and intercept $2-\mathrm{mV}$ values) for the device force transducer

3.1.2 $\mathrm{V}=$ device readout

3.1.3 $\mathrm{K}_{\mathrm{s}}=$ stiffness of the device spring assembly, $\mathrm{kN} / \mathrm{mm}$

3.1.4 $\mathrm{F}=$ test machine applied load, $\mathrm{kN}$

3.1.5 $\delta=$ displacement of the device top plate, $\mathrm{mm}$

3.2 Description of Terms Specific to this Standard

3.2.1 Data Set - One of three ensembles of 75 or 100 force time histories recorded as part of the calibration procedure

${ }^{1}$ This standard is based on research described in NISTIR 5338 and NISTIR XXXX (reference to this report). 
3.2.2 Peak Force; $\mathrm{kN}$ - The maximum force recorded for an individual blow

3.2.3 Average Peak Force; $\mathrm{kN}$ - The average of the peak forces for a data set

3.2.4 Impulse; $\mathrm{kN}-\mathrm{s}$ - The integrated force time history for an individual blow

3.2.5 Cumulative Impulse; $\mathrm{kN}-\mathrm{s}$ - The running sum total of the impulses as a function of blow count

3.2.6 Standard Cumulative Impulse; $\mathrm{kN}-\mathrm{s}$ - The standard compactive effort, expressed in terms of cumulative impulse, required for calibration (Usually a compactive effort equivalent to a 50 or 75 blow Marshall procedure is specified.)

\section{Summary of Calibration Procedure}

4.1 Three data sets are recorded with the calibration device positioned in the machine at 12, 4, and 8 o'clock. Seventy-five or one hundred blows are recorded per data set. The peak force and impulse is determined for each blow of the compaction hammer.

4.2 The average peak force for each data set is obtained to determine if the mechanical hammer can be calibrated.

4.3 The cumulative impulse is computed for each data set and the number of blows required to deliver the specified standard compactive effort is established for the device.

\section{Significance and Use}

5.1 The procedures described in this practice are used to determine the number of blows required for a given mechanical hammer to provide a compactive effort equivalent to a standard 50- or 75-blow Marshall procedure as described in T245.

5.2 The application of the calibration procedures described in this practice can greatly reduce the variability of tests performed on Marshall test specimens prepared using different mechanical compactors.

\section{Apparatus}

6.1 Calibration Device - A calibration device as shown in Figure 1 and described in Annex A1.

6.2 Data Acquisition System - The data acquisition shall have, at a minimum, an 8-bit A/D converter and shall be capable of sampling a single channel at a rate of at least 100,000 samples/s. The system shall have trigger and storage capabilities such that multiple force time histories can be automatically captured and stored for subsequent processing. The system shall be capable of storing a minimum of 100 sample time histories of 500 data points each. Triggering shall be such that the start of the pulse is easily and clearly defined for any given time history. Software or switch selectable gains are a desirable option.

Note 1 -- The prototype system described in NISTIR 5338 included a portable "lunch box" 386 DX/33 with an $80 \mathrm{MB}$ hard disk, one 1.44-MB floppy disk drive and 4-MB memory; a Keithley/Metrabyte, Taunton, MA, Model DAS-1402 high-speed analog input board; and Keithley/Metrabyte Taunton, MA, STREAMER software, version 3.3, compatible with DAS-1402.

6.3 Data Processing Software - The data processing software shall be capable of processing individual force time histories to determine the peak force and impulse (impulse is defined as the area under the force time history between 
the start of the initial pulse and the first zero crossing). The software shall be capable of evaluating the average and standard deviation of the peak force and impulse, for a sample set of up to 100 time histories.

Note 2 -- The force time histories may be processed using custom-developed software. Appendix B of NISTIR 5338 lists two programs written in Microsoft C5.1 that were used with the prototype system.

\section{Calibration and Standardization}

7.1 Measure the stiffness of the device spring assembly at least once a year, or more frequently as use requires. Determine the spring stiffness as described in Annex A2. The spring stiffness $\mathrm{K}_{\mathrm{s}}$ shall be $150 \pm 10 \mathrm{kN} / \mathrm{mm}$.

7.2 Calibrate the device force transducer whenever any component of the data acquisition system is replaced, or more frequently as use requires, but at least once a year. Determine the transducer calibration factors $m_{1}, m_{2}, b_{2}$, as described in Annex A3. These factors are needed to convert the analog output of the device to engineering units.

\section{Procedure}

8.1 Place the calibration device in the compaction machine and secure with the specimen mold holder. Position the device in the machine such that the port hole for the transducer cable is in the 12 o'clock position, as viewed when facing the machine.

8.2 Place the compaction hammer on top of the calibration device and secure it in the machine as usual during normal operation. Rest the drop weight on top of the hammer foot before starting the machine.

8.3 Begin recording data and immediately start the compaction hammer.

8.4 Record the force time history for each blow. Apply 75 blows when calibration for a 50-blow Marshall procedure is desired. Apply 100 blows when calibration for a 75-blow Marshall procedure is desired.

8.5 Sufficient "pre-trigger" shall be recorded for each blow to ensure that the start of the blow is captured. The duration of the recorded force time history shall be of a length such that all significant/measurable force is recorded (Figure 2). Individual force time histories shall be stored, either temporarily or permanently, for subsequent processing.

8.6 Repeat Sections 8.1 to 8.4 with the port hole for the transducer cable in the 4 o'clock (second data set) and 8 o'clock (third data set) positions.

\section{Calculation and Interpretation of Results}

9.1 Determine the peak force of each recorded force time history, the average peak force for each data set, and the average of the average peak forces to the nearest $\mathrm{kN}$ (Figure 2).

9.2 If the average of the average peak forces is less than $33 \mathrm{kN}$, calibration of the compaction device is not valid.

Note 3 -- A very low average peak force is an indication of a machine that is in need of repair or maintenance. Calibration can be carried out; however, the calibrated blow count is likely to be excessive when compared to the calibrated blow count of typical machines. In this case, the machine should be inspected and repaired as necessary and the average peak force measured again. 
9.3 Determine the impulse for each recorded force time history and the average of the impulses for each data set. The impulse is defined as the area under the force time history curve from the start of the blow to the first zero crossing. (Figure 2)

9.4 Determine the cumulative impulse for each data set in $\mathrm{kN} \cdot \mathrm{s}$. The cumulative impulse is the running total sum of the individual impulses, computed as a function of the blow count.

9.5 From the cumulative impulse data, determine the blow count for each data set that corresponds to the standard cumulative impulse specified. Use a standard cumulative impulse value of $1100 \times 10^{-3} \mathrm{kN} \cdot \mathrm{s}\left(247 \times 10^{-3} \mathrm{kip} \cdot \mathrm{s}\right)$ when calibration for a 50-blow Marshall procedure is desired, and a standard cumulative impulse value of $1650 \times 10^{-3} \mathrm{kN} \cdot \mathrm{s}$ $\left(371 \times 10^{-3} \mathrm{kip}-\mathrm{s}\right)$ when calibration for a 75 -blow Marshall procedure is desired.

9.6 Average the blow count from each data set that corresponds to the standard cumulative impulse specified.

\section{Report}

10.1 For each data set report the following:

10.1.1 the average of the peak forces, nearest $\mathrm{kN}$,

10.1.2 the average of the impulses, nearest $\mathrm{kN} \cdot \mathrm{s}$, and

10.1.3 the blow count that corresponds to the standard cumulative impulse.

10.2 The report shall include an identification of the hammer being calibrated.

10.3 Report the average of the average peak forces for the 3 data sets, nearest $\mathrm{kN}$.

10.4 Report the standard cumulative impulse used, nearest $\mathrm{kN} \cdot \mathrm{s}$.

10.5 Report the average blow count for the three data sets as the calibrated blow count $\mathrm{N}_{50}$ or $\mathrm{N}_{75}$.

11. Keywords - Calibration, Mechanical Compactor, Marshall Test 


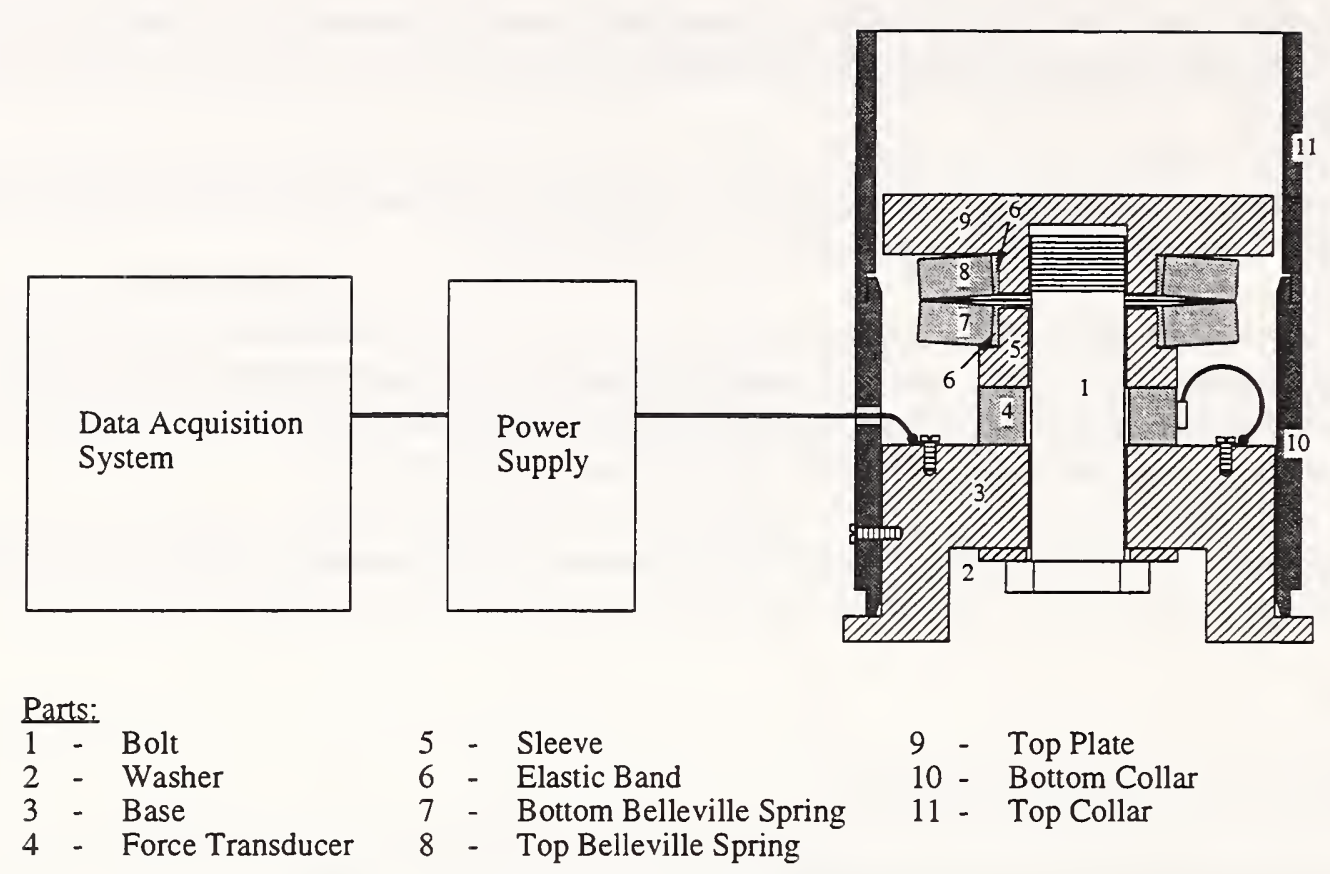

Figure 11. Calibration device

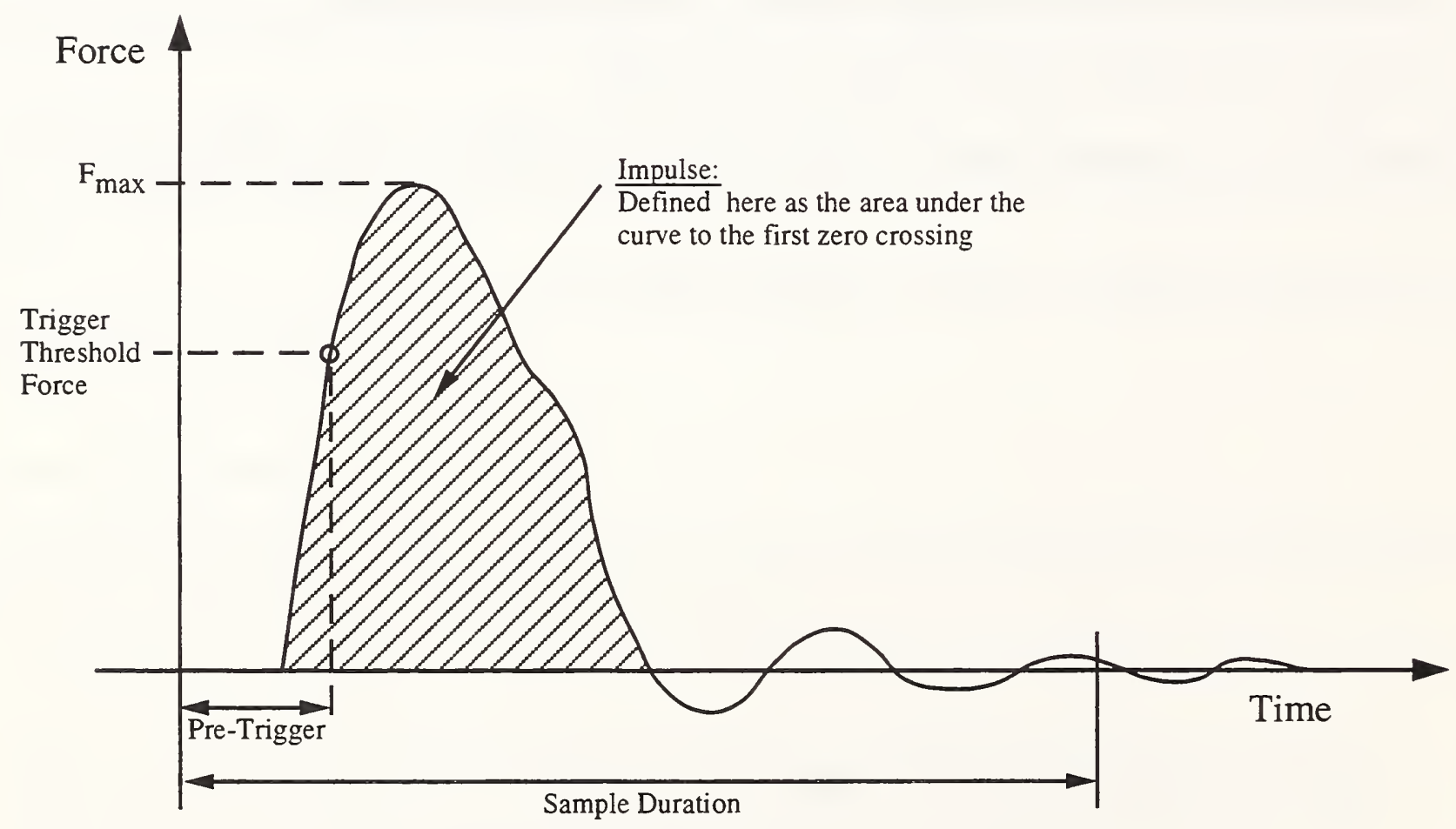

Figure 12. Typical force-time history showing peak force and impulse 


\section{ANNEX A1 - Calibration Device Parts List and Drawings \\ (Mandatory Information)}

A1.1 Parts List - The parts list for the calibration device is presented in Table A1.1. Parts are referenced by part number and part name. Specifications for each part are listed in the table along with the supplier of the part for the prototype device.

Note A1.1 -- This should not be construed as an endorsement of a particular manufacturer or supplier. The suppliers are listed only so that the interested reader can obtain more detailed specifications if they so desire, which should aid in the selection of the part.

A1.2 Engineering Drawings - Engineering drawings are presented in Figures A1.1 through A1.5 for all parts that require custom fabrication, or are modified from an "off-the-shelf" item. Engineering drawings are not included for stock parts that are used as purchased (e.g., washer, Belleville spring, etc.). An assembly drawing is presented in Figure A1.6.

Note A1.2 -- Particular attention should be paid to the details of the cable connection of the force transducer since there is limited clearance between the transducer and bottom collar, and transducer and Belleville springs. The bottom collar should slide freely on and off without having to disassemble the device.

\section{A1.3 Assembly Instructions: '}

A1.3.1 Apply a small amount of general purpose or high-strength thread adhesive/bonding agent (e.g, LockTite ${ }^{\mathrm{TM}}$ or equivalent) to the inside threads of the top plate.

A1.3.2 Secure the top plate upside-down in a bench vise. Use small blocks of wood if necessary to prevent damage to the plate.

A1.3.3 Apply a lubricant to the contact surfaces of the force transducer, sleeve, and base as recommended by the transducer manufacturer (a molybdenum-based lubricant was used in the prototype device). Apply a small amount of the same lubricant to the outer diameter edges of the Belleville springs where the two springs come in contact.

A1.3.4 Place the elastic band around the hub of the sleeve and hub of the top plate (the elastic band reduces the clearance between the spring and sleeve (top plate) hub, while permiting radial displacement of the spring relative to the hub).

A1.3.5 Position the Belleville springs, sleeve, force transducer, base, and washer on top of the top plate in the order shown in figure Al.6.

A1.3.6 Apply a small amount of adhesive/bonding agent to the threads of the assembly bolt.

A1.3.7 Slide the assembly bolt down through the device parts and tighten the assembly by hand until snug.

A1.3.8 Center and align all the parts relative to one another. Rotate the force transducer relative to the base so that the transducer cable is positioned properly to allow for installation and removal of the bottom collar.

A1.3.9 Tighten the assembly using a torque wrench to $41 \mathrm{~N}-\mathrm{m}$ (30 ft-lb). 
A1.3.10 Remove the device from the vise. Place the device upside down on a table and allow the thread adhesive to fully cure, as recommended by the adhesive manufacturer.

Warning - Do not use an excessive amount of thread adhesive on the top plate and assembly bolt. Also, do not turn the device right-side up until the adhesive is fully cured. Excess adhesive may backup or drain down the shaft of the assembly bolt and obstruct the smooth operation of the device. 
Table A1.1: Calibration Device - Parts List

\begin{tabular}{|c|c|c|c|}
\hline $\begin{array}{c}\text { Part } \\
\#\end{array}$ & Name & Specification & Prototype Device Supplier \\
\hline 1 & $\begin{array}{l}\text { Assembly } \\
\text { Bolt }\end{array}$ & $\begin{array}{l}25-\mathrm{mm}(1 ") \# 14 \text { fine thread, } 152-\mathrm{mm}(6 ") \text { hex-head } \\
\text { medium-strength cap screw, modified as shown in } \\
\text { fabrication drawing }\end{array}$ & $\begin{array}{l}\text { McMaster-Carr, Brunswick, } \\
\text { NJ; } \\
\text { Part \# 91248A927 }\end{array}$ \\
\hline 2 & Washer & $25 \mathrm{~mm}$ (1") SAE flat washer & $\begin{array}{l}\text { McMaster-Carr, Brunswick, } \\
\text { NJ; } \\
\text { Part \# 91083A038 }\end{array}$ \\
\hline 3 & Base & Mild steel, see fabrication drawing & Local \\
\hline 4 & Force Ring & $\begin{array}{l}\text { Piezoelectric force transducer, compression type, } \\
\text { maximum force of } 20 \text { - } 30 \mathrm{kips} \text {, nominal inner diameter - } \\
25 \mathrm{~mm}(1 ") \text {, nominal outer diameter }-51 \mathrm{~mm}(2 ") \text {, } \\
\text { nominal height less than } 15 \mathrm{~mm}(0.6 ") \text {, size and } \\
\text { configuration of connection that fits the space } \\
\text { constraint of device }\end{array}$ & $\begin{array}{l}\text { PCB Piezotronics, Inc., } \\
\text { Depew, New York; } \\
\text { Model 216A Force Ring with } \\
\text { M05 built-in option ( } 1.5 \mathrm{~m} \\
\text { (5') low noise integral cable) }\end{array}$ \\
\hline 5 & Sleeve & Mild steel, see fabrication drawing & Local \\
\hline 6 & Elastic band & $\begin{array}{l}\text { 1-mm thick elastic band; diameter to permit snug fit } \\
\text { around hub of sleeve and top plate }\end{array}$ & Local; standard office supply \\
\hline 7 & $\begin{array}{l}\text { Bottom } \\
\text { Belleville } \\
\text { Spring }\end{array}$ & High-carbon steel Belleville spring/washer & $\begin{array}{l}\text { Key Belleville, Inc., } \\
\text { Leechburg, PA; } \\
\text { Part M3250-P-420 }\end{array}$ \\
\hline 8 & $\begin{array}{l}\text { Top } \\
\text { Belleville } \\
\text { Spring }\end{array}$ & High-carbon steel Belleville spring/washer & $\begin{array}{l}\text { Key Belleville, Inc., } \\
\text { Leechburg, PA; } \\
\text { Part M3250-P-420 }\end{array}$ \\
\hline 9 & Top Plate & Mild steel, see fabrication drawing & Local \\
\hline 10 & $\begin{array}{l}\text { Bottom } \\
\text { Collar }\end{array}$ & $\begin{array}{l}\text { Bottom collar, modified from a standard } 102 \mathrm{~mm}(4 ") \\
\text { diameter Marshall cylinder mold as shown in the } \\
\text { fabrication drawing }\end{array}$ & $\begin{array}{l}\text { Rainhart Co., } \\
\text { Austin, TX; } \\
\text { Model 110CM4 Compaction } \\
\text { Mold Assembly }\end{array}$ \\
\hline 11 & Top Collar & $\begin{array}{l}\text { Top collar, from a standard } 102 \mathrm{~mm}(4 ") \text { diameter } \\
\text { Marshall cylinder mold }\end{array}$ & $\begin{array}{l}\text { Rainhart Co., } \\
\text { Austin, TX; } \\
\text { Model 110CM4 Compaction } \\
\text { Mold Assembly }\end{array}$ \\
\hline 12 & $\begin{array}{l}\text { In-Line } \\
\text { Charge } \\
\text { Converter }\end{array}$ & $\begin{array}{l}\text { In-line charge converter (amplifier) converts high- } \\
\text { impedance charge output of a piezoelectric sensor into } \\
\text { low-impedance voltage signal }\end{array}$ & $\begin{array}{l}\text { PCB Piezotronics, Inc., } \\
\text { Depew, New York; } \\
\text { Model 402A In-Line Charge } \\
\text { Converter with M144 built-in } \\
\text { option }\end{array}$ \\
\hline 13 & $\begin{array}{l}\text { AC Power } \\
\text { Supply }\end{array}$ & $\begin{array}{l}\text { AC power supply for low-impedance piezoelectric } \\
\text { transducers with built-in or attached amplifiers }\end{array}$ & $\begin{array}{l}\text { PCB Piezotronics, Inc., } \\
\text { Depew, New York; } \\
\text { Model 482A06, Single- } \\
\text { Channel Line Power Supply } \\
\text { with BNC input/output }\end{array}$ \\
\hline
\end{tabular}




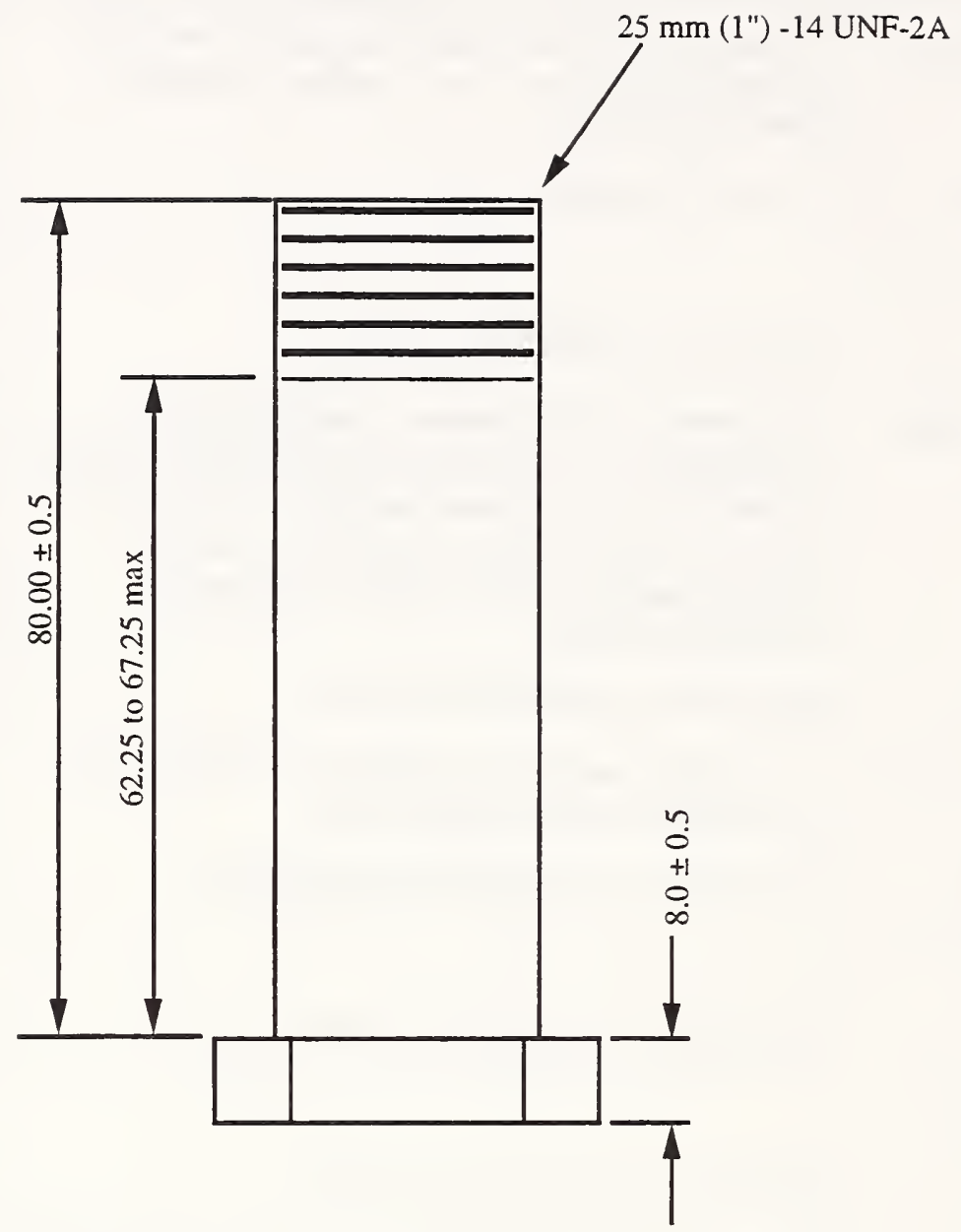

Note:

Part fabricated from a $25 \mathrm{~mm}\left(\mathrm{1}^{\prime \prime}\right)$ - 14 fine thread, $152 \mathrm{~mm}\left(6^{\prime \prime}\right)$ long (threaded length $64 \mathrm{~m}$ (2.5") ) hex-head medium-strength cap screw. Thread shaft to indicated length, turn bolt head, and cut bolt to length.

PART NAME: Assembly Bolt

PART NUMBER: 1

MATERIAL: Steel

UNITS: Millimeters unless otherwise specified

Figure 13. Assembly bolt 


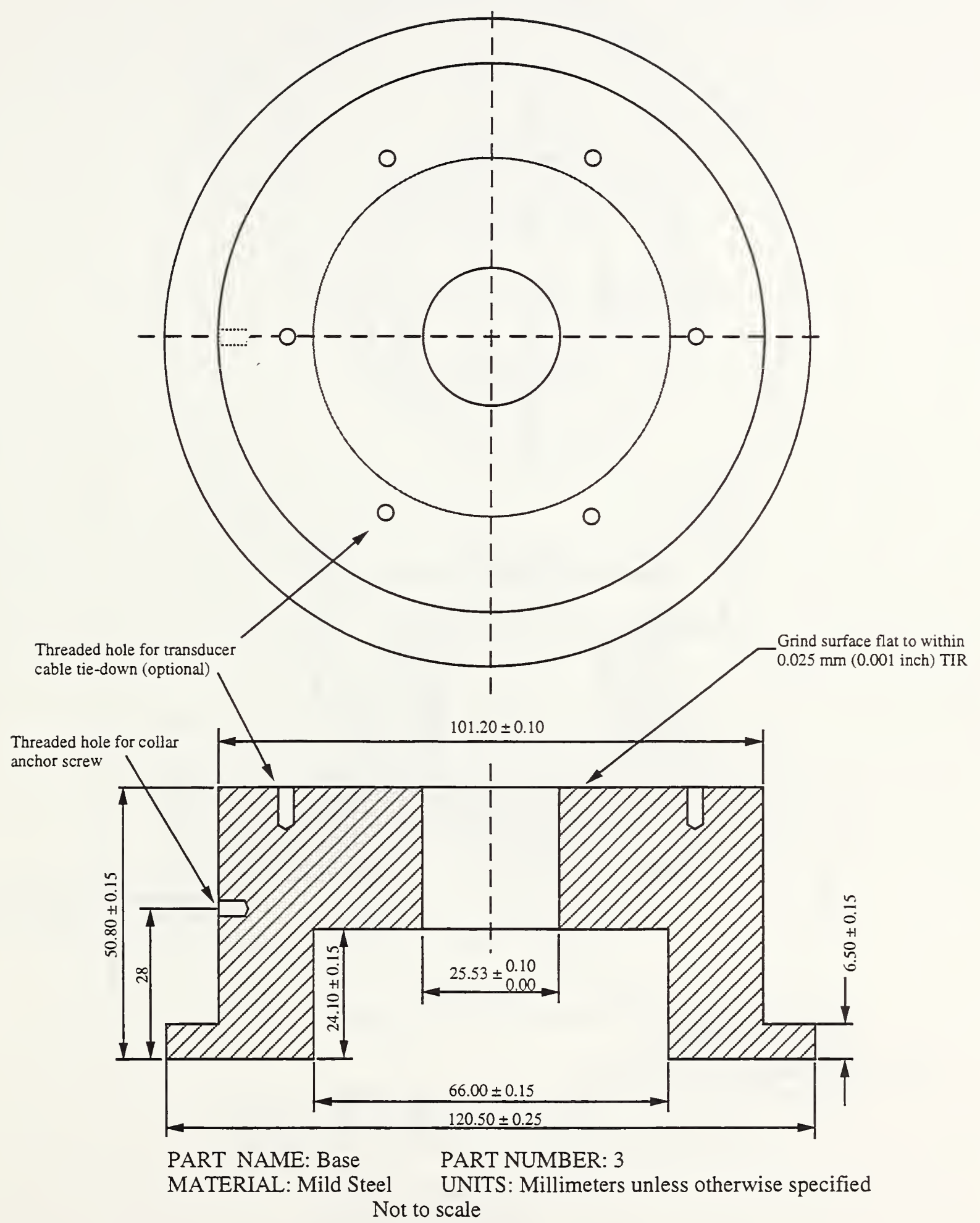

Figure 14. Base 

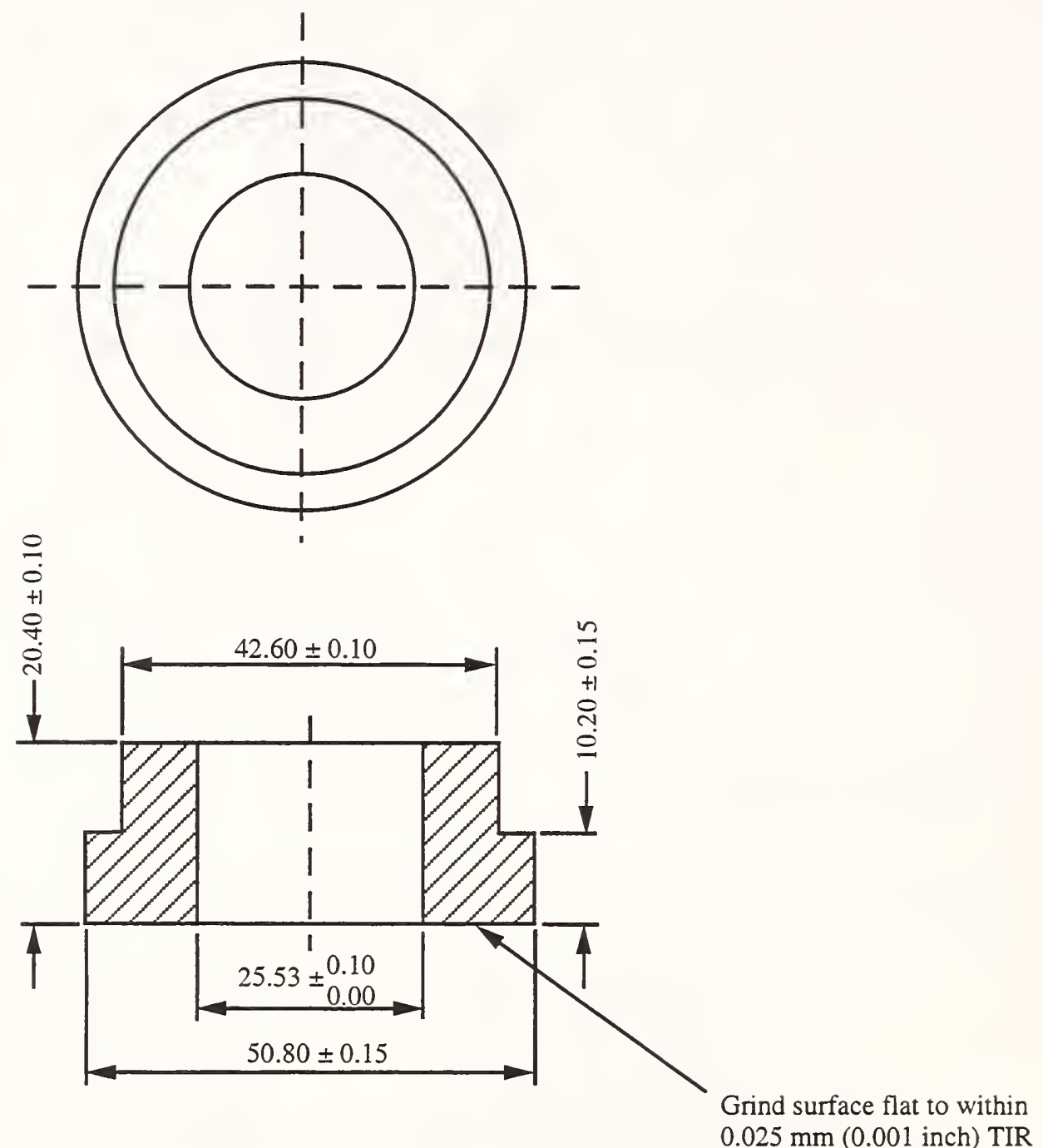

PART NAME: Sleeve

PART NUMBER: 5

MATERIAL: Mild Steel

UNITS: Millimeters unless otherwise specified

Figure 15. Sleeve 

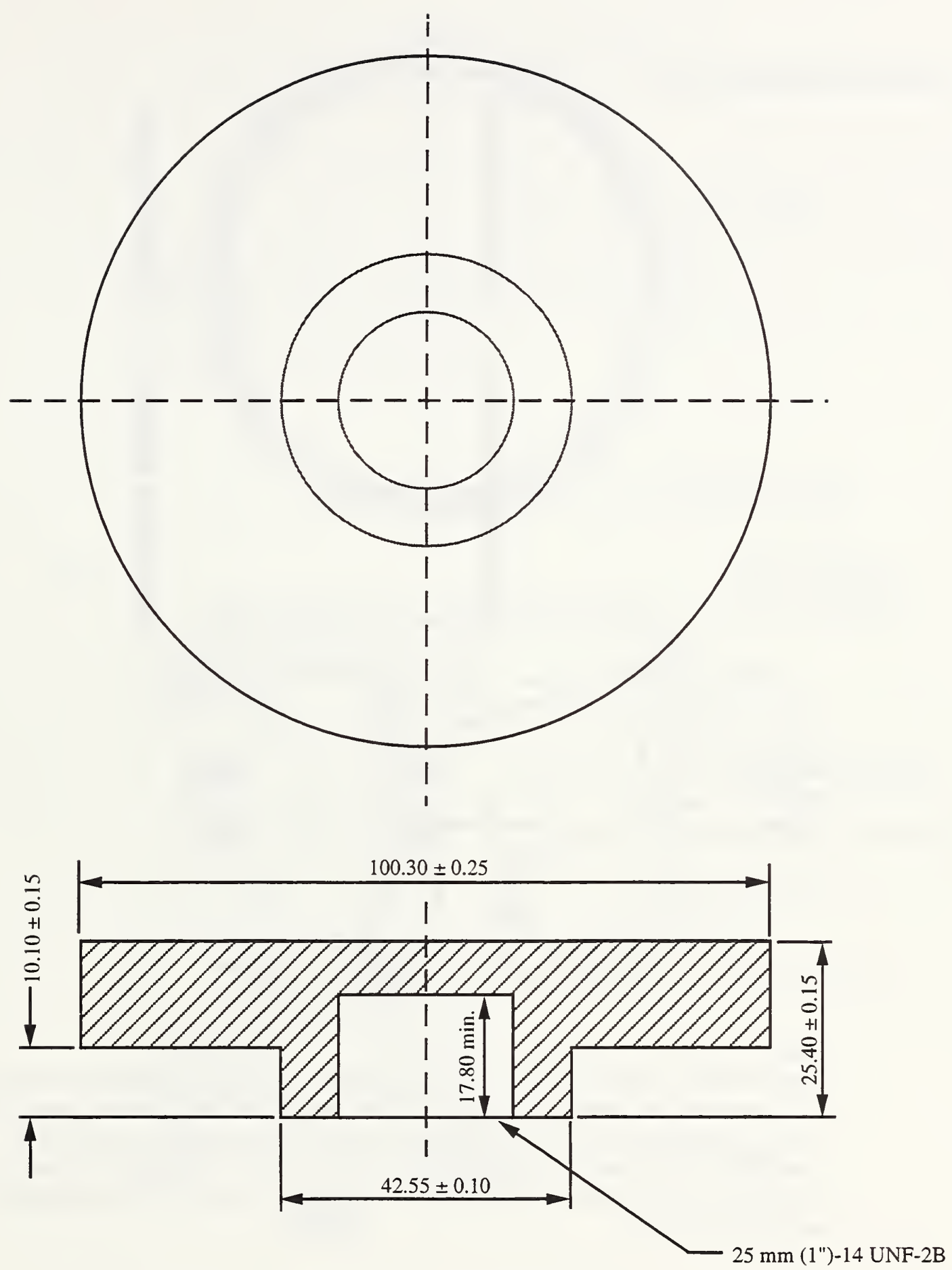

Notes:

1. Harden to minimum RC-55 after fabrication.

2. Chamfer corners as needed to prevent cracking during hardening.

PART NAME: Top Plate

PART NUMBER: 9

MATERIAL: Mild Steel

UNITS: Millimeters unless otherwise specified

Figure 16. Top plate 


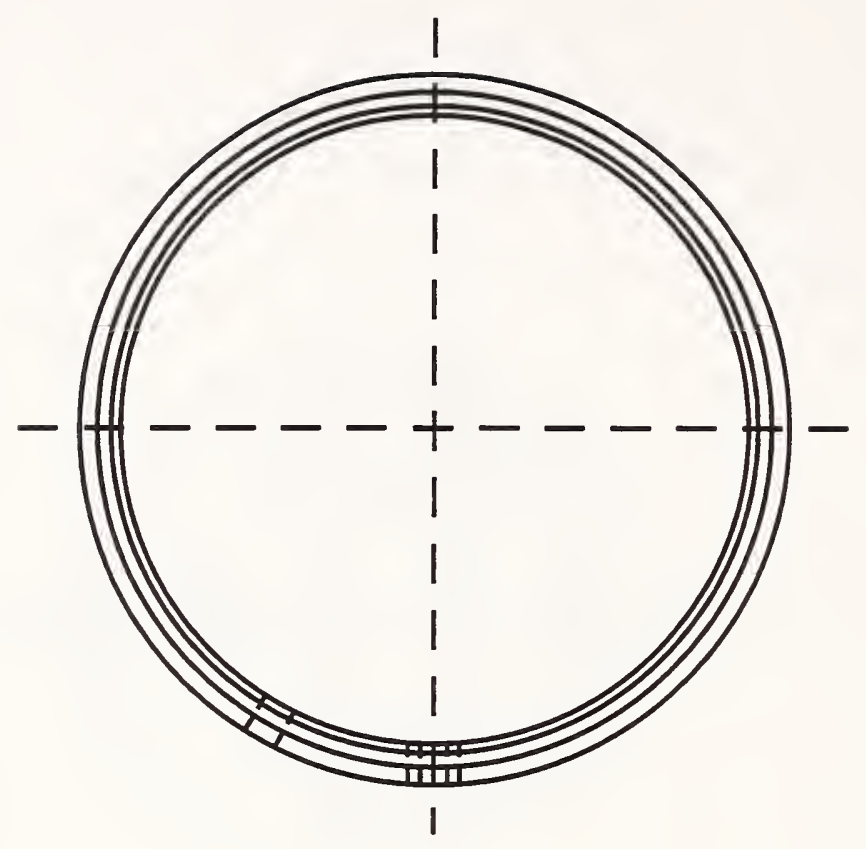

Transducer cable port hole

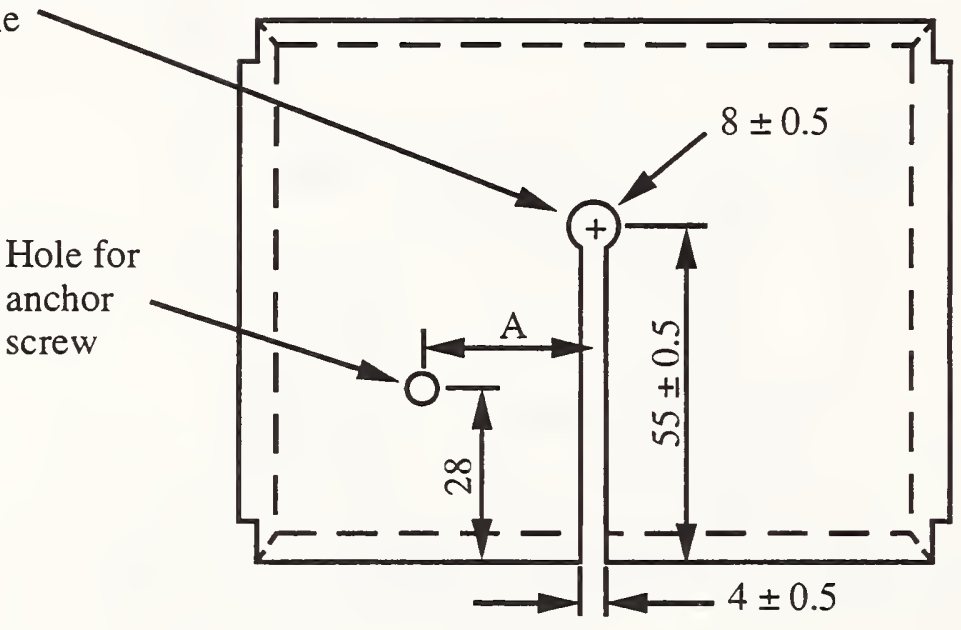

Notes:

Part fabricated from bottom collar of a standard $102 \mathrm{~mm}$ (4") diameter Marshall cylinder mold. Modifications include milling slot and drilling hole for transducer cable, and drilling hole for anchor screw. Slot and hole must be tailored to be compatible with transducer connection details. Measure " $\mathrm{A}$ " and the diameter of the anchor hole are arbitrary but must be compatible with connection detail and tapped hole in base.

PART NAME: Bottom Collar

PART NUMBER: 10

MATERIAL: Steel

UNITS: Millimeters unless otherwise specified SCALE: $1 / 2$

Figure 17. Bottom collar 
Part Number and Part Name

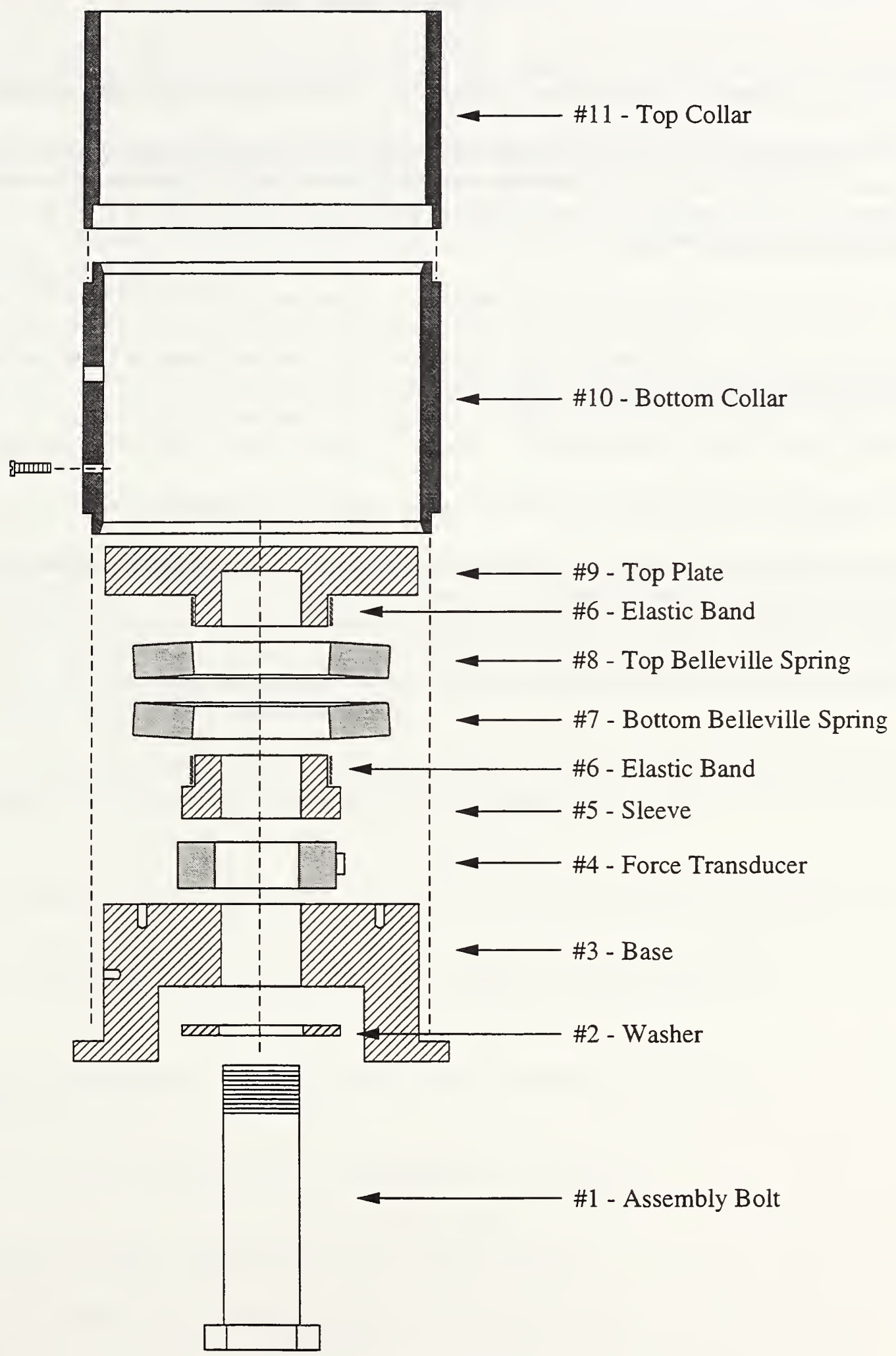

Figure 18. Assembly drawing 


\section{ANNEX A2 - Spring Stiffness Determination \\ (Mandatory Information)}

A2.1 Place the device in a universal test machine having a load range between 130 and $450 \mathrm{kN}$.

A2.2 Measure the displacement of the top plate of the calibration device with a displacement measuring device (e.g., dial gauge or LVDT) that has a resolution of at least $0.0025 \mathrm{~mm}(0.0001 ")$. Care should be taken to ensure that the measuring device has rigid support and is securely anchored to ensure that there is no relative movement of the measuring device during testing.

A2.3 Condition the calibration device by completing 3 cycles, loading between 20 and 120 percent $F_{\max }$.

A2.4 Complete 3 load cycles between 20 and 100 percent $F_{\max }$. Load and unload in 5 equal increments. At each load increment record the displacement $(\delta)$ of the top plate.

A2.5 Plot load $(F)$ versus deflection $(\delta)$.

A2.6 Determine the best fit line to the data using the method of least squares.

A2.7 The slope of the fitted curve is the calibrated stiffness $K_{s}$. The calibrated stiffness $K_{s}$ shall be $150 \pm 10$ $\mathrm{kN} / \mathrm{mm}$. 


\section{ANNEX A3 - Load Cell Calibration \\ (Mandatory Information)}

A3.1 Place the device in a universal test machine having a load capacity of at least $135 \mathrm{kN}$ (30 kip), and a resolution of at least $0.5 \mathrm{kN}(0.1 \mathrm{kip})$.

A3.2 Record the load during calibration using the actual data acquisition system to be used during Marshall hammer calibration; this includes power supply, cables, and recording instrument.

A3.3 Power the force transducer and allow sufficient time, as noted in the manufacturers specifications, for the instrument to thermally stabilize.

A3.4 Condition the device by completing 3 cycles between 0 and $90 \mathrm{kN}$ ( 0 and $20 \mathrm{kip}$ ).

A3.5 Apply loads of 5, 10, 15, 25, 40, 50, and $70 \mathrm{kN}(1,2,3,6,9,12$, and $15 \mathrm{kip})$, in that order. At each load increment, record the force transducer readout $(\mathrm{V})$. Apply the loading sequence three times, such that three independent readings are taken at each load increment for a total of 21 data points.

\section{A3.6 Plot readout (V) versus load (F).}

Note A3.1 -- The sensitivity of a piezoelectric force transducer varies with the pre-load on the instrument: sensitivity decreases with an increase in pre-load. As a result, the calibration curve for the instrument is likely to be bilinear, as shown by a typical example in Figure A3.1. For low loads, the transducer has a certain sensitivity because of the pre-load in the assembly bolt. Sensitivity increases, however, as the springs are compressed and the pre-load on the bolt is relieved. Accurate calibration requires determining the best fit lines to the two legs of the calibration curve.

A3.7 Determine the best fit line to the data corresponding to loads of 0,5 , and $10 \mathrm{kN}(0,1$ and $2 \mathrm{kip})$ using the method of least squares. The equation for the fitted line shall be in the form:

$$
V=m_{1} F ; \quad 0 \leq F \leq F_{i}
$$

in which $\mathrm{V}$ is the instrument readout, $\mathrm{F}$ is the force, $m_{1}$ is the slope of the fitted line, and $\mathrm{F}_{\mathrm{i}}$ is determined in $\mathrm{A} 3.9$.

A3.8 Determine the best fit line to the data corresponding to loads of $15,25,40,50$, and $70 \mathrm{kN}(3,6,9,12$, and $15 \mathrm{kip})$ using the method of least squares. The equation for the fitted line shall be in the form:

$$
V=m_{2} F+b_{2} ; \quad F_{i}<F
$$

in which $\mathrm{V}$ is the instrument readout, $\mathrm{F}$ is the force, $m_{2}$ is the slope of the fitted line, $\mathrm{b}_{2}$ is the $\mathrm{y}$-intercept of the fitted line, and $F_{i}$ is determined in A3.9.

A3.9 The intercept of the two calibration curves, corresponding to $F_{i}$, is given by

$$
F_{i}=b_{2} /\left(m_{1}-m_{2}\right)
$$

Note A3.2 -- $F_{i}$ is an estimate of the pre-load in the calibration device.

A3.10 Factors $m_{1}, m_{2}$, and $b_{2}$ define the calibration curve of the force transducer. 


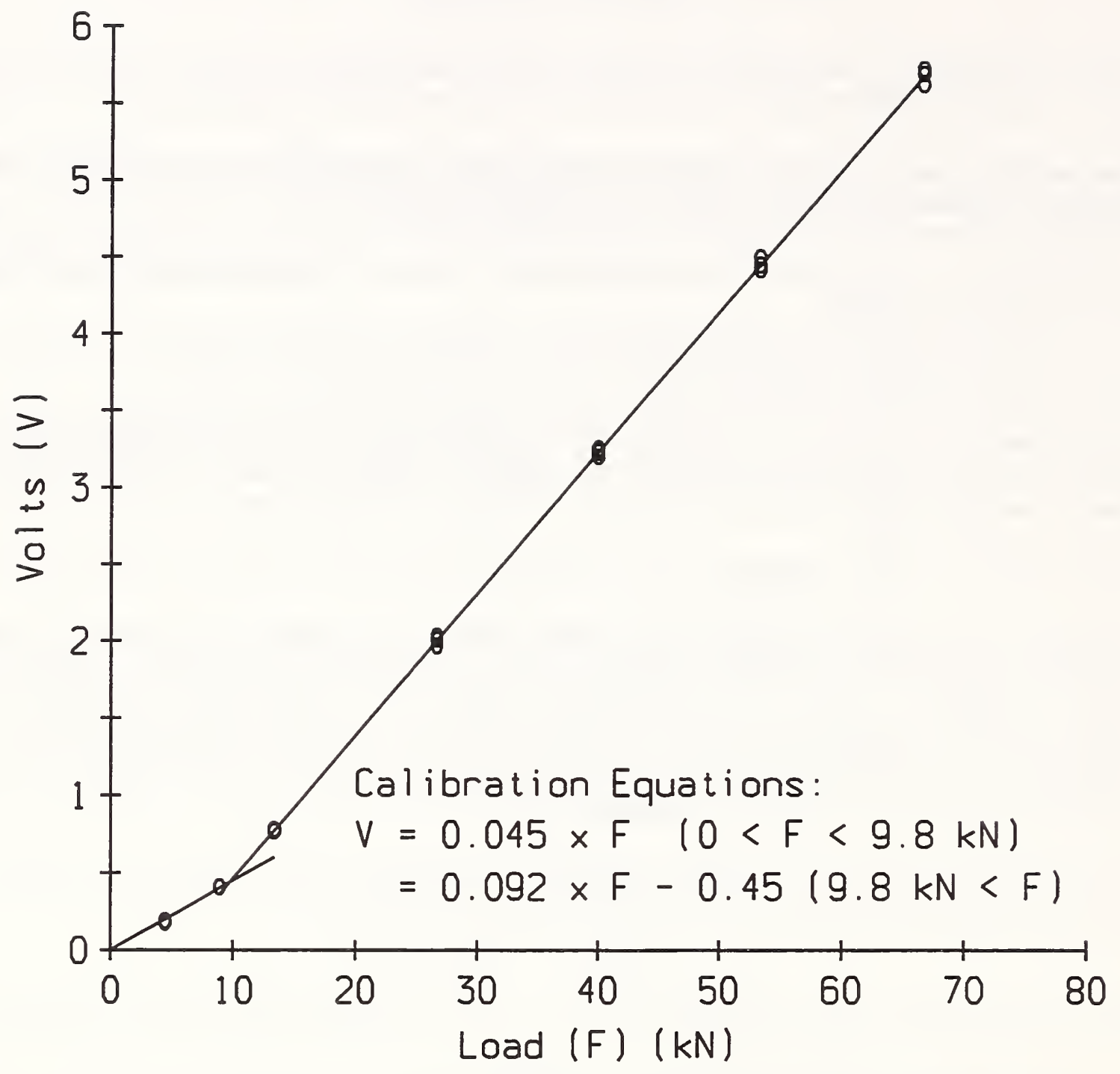

Figure 19. Typical bi-linear calibration curve 


\section{REFERENCES}

Dickey, D., Compilation of Statistics from the AMRL Proficiency Sample Program, American Association of State Highway Transportation Officials, Materials Reference Laboratory, Gaithersburg, Maryland, 1992.

Shenton, H.W., Cassidy, Michael M, Spellerberg, Peter A. and Savage, David A., A System for Calibration of the Marshall Compaction Hammer, Federal Highway Administration, Federal Highway Research Report FHWA-RD-94-002, January 1994.

Siddiqui, Z., Tretheway, M.W., and Anderson, D.A., Calibration of Marshall Hammer: State of the Art, Final Report, Arizona Department of Transportation, Report Number FHWAAZ87-808, June 1987.

Siddiqui, Z., Tretheway, M.W., and Anderson, D.A., "Variables Affecting Marshall Test Results," Transportation Research Record, No. 1171, pp. 139-148, 1988. 




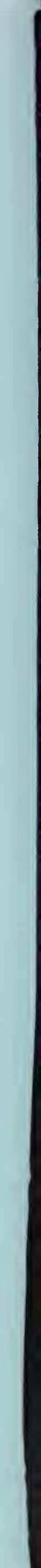

